Florida International University

FIU Digital Commons

FIU Electronic Theses and Dissertations

University Graduate School

$6-22-2020$

\title{
Zine-Making as a Pedagogical Practice: A Phenomenographic Study of Teachers' Experiences
}

Diana Levy

Florida International University, dlevy001@fiu.edu

Follow this and additional works at: https://digitalcommons.fiu.edu/etd

Part of the Art Education Commons, and the Language and Literacy Education Commons

\section{Recommended Citation}

Levy, Diana, "Zine-Making as a Pedagogical Practice: A Phenomenographic Study of Teachers' Experiences" (2020). FIU Electronic Theses and Dissertations. 4485.

https://digitalcommons.fiu.edu/etd/4485

This work is brought to you for free and open access by the University Graduate School at FIU Digital Commons. It has been accepted for inclusion in FIU Electronic Theses and Dissertations by an authorized administrator of FIU Digital Commons. For more information, please contact dcc@fiu.edu. 


\section{FLORIDA INTERNATIONAL UNIVERSITY}

Miami, Florida

ZINE-MAKING AS A PEDAGOGICAL PRACTICE:

A PHENOMENOGRAPHIC STUDY OF TEACHERS' EXPERIENCES

A dissertation submitted in partial fulfillment of

the requirements for the degree of

DOCTOR OF PHILOSOPHY

in

TEACHING AND LEARNING

by

Diana Levy 
To: Dean Michael R. Heithaus

College of Arts, Sciences and Education

This dissertation, written by Diana Levy, and entitled, Zine-Making as a Pedagogical Practice: A Phenomenographic Study of Teachers' Experiences, having been approved in respect to style and intellectual content, is referred to you for judgment.

We have read this dissertation and recommend that it be approved.

Laura Dinehart

Haiying Long

Sarah Mathews

Joyce Fine, Major Professor

Date of Defense: June 22, 2020

The dissertation of Diana Levy is approved.

Dean Michael R. Heithaus

College of Arts, Sciences and Education

Andrés G. Gil

Vice President for Research and Economic Development and Dean of the University Graduate School

Florida International University, 2020 
(C) Copyright 2020 by Diana Levy

All rights reserved. 


\section{DEDICATION}

To my husband, Lawrence, thank you for your unwavering support and for believing in me. To my children, Francesca and Joseph, thank you for being proud of me and reminding me that the future is now. To my Tia Gladys, everything that I have ever accomplished is because of you. 


\section{ACKNOWLEDGMENTS}

I would like to thank my major professor, Dr. Joyce Fine. You have been my

mentor, friend, and source of encouragement throughout this long journey.

I am also thankful for my committee members, Dr. Laura Dinehart, Dr. Haiying

Long, and Dr. Sarah Mathews. Each of you have provided me with unconditional support and are true models of professionalism and leadership.

Finally, I'd like to thank the incredible, creative, and passionate educators who participated in this study for sharing your experiences with me. The way you inspire your students to become creators of knowledge and communicators of their ideas is the ultimate example of what education should be. 


\section{ABSTRACT OF THE DISSERTATION \\ ZINE-MAKING AS A PEDAGOGICAL PRACTICE: \\ A PHENOMENOGRAPHIC STUDY OF TEACHERS' EXPERIENCES}

by

\section{Diana Levy}

Florida International University, 2020

Miami, Florida

Professor Joyce Fine, Major Professor

A zine (pronounced zeen) is a short, self-created and self-published booklet filled with a combination of writing, drawing, poetry, collage, and other text and images that create a message. Historically, zines have been associated with an underground, activist or radical literary subculture. Zines embody a breadth of literacies and have the potential to create critical readers, writers, and thinkers; however, minimal scholarly research exists on school zines. The purpose of the current study was to explore the experiences of educators using zine-making in elementary, middle, and high school classrooms. Phenomenographical analysis of nine, in-depth, semi-structured interviews revealed that participants described the content, process, product and purpose of zine-making in four qualitatively different ways: The Author, The Artist, The Activist, and The Academic. The categories of experience represent a phenomenographic outcome space that can be useful in understanding teachers' experiences with classroom zine-making. Additionally, the data revealed six common themes that influence a teacher's disposition and ability to introduce a zine-making project in the classroom: experience, inspiration, mindset, resources, support, and setting. The results of my study provide insight into teachers' 
experience with zine-making in the classroom and hope to contribute to the existing zine pedagogy by identifying the literacy benefits as well as challenges. The results of the study may be significant in its potential contributions to the understanding of the educational significance of zines, the development of usable zine pedagogy and the understanding of zine-making as a classroom literacy practice that promotes literacy, learning and student voice. 


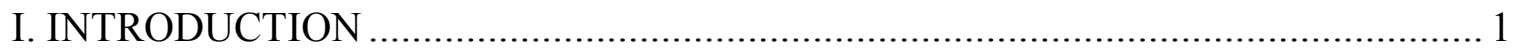

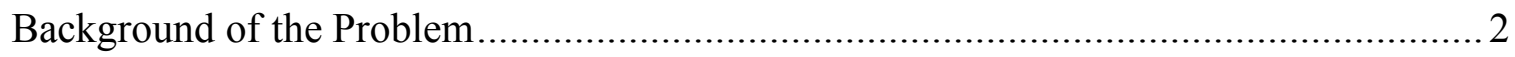

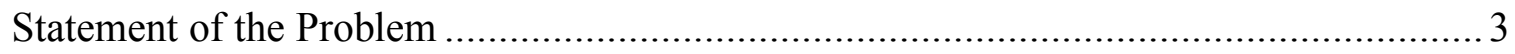

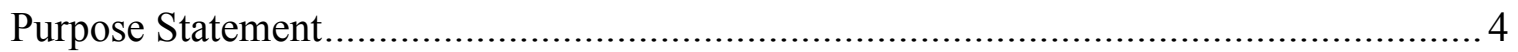

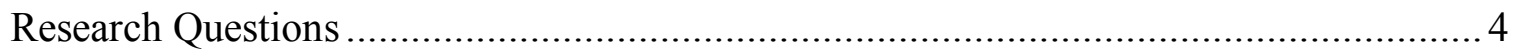

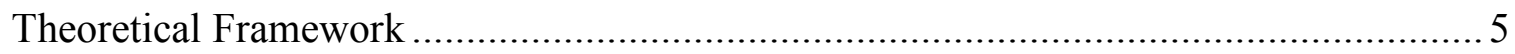

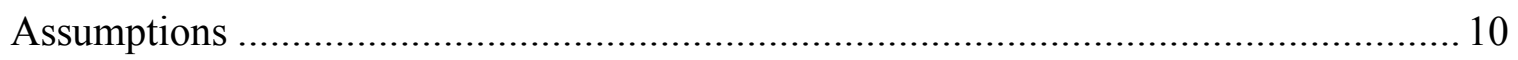

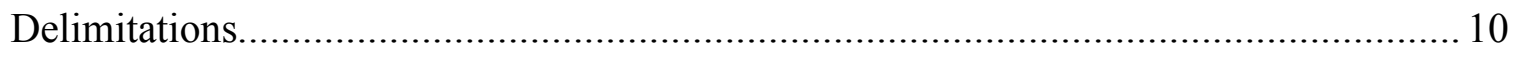

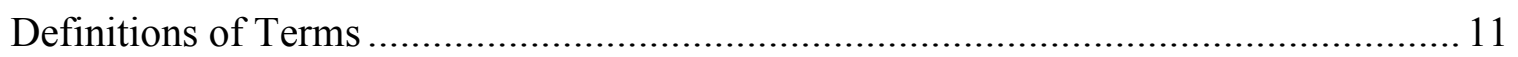

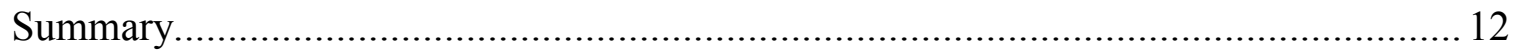

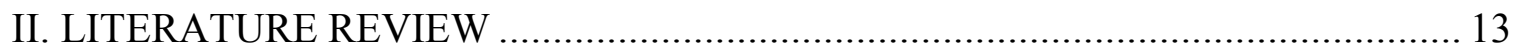

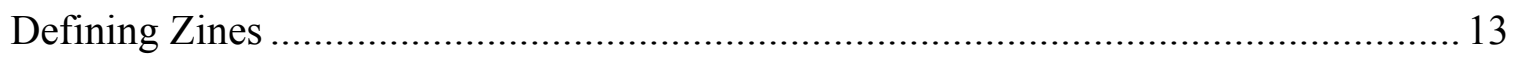

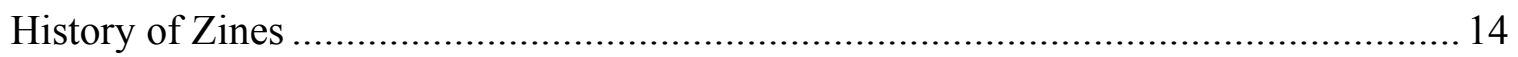

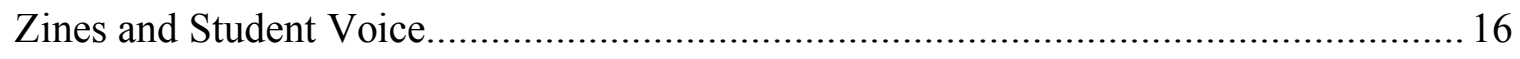

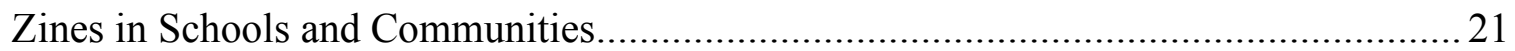

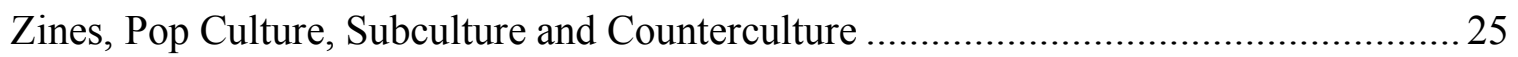

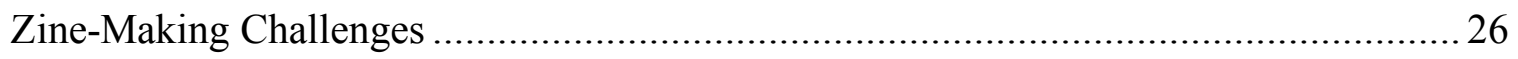

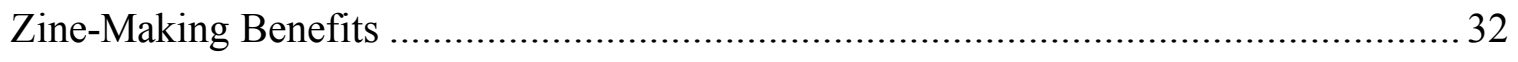

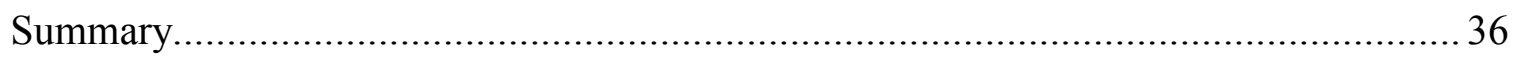

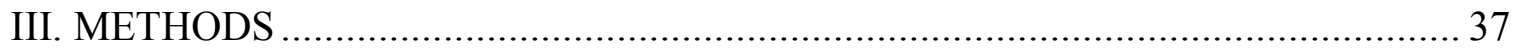

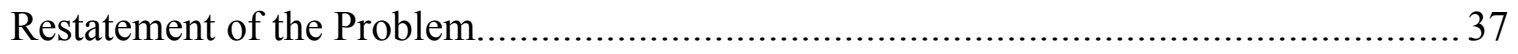

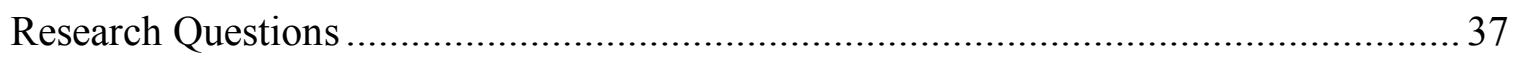

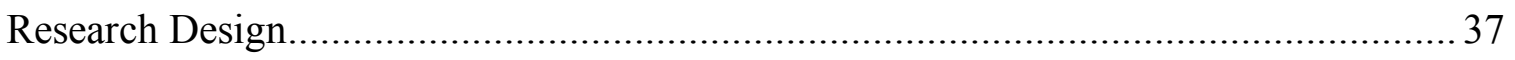

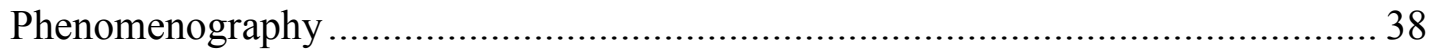

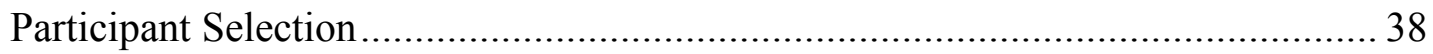

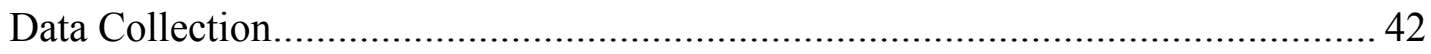

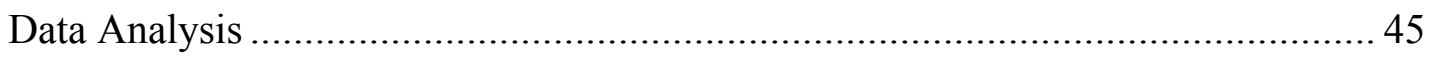

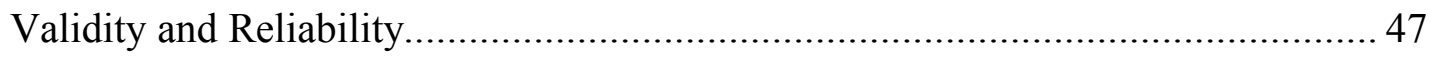




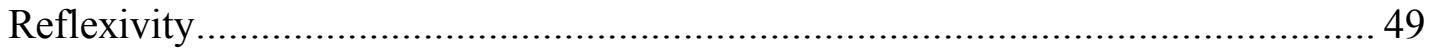

Summary

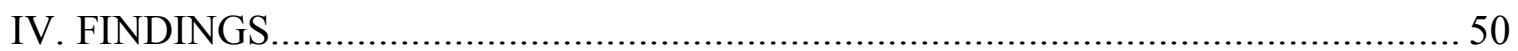

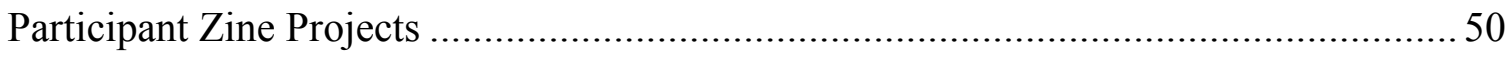

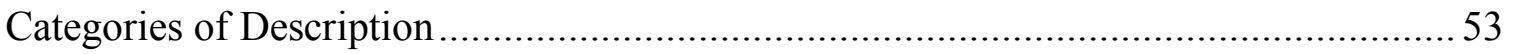

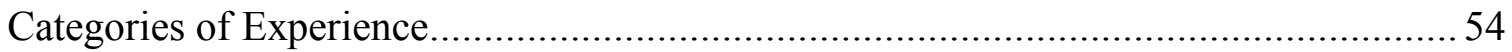

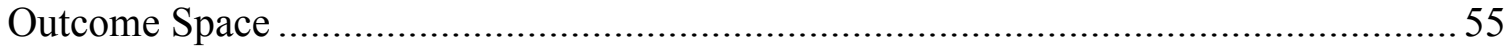

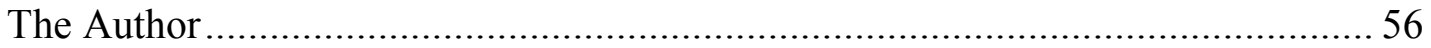

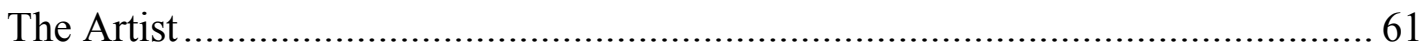

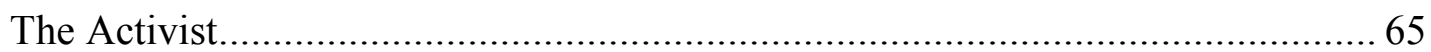

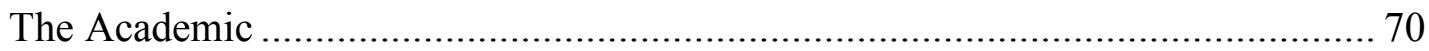

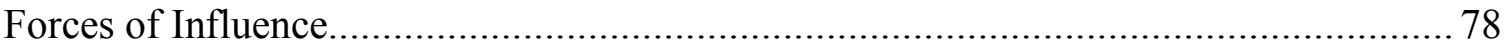

Summary

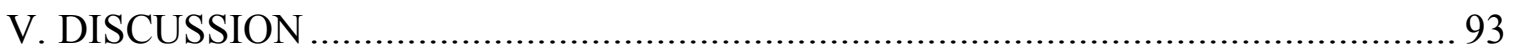

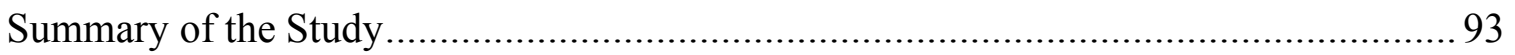

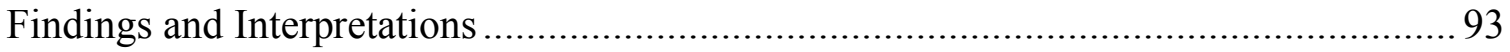

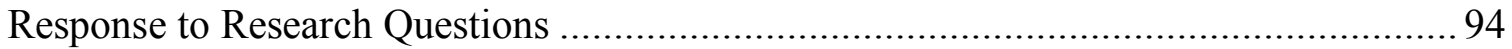

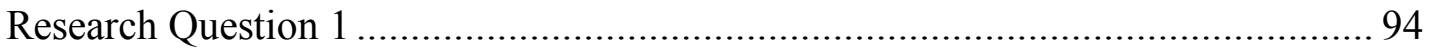

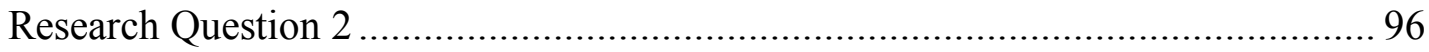

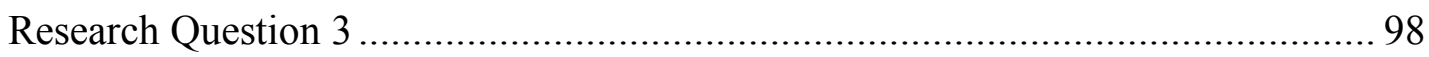

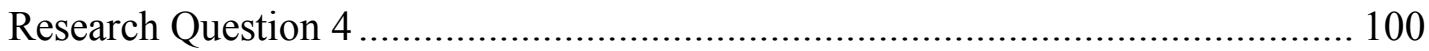

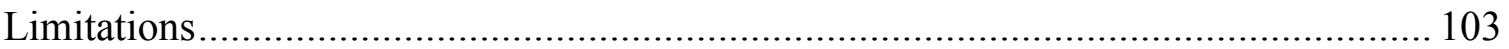

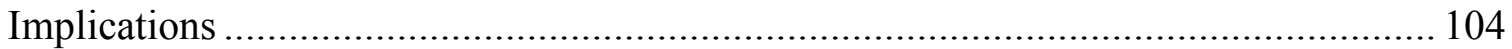

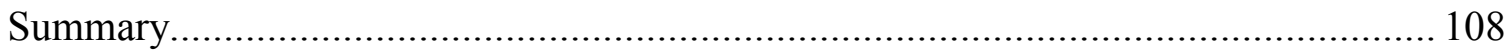

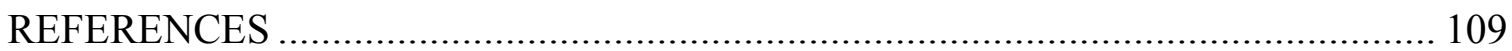

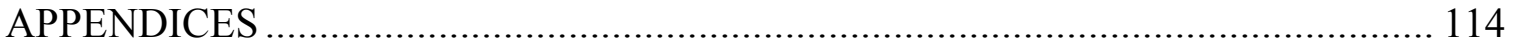

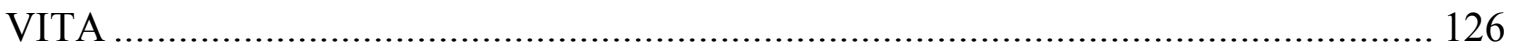




\section{LIST OF FIGURES}

FIGURE

PAGE

1. Theoretical Framework ................................................................................. 5

2. Zine-Making as Transdisciplinary Learning ....................................................... 10

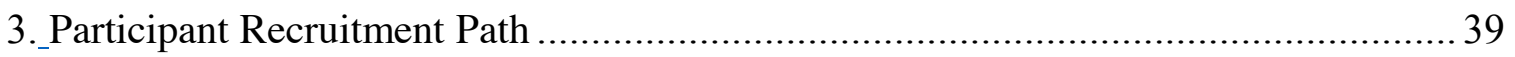

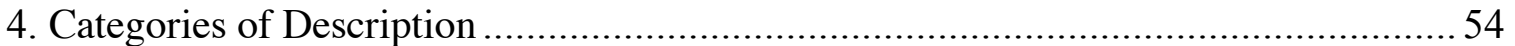

5. Phenomenographic Outcome Space............................................................... 76

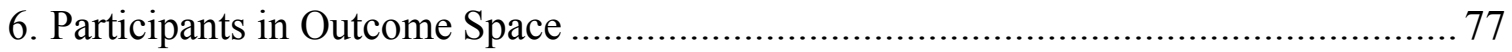

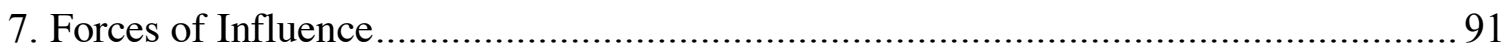




\section{CHAPTER I}

\section{INTRODUCTION}

A zine (pronounced zeen), derived from the word magazine, is a short, selfcreated, and self-published booklet filled with writing, drawing, poetry, collage, and other text and images. Zines cover a wide array of topics and can be about anything at all. Zines differ from traditional magazines in their format and purpose because they are usually handmade and not for profit.

Historically, zines have been associated with an underground, activist or radical literary subculture, as they "embody ideas and assume action" (Guzzetti, Foley, \& Lesley, 2015, p. 592). However, recently, zines have caught the attention of academia for their potential as a pedagogical practice (Lymn, 2018).

Common themes across the research on zines address the areas of power, participation and voice. The present study aims to expand on those themes in order to understand the different ways teachers approach and create space for zine-making in school.

Despite zines being a potentially powerful tool for literacy, learning, and student voice, zines are largely absent from school. While there is a body of research that exists about zine subculture, especially as it relates to activism, relatively little scholarly research exists on using zines as a pedagogical practice to promote literacy, learning, and student voice inside the traditional classroom. Chapter I will introduce the background of the problem, problem statement, purpose of the study, research questions, theoretical framework, assumptions, delimitations, and definitions of terms for the present study. 


\section{Background of the Problem}

Research shows that adolescents "frequently describe their school experiences as anonymous places in which they have no voice, and no one cares about them" (Mitra, 2018, p. 473). Researchers have proposed this disengagement often has negative outcomes such as poor grades, low self-esteem, and high drop-out rates (Mitra, 2018). To address the growing feeling of alienation among young people, there has been an increased effort to include student voice in schools over the past three decades (Mitra, 2018).

Numerous researchers have studied zines as an out-of-school literacy practice as a platform for youth voices and have discovered that zines often give voice to sociallymarginalized groups to express to their opinions and beliefs (Guzzetti et al., 2015;

Guzzetti \& Gamboa, 2004; Jacobi, 2007; Knobel \& Lankshear, 2002; Piepmeier, 2008). Many have contended that zines hold the promise of creating a space for student voice that may not otherwise be available in school (Congdon \& Blandy, 2003; Jacobi, 2007; Piepmeier, 2008).

There have been several studies that describe individual classroom zine projects where teachers have found zine-making to be a useful and powerful literacy tool for disciplinary learning and civic engagement (Bott, 2002; Congdon \& Blandy, 2003; Kawai \& Cody, 2015; Yang, 2010). In addition, the unique format of zines, which combines art and writing, makes them an ideal medium for arts-literacy integration. Yet, despite zines potential as powerful literacy tool, relatively little scholarly research exists on school zines and "the medium has been all but ignored by educational researchers" (Knobel \& Lankshear, 2002, p.164). 
As educators, it is important that we teach students to move beyond being mere consumers of knowledge and help them become producers of knowledge and communicators of their ideas (Yang, 2010). If the goal of literacy education is to produce critical readers, writers and thinkers, then "it is more important now more than ever that schools encourage students to produce texts that matter to them in different formats and for different audiences and purposes" (Janks, 2010, p.156).

Zine-making can be a powerful tool because it "asks students to be active, to participate, and to engage in dialogue as opposed to being passive receivers of expert information" (Congdon \& Blandy, 2003, p.45). In a larger sense, zines give students the opportunity to write back to power (Janks, 2010).

However, there are unique challenges posed when integrating zines into the classroom (Congdon \& Blandy, 2003; Guzzetti et al., 2015; Jacobi, 2007; Kawai \& Cody, 2015), as well as concerns about mainstreaming zines, which have thrived as a subcultural trend (Jacobi, 2007). Because zines exist as a subcultural trend, some have asked whether zines belong in the classroom at all (Guzzetti et al., 2015). Although zines challenge the norm, Lymn (2018) argues that "if literacy extends to a visual, artistic and/or embodied way of knowing the world, then zines have a place in the classroom" (p.24). A body of qualitative research shows that zines embody a breadth of literacies and possibilities, (Knobel \& Lankshear, 2002; Lankshear \& Knobel, 2018; Lymm, 2018), therefore, researchers urge further study of school zines.

\section{Statement of the Problem}

Zines are a medium that have the power to create critical readers, writers and thinkers, yet there are challenges to integrating zines into the constraints of a classroom 
setting. If we want to employ zines as a pedagogical practice to promote literacy, learning, and student voice, then examining the use zines in the classroom is worthy of continued attention.

\section{Purpose Statement}

The purpose of this qualitative research study is to explore the experiences of elementary, middle and high school teachers using zine-making as a pedagogical tool to promote literacy, learning, and student voice in schools throughout the United States.

\section{Research Questions}

The present study explores four qualitative research questions as follows:

1. What are the different ways educators experience, think about and approach zine-making in the classroom?

2. From their experience, what do educators view as the purpose and literacy benefits of zine-making in the classroom?

3. How do educators create space for student voice to thrive in the classroom through zine-making?

4. What do educators see as the benefits and challenges of integrating zinemaking in the classroom?

\section{Significance of the Study}

The results of the present study may be significant in their potential contributions to the understanding of the educational significance of zines, the development of usable zine pedagogy, and the understanding of zine-making as a classroom literacy practice. From a practice perspective, the results may provide insight on how to create space for zines in the classroom to promotes literacy, learning, and student voice. 


\section{Theoretical Framework}

The theoretical framework of the present study situates zine-making within a sociocultural orientation to literacy. Using participatory literacy and critical literacy as a lens, we can further position zines at the intersection of critical text production (Janks, 2010), student voice (Robinson \& Taylor, 2007; Rudduck \& Fielding 2006; Taylor \& Robinson, 2009) and transdisciplinary learning theories (McGregor, 2004). Figure 1 provides a representation of the theories and concepts central to the understanding of zine-making as a pedagogical practice.

\section{Figure 1}

Theoretical Framework

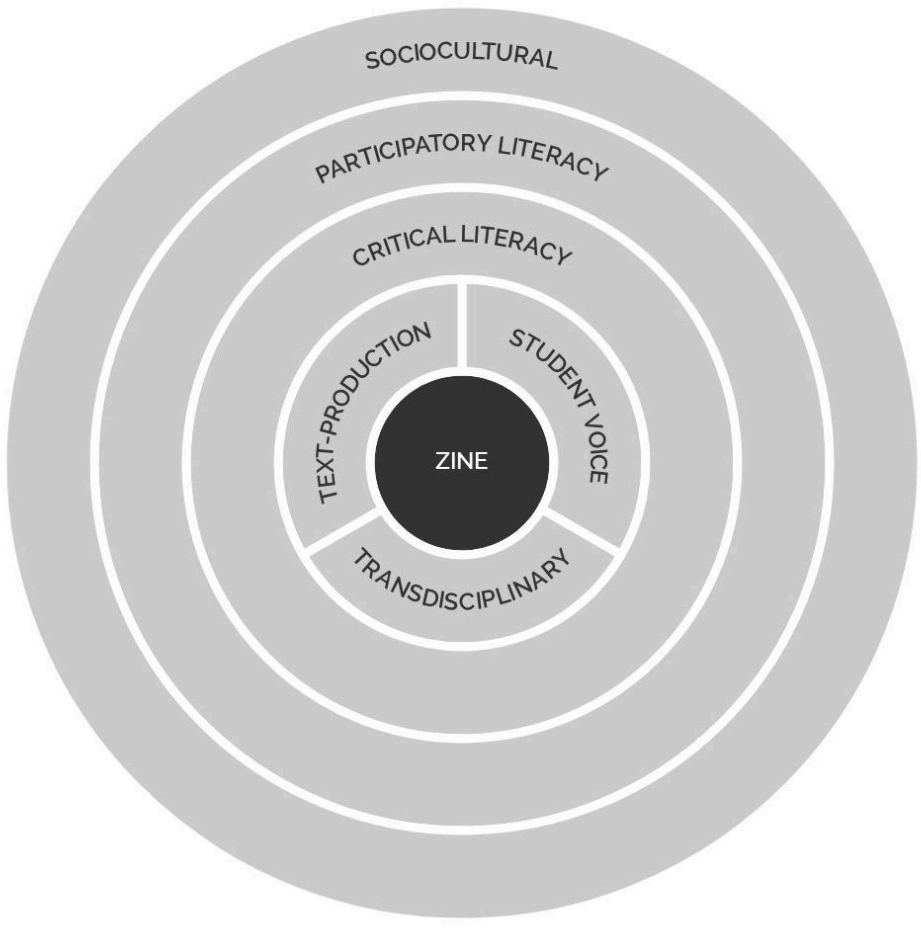




\section{Sociocultural Theory}

A sociocultural orientation of literacy maintains that literacy is not just a set of skills, but rather "literacy is a social practice tied to culture and power structures" (Street, 1993, as cited in Janks, 2010, p. 118). Janks (2010), maintains that literacy is tied to power where power is used "to sustain a particular discourse and to establish its hegemony" (p. 50).

\section{Participatory Literacy}

Rooted in the work of Paulo Freire (1972), is the concept of participatory literacy. Freire (1972) theorized in his writing, Pedagogy of the Oppressed, that the goal of literacy education was to promote democracy and social change through dialogue for those who were oppressed or marginalized (Robinson \& Taylor, 2007).

According to Freirean pedagogy, "the task of the oppressed is to liberate themselves and, in the process, liberate their oppressors" (Taylor \& Robinson, 2009, p.165). The process through which social change occurs is through democratic or participatory learning (Taylor \& Robinson, 2009). According to Jurmo (1989), participatory literacy creates social change by enabling learners to participate in their learning with higher degree of responsibility and control.

Zines embody a form of participatory literacy because they require that students be active producers of knowledge and communicators of ideas. Participatory literacy requires action (Jurmo, 1989). Furthermore, participatory literacy fosters critical literacy.

\section{Critical Literacy}

A critical literacy framework is useful for examining literacy work whose goal is to create "a more critically informed and just world" (Vasquez, 2017, p. 1). Critical 
literacy is also rooted in the work of Paulo Freire. In his work, Freire (1972) famously argued that "the human word is more than mere vocabulary - it is word-and-action. The cognitive dimensions of the literacy process must include the relationships of men [and women] with their world" (Freire, 1972, as cited in Janks, 2013, p. 22).

According to Janks (2013), “critical literacy is about enabling young people to read both the word and the world in relation to power, identity, difference and access to knowledge, skills, tools and resources" (p. 227). Critical literacy research has largely focused its attention on critical reading and the reception of texts (Janks, 2010). However, the present study, will examine zine-making through the lens of critical writing and the production of texts.

\section{Critical Writing \& Text Production}

Janks (2010) maintains that critical writing can contribute to social and identity transformation through the production of text. Critical writing should foster the ability to produce texts "that enable students to choose what meanings to make; produce texts that enables students to act on the world; construct texts that gives students a better understanding of the affordances and constraints of different modes; actively combine and recombine symbolic forms; produce texts that enable students to redesign their texts and the texts of others" (p.156).

Janks (2010) theorizes an Interdependent Model of critical text production, which examines the relationships of four interdependent elements: design, power, access and diversity. Janks (2013) defines the elements in her model as follows: design refers to text production and multimodality; power refers to the struggle of "whose meanings, identity, values and culture prevail" (p. 234); access refers to who has access to which discourses 
and who has access to real audiences; diversity recognizes that different communities use literacy for different purposes. Janks (2013) further theorizes that as these four elements are interdependent, each one of the elements can become foregrounded or backgrounded in different literacy projects. For example, "design without power is unable to effect change; design without access runs the risk that whatever is designed will remain in the margins" (p. 226). Situating zine-making within Janks' Interdependent Model of text production, we can argue that the elements design, power, access and diversity are all central to zine-making. Zine-making can be further justified within a critical text production framework, as Janks (2013) maintains critical text production encourages students to make texts about things that matter to them. By focusing on what they produce rather than on what they consume; by fostering creativity; by providing opportunities for them share their work with audiences; we can help students see what the purpose of literacy is for (Janks, 2013).

\section{Student Voice}

Freire's pedagogy has served as a cornerstone for almost all student voice work. Until recently, understanding of student voice has been situated within a Freirean democratic and participatory framework (Robinson \& Taylor, 2007; Taylor \& Robinson, 2009). However, current postmodern theorists have offered a critique of Freire's framework in that "it sees power as something you have or don't have. Something quantifiable to be given or taken away" (Robinson \& Taylor, 2007, p. 13). A postmodern view asserts that this binary view of power fails to recognize that power is constantly changing and negotiated (Taylor \& Robinson, 2009). 
Contemporary student voice work is situated within an understanding that power relations are not straightforward (Robinson \& Taylor, 2007). A postmodern view of student voice considers power relations as dynamic between teachers and students. A postmodern understanding of power relations has yielded a more contemporary theoretical framework that addresses student voice in practice. According to Rudduck and Fielding (2006), three issues that underlie student voice are power relations between teachers and students, the commitment to authenticity, and inclusiveness (Rudduck \& Fielding, 2006; Taylor \& Robinson, 2009). Because student voice is central to zinemaking, we must examine zines within a student voice framework that takes into account the issues of power, authenticity and inclusiveness.

\section{Transdisciplinary Learning}

Transdisciplinary learning is learning that happens across the disciplines, between the disciplines, and beyond the disciplines (McGregor, 2004). Because it traverses all disciplines, transdisciplinary learning moves beyond interdisciplinary learning in that interdisciplinary learning synthesizes information from more than one discipline, while transdisciplinary relates all disciplines into a whole to create something entirely new (McGregor, 2004). Transdisciplinary learning requires active learning and therefore, combines interdisciplinary learning with participatory approach (Tress, Tress \& Fry, 2005). Because transdisciplinary learning requires participatory, active learning, it can engage students across grade levels and subjects. A transdisciplinary approach requires a higher level of integration of knowledge, concepts, and skills through multiple disciplines in order to help learners make connections that broaden understanding (Helmane \& Briska, 2017). 
Zines-making embodies a transdisciplinary approach to learning because it combines reading, writing, art, social studies, math and science and other disciplines to create something new. Figure 2 illustrates the space where zine-making conceptually exists in relationship to transdisciplinary learning (Increasing Levels of Integration Model adapted and modified from Kaufmann, Moss, \& Osborn, 2003, as cited in Helmane \& Briska, 2017).

\section{Figure 2}

\section{Zine-Making as Transdisciplinary Learning}

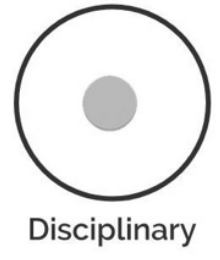

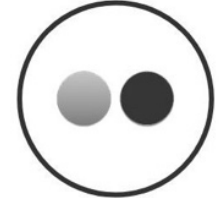

Multidisciplinary

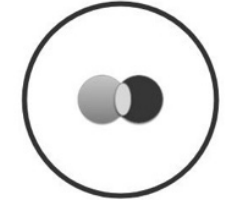

Interdisciplinary

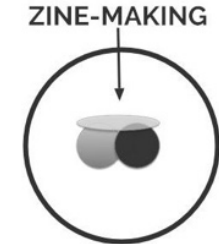

Transdisciplinary

Increasing Levels of Integration

\section{Assumptions}

The present study is supported by three main assumptions. First, that zine-making is a potentially valuable tool for student learning. Second, that zine-making within a classroom setting poses challenges. Third, there is a need to further explore zine-making in the classroom.

\section{Delimitations}

The present study explores zine-making from the perspective of educators and is delimited to interviews with educators who have had at least one zine-making experience with elementary, middle, or high school students. The present study does not include 
perspectives from students, administrators, or the larger zine community. Furthermore, the present study was limited to the nine participants who were purposefully selected because of their experience with zine-making with kindergarten through $12^{\text {th }}$-grade students.

\section{Definitions of Terms}

The following terms related to zine-making are found throughout the literature and are briefly defined here: (Wrekk, 2014):

- Zine: A zine is (short for magazine) short self-made, self-published, not for profit booklet that contains a combination of writing and art.

- Zinester: A zinester is a term for any person who creates a zine.

- Zining: Zining (as a verb) is the act of making a zine.

- DIY: (Do It Yourself) refers to the homemade quality and process of zining.

- Zine fest: A zine fest (also referred to as a zine fair) is a community event organized by zinesters where they gather to showcase, buy, sell, trade and distribute their zines.

- Zine distro: A zine distro (short for distribution) is any place where zines are distributed such as bookstores, zine fairs, or online platforms

- Zine culture: Zine culture is the out of the mainstream, sometimes considered underground, activist, or radical literary culture that participates in zining. 
- Zine libraries: Libraries (either physical or online) dedicated to the collection, circulation, and archiving of zines.

- Zine pedagogy: The method of practicing or teaching with zines.

\section{Summary}

This chapter introduced zine-making as a literacy practice and proposed that there is a need for further study of the educational significance of zines. This qualitative study will focus on exploring teachers experiences with integrating zines in the classroom setting. The chapter set forth the study's theoretical framework, situating zines within a sociocultural, participatory literacy, critical literacy, framework, further positioning zines at the intersection of critical text production, student voice, and transdisciplinary learning theories. The final section set forth the study's assumptions, delimitations and provided definitions of key terms. 


\section{CHAPTER II}

\section{LITERATURE REVIEW}

This literature review will bring into focus the current research that exists about zines. This will include the definition of zines, the history of zines, zines and student voice, zines in schools and communities, zines in relation to pop culture, subculture and counterculture. Finally, this chapter will examine the existing literature on benefits and challenges of integrating zines in a school setting.

\section{Defining Zines}

There is no single definition of zines and although the definition of zines may differ, zines share certain distinct characteristics: They are self-made, self-published and not for profit.

Guzzetti et al. (2015) defines zines as "self-publication written by youth and adults (referred to as zinesters) as alternatives to commercial magazines” (p. 591). Kawai and Cody (2015) define zines as "homemade magazines centered on a current events topic that is of great interest to the students" (p. 22). Yang (2010) states, zines are small independent, noncommercial and self-made books.

According to Lymn (2018):

Zines are messy; they're hard to define and they make things feel a little bit uncomfortable. And this is their beauty. By challenging assumptions about definition, location and genre, they engage and inspire, and they encourage us to think even a little bit differently about the world. In some ways the easiest way to define zines is by what they are not: they aren't part of a formal, defined writing and publishing culture governed by rules and institutions in the way that books or magazines are (p.18).

Perhaps the most colorful definition of zines is provided by Congdon and Blandy (2003), in which they describe zines as: 
An amalgam of original and appropriated images and text from a variety of sources including comic books, posters, album covers, graffiti, tagging, thrasher [skateboard] art, tattoo flash, television, and the history of "fine art" and literature. Zinesters combine iconography and text to create publications that can be chaotic, disturbing, uncomfortable, sensual, complex, loud, confrontive, and often a social critique of contemporary life. Gender roles, religion, familial relationships, politics, sexual orientation, the environment, academic disciplines, the arts, class structure, ethnicity, generational differences, economics, and pop culture are among the many issues celebrated, skewered, deconstructed, reconstructed, and illuminated by zinesters ( p.45).

Nemergut (2018) in her published zine, poetically writes:

I love zines. They are beautiful and punk rock, sloppy and earnest, delicate and bold. They are short (or sometimes long) love letters to friends, ancestors and yourself. They give you a thread to hold on to and connect across generations and continents. They are a place to scream and cry into when there isn't a physical one. They are secret skills that are whispered to one another for survival. They are the stories that no one else will make room for. They are questionings and reckonings, flares for other to find. But if that isn't super helpful, zines are small, self-published, and easily reproducible magazines (p.1).

In simplest terms, the present study, defines zines as small, self-created and self-

published booklets filled with a combination of text and images that create a

message.

\section{History of Zines}

Zines have a long and rich history as a subcultural trend. Zine historians trace the beginning of the use of the word zine to the 1930s when science fiction fans created fanzines. But zines can be traced back to political pamphlets of the 17 th century. (Congdon \& Blandy, 2003). According to Congdon and Blandy (2003), "political pamphlets were crucial to the American Revolution, the emancipation of slaves, the women's suffrage movement, the labor movement, and the civil rights movement. 
Probably the most famous pamphlet in U.S. history is Thomas Paine's Common Sense" (p. 46).

During the 1960s and 1970s popular culture and political zines merged and young people created thousands of zines with social commentary. In the late 1970s, these influences merged again with the punk rock scene, drawing heavily on visual images (Congdon \& Blandy, 2003). In the 1980s zines as an art form emerged. In 1982, a publication called Factsheet Five (no longer published), reviewed and catalogued zines, creating a network for zinesters to circulate their work and trade zines with each other (Porter, 2016). With the invention of photocopying, zines flourished and in the late 1990's, and the political nature of zines expanded to include feminist perspectives through zines such as Riot Grrrl, an underground feminist movement closely tied to punk music, radical politics, activism and the creation of zines (Marcus, 2010). Up until the early 2000's, zines were essentially a subcultural trend operating outside the mainstream within an entire zine culture of mostly young zinesters making zines at home, at kitchen tables, in basements, in coffee shops, mailing them to their friends, distributing, trading them at independent bookstores and Zine Fests all over the country (Guzzetti et al., 2015; Knobel \& Lankshear, 2002; Lymn, 2018).

As zines have gained popularity, zine-making workshops have been organized by museums, libraries and community outreach programs. Many academic libraries have recognized the importance of zine voices in the larger narrative and have begun to catalogue and archive zines in their collections (Congdon \& Blandy, 2003; Thomas, 2018). Barnard's Zine Library (zines.barnard.edu) holds an extensive collection of zines in a searchable database. Their collection includes art zines, DIY zines, Fanzines, 
Literary zines, Mamazines, Metazines, Minicomics, One-page folding zines, personal zines (perzines), political zines, program zines, school zines and 24-hour zines. It is important to note for this study that school zines form their own category and may be of specific interest to this study in exploring school zine pedagogy.

Among others, University of Miami Libraries (merrick.library.miami) maintains a special collection of zines; and the Florida International University Wolfsonian Museum (zines.wolfsonian.org) archives and publishes the student made zines online. Universities and libraries that catalogue zines capture authentic writing that reflects the social issues of the day, capture voices that may otherwise be marginalized or erased, and also lend support for zines to be considered legitimate forms of knowledge and information (Thomas, 2018).

\section{Zine and Student Voice}

Zines matter because zines often give voice to socially marginalized groups to voice to their opinions and beliefs (Piepmeier, 2008). According to Erika Rienstien, founder of Riot Grrrl Press, zines matter "because every time we pick up a pen, or an instrument, or get anything done, we are creating the revolution. We are the revolution" (Porter, 2016). Fletcher (2017) echoes the revolutionary quality of zines by saying, "zines can be deemed revolutionary as a communication tool in the sense that they have enabled ordinary people to carve out a space to voice their ideas, concerns and convictions within a cultural, political and media landscape that largely fails to represent their lived reality" (p. 58). Fletcher (2017) believes that it can be a transformative experience when youth voices are taken seriously. He states the benefits of creating space for youth voices 
include access to multiple ways of learning, more equalized relationships with adults, and a genuine sense that their voices matter.

In education, the concept of student voice has been oriented to action, participation and change (Taylor \& Robinson, 2009). There is no one definition for student voice and it is a term that can include a wide array of practices including student consultation, participation, collaboration and leadership (Mitra, 2018). The term student voice "can range from the most basic level of youth sharing their opinions on problems and potential solutions; to allowing young people to collaborate with adults to address the problems in their schools; to youth taking the lead on seeking change" (Mitra, 2018, p. 473). The concept of student voice can include even simply talking to students about things that matter to them at school (Rudduck \& Fielding, 2006). Recent research also argues for the inclusion of poetry, hip-hop and protest, into the definition of what constitutes student voice (Mitra, 2018). Similarly, zines can serve as a powerful literacy tool to develop student voice in the classroom (Kawai \& Cody, 2015; Piepmeier, 2008).

In the past ten years, key researchers in the area of student voice have worked towards forming a theoretical framework that addresses student voice in practice. According to Rudduck and Fielding (2006), three of the big issues that underlie student voice are (1) power relations between teachers and students, (2) the commitment to authenticity, and (3) inclusiveness (Rudduck \& Fielding, 2006; Taylor \& Robinson, 2009).

Power. Student voice work begins with the recognition that "power inhabits all processes of social communication" (Robinson \& Taylor, 2007, p.12). In examining student voice and its relationship to power, we turn back to Freire. His theories of the 
purpose of education as a means to transform the self and thereby transform the world have shaped critical pedagogy (Taylor \& Robinson, 2009). Freire distinguished between the transmission or banking forms of education and social constructivist or liberatory forms of education (Taylor \& Robinson, 2009). According to Freirean theory, "banking education transmits pre-selected knowledge, it presumes a world of subjects (teachers) and objects (students) arranged in a hierarchical relation in which only the former have power" (Cook-Sather, 2002, p.4). In a Freirean framework, student voice work challenges the idea of students as blank slates, teachers as sole authors of what students learn (CookSather, 2002).

However, current postmodern theorists have offered a critique of Freire's framework in that "it sees power as something you have or don't have. Something quantifiable to be given or taken away" (Robinson \& Taylor, 2007, p. 13). Radical pedagogy makes the fundamental assumption that power is a possession of a particular group and that it is wielded over others (Robinson \& Taylor, 2007). A postmodern view asserts that this binary view of power fails to recognize that power is constantly changing and negotiated (Taylor \& Robinson, 2009).

A postmodern view of student voice considers power relations as dynamic between teachers and students. In a postmodern theorization, power is constantly negotiated (Robinson \& Taylor 2007). Taylor and Robinson (2009) argue that postmodernist theorizations of power may offer greater understanding of what constitutes student voice and power beyond binary theories.

Robinson and Taylor (2007) theorize that at the heart of the practice of student voice practice are four core values: "1. A conception of communication as dialogue. 2. 
The requirement for participation and democratic inclusiveness. 3 . The recognition that power relations are unequal and problematic. 4. The possibility for change and transformation" (p. 8).

Authenticity. One of the aims of student voice work is to listen to students' views, thoughts, feelings and experiences. Authenticity includes the genuine interest in what students think and have to say (Quinn \& Owen, 2016). However, listening to students is not enough. What happens with the information is also important. According to Rudduck and Fielding (2006), for students, authenticity rests on three things: whether they have been involved in determining the topic; whether adults interest in what they have to say is real; and whether there is active follow through on their ideas. If student voice is not combined with authenticity, then the result can be empty rhetoric (CookSather, 2014; Rudduck \& Fielding, 2006). According to Mitra (2018), “when student voice is poorly designed and tokenistic, students may be disempowered and have reduced self-concept when participating in student voice activities" (p. 479). Furthermore, the promise of voice without actually being heard can lead to "increased alienation and disconnection from schooling" (Mitra, 2018, p. 474).

Zines can be an authentic medium for expression. Spencer (2008) explains, "zines give a voice to the everyday anonymous person. The basic idea is that someone sits down, writes, collects, draws or edits a bunch of stuff they are interested in or care deeply about...and distributes it. The zine creating process is a direct one, remaining under the writer's control at all times. Perhaps its outstanding facet is that it exists without any outside interference, without any control from above, without any censorship, without any supervision or manipulation" (p. 122). However, zines in school run the risk of being 
censored, mediated or controlled by teachers and therefore, they stand to lose authenticity (Gibb, 2013).

Inclusiveness. In addition to challenging the idea of binary power, postmodernism challenges the concept of student voice being singular. According to Taylor and Robinson (2009), postmodernism recognizes differences and refuses to reduce the multitude of competing voices to one.

Inclusiveness in student voice centers around whose voices are heard and whose are left out. Rudduck and Fielding (2006), contend that we need to pay attention to whose voices are heard in school. Many students feel that teachers only listen to the good kids (Rudduck \& Fielding, 2006; Taylor \& Robinson, 2009). Taylor and Robinson (2009) note that that students "who speak responsibly, intelligibly and usefully are heard and, that those whose voices are incomprehensible, recalcitrant or even obnoxious, are the voices we do not wish or choose to hear" (p. 167). In addition, many scholars have called for greater diversity of ethnicity, gender and ability in student voice (Cook-Sather, 2014; Mitra, 2018).

Zines have historically included marginalized voices. However, if teachers force students to make zines or to share zines, they may not be comfortable sharing, then they risk silencing the voices of those who are not comfortable in this medium. Sharing personal stories through zines can serve to isolate some students. Bernhardt (2009) incorporated an autobiography assignment in his class similar to creating a perzine (personal zine). He recalls "the only risks I was concerned about were those that I was taking as a teacher... as a result I did not leave space for students who may have needed 
more time to become comfortable ...nor did I provide options for those who were not prepared to explore or reveal the personal" (p.65).

\section{Zines in Schools and Communities}

Although there is a lack of scholarly research on school zines, there are many published articles that describe zine projects that have been integrated into school and community settings. Programs such as FIU's Wolfsonian Zines for Progress partner with local high schools in Miami-Dade County to make zines where students can express their creativity and find their voice on social issues (Kiah, 2017). According to Welch, the

director of the program, "The idea was to give voice to marginalized, unconventional and controversial points of view and experiences, and I would say in certain cases there was definitely a tone of anarchy and an attempt to subvert the dominant paradigm" (Kia, 2017, p.1).

Another university teen partnership called the Zine Project is described by Jacobi, (2007). In this project, Colorado State University students and community youth writers participate in an eight-week community zine-making program. In this project, Jacobi (2007) saw how zine-making in this setting "makes space for students to experiment with discourse and power" (p. 4). From this community project, Jacobi (2007) concludes that zines "demonstrate a critical literacy in which writers are more than quiet participants in traditional school curricula increasingly driven by test scores and contextually empty, ignorant mandates" (p. 4).

While zines have become visible at universities, museums and community outreach programs, not a lot is known about zine-making happening inside individual classrooms. When examining zines in the classroom, Lymn (2018) has asked, "Who 
brings the zines into the classroom? How did they get them? Is the content something that belongs in a classroom? Whose classroom are they in (Art, English Social Studies?) Can you teach zine-making in a classroom? Who is going to judge the zines? Censor them? Assess them?" (p. 19). These are important questions that remain to be answered from future research.

From the current literature it appears that relatively few teachers use zines in the classroom and only a small amount of scholarly research has been done on classroom zines. To date in the current research, there is a lack of research that examines multiple teachers experiences across disciplines with zine-making to compare their experiences. However, there are some individual teachers who have described their zine projects and their experiences can contribute to the existing zine pedagogy.

Piepmeier (2008) says, "I became aware of the significance of the materiality of zines through my teaching. Every time I teach a class about zines, a significant percentage of the students begin making their own. Many of them have never heard of zines, but when I bring in a pile for them to flip through and take home, they become inspired" (p. 57).

Bott (2002) described how she used zines in her classroom as a creative writing project. Using the novel, Hard Love by Ellen Wittlinger as a springboard, she created a zine-making project in her language arts classroom. She had no prior experience making zines, but she saw it as a literacy opportunity. Before starting her project, Bott (2002) says, "at school I talked about the project with other teachers and set-up a meeting for all who would be risk-takers" (Bott, 2002, p. 27). The fact that Bott (2002) refers to herself and the other teachers as risk-takers shows the unconventionality of zine-making in the 
classroom. Bott (2002) describes a benefit of her project as follows, "as the students invested more time and effort in their work, they started to share their writings. The contagious enthusiasm, pride and courage to try were evident in every corner of our room. Each student's success motivated the other students" (p. 31).

Zines are not only applicable in the area of language arts, as in Bott's (2002) zine project, they may be especially relevant in social studies education. Kawai and Cody (2015) describe a fifth-grade civics zine project. They began with a central question of how they could help students develop of sense of civic agency in classroom. To introduce the unit, they began with an open-ended question, such as "What do you know that's going on in the world around you? So, what can we do about these in our own neighborhoods?" (Kawai \& Cody, p. 22).

Kawai and Cody (2015) developed a five-step process for making civics zines: "Select a topic of personal interest; research the topic for broad understanding; write for the authentic civic purpose; propose and plan for civic action, and; take local civic action" (p. 22). In addition to the five-step process, they prepared students to support the importance of their topic by posing the following five questions: "What is your zine topic? Why do you care about it? Who will be helped because of your research? Why is it important? How can you make a change?" (p. 23).

Yang (2010) also makes suggestions for helping students plan zines. When creating science zines in the classroom, he suggests that students brainstorm three or four ideas and then decide based on the information available to research the topic and the complexity of communicating the ideas. He asks students, "What topic will make a good zine? Who will read your zine? And why will people want to read your zine? Is it eye- 
catching? Does it have an interesting title?” (Yang, 2010, p. 575). Yang (2010) notes some examples of science zines topics such as dinosaurs, biodiversity, environment and health. Kawai and Cody (2015) describe that students made zines on a variety of subjects, for example, global hunger, obesity, animal cruelty, donating blood. Some of the zine makers took action resulting from their zine, for example organizing a blood drive with the Red Cross.

Although it appears that relatively few teachers have used zine-making as a classroom project, Knobel and Lankshear (2002) believe that "many learners and teachers might benefit greatly simply from becoming more aware of zine culture. Teachers who have described zine-making projects in their classroom have found that zines are a powerful tool for developing critical literacy. Zines serve as models for using multitextual forms in their writing including collage, images, graphics, photographs and drawings. Zines can also serve to teach students "to read and write texts like experts" (Guzzetti et al., 2015).

From their unit on civics zines, Cody and Kawai (2015) concluded that zinemaking can encourage students to be more thoughtful, capable and active citizens. From their research using zines to teach postmodernism, Congdon and Blandy (2003) found that zine-making was a successful pedagogical strategy for encouraging students to participate in discourse. Finally, Guzzetti et al. (2015) proposes that we can use zinemaking to foster a passion and produce "lifetime learners that are active participants in and creators of disciplinary knowledge and culture" (p. 599). 


\section{Zines, Pop Culture, Subculture and Counterculture}

In order engage young people in school, it has become increasingly popular for educators to incorporate youth pop culture and out of school literacies into their classrooms as a pedagogical tool (Fisher, 2005). Mahiri (2000), found strong connections between urban youth's literacy practices with popular culture and the types of literacies required in schools. Morrell (2002) suggests that teaching of popular culture serves to make connections for students that are relevant.

The definition of pop culture varies by who is defining it and in what context. In its broadest definition, popular culture reflects the pattern of cultural experiences and attitudes that exist in mainstream society and is usually transmitted and expressed through mass media such as TV, movies, publishers, and websites and is sometimes referred to as mass culture (Mahiri, 2000). Pop culture includes hip-hop, rap, music, videos, TV shows, cartoons, comic books, graphic novels, graffiti, fashion trends, sports figures, comedians and celebrities (Akom, 2009; Mahiri, 2000).

Mahiri (2000) argues that pop culture includes the many ways that young people "practice non-school literacy and express themselves" (p. 384). Critical researchers in pop culture pedagogy have made the distinction between pop culture and mass culture. For example, Morrell (2002), defines popular culture as "a site of struggle between the subordinate and the dominant groups in society (p. 73). He argues that "popular culture is not an imposed mass culture or a people's culture; it is more a terrain of exchange between the two" (p. 73). Therefore, we could ask if zines are considered pop culture? Looking at the literature one could say technically and historically that zines are not pop culture (Congdon \& Blandy, 2003; Guzzetti et al., 2015; Knobel \& Lankshear, 2002). In 
the broadest definitions of pop culture, zines do not reflect the experiences and attitudes that exist in mainstream society spread via commercial media. In contrast, zines are considered a counterculture that rejects some of the larger culture's norms and values. They often express the voices of feminist, LGBTQ, liberal, anti-commercialism and activist viewpoints (Guzzetti, Campbell, Duke, \& Irving, 2003; Guzzetti et al., 2015). Zines have also been referred to as underground culture, subversive, alternative and radical (Guzzetti et al., 2003; Guzzetti et al., 2015; Knobel \& Lankshear, 2002).

Although zines have a history as a subcultural trend, recently popular culture has taken notice of zines and they have received mainstream attention. Whatever cultural space zines occupy, zines and pop-culture are inextricably related, as counterculture cannot exist without resistance to popular culture (Duncum, 2009). Duncum (2009) states that "popular culture is both conformist and transgressive in nature. Moreover, these opposed tendencies frequently operate within the one site, as if folding into one another" $(p, 232)$. Although zines are considered primarily as a subcultural trend, zine pedagogy embodies many of the same benefits and faces many of the same challenges as pop culture pedagogies, and therefore parallels for integrating zine culture into the classroom can be easily drawn.

\section{Zine-Making Challenges}

While the idea of incorporating popular culture in the classroom is exciting, teachers who support the idea may feel out of touch and "often experience confusion and anxiety, and feel unprepared for the project" (Morrell, 2002, p. 73). According to Callahan and Bronwen (2004), introducing pop culture into the classroom is sometimes risky due to the content. 
Teachers aren't the only ones who feel vulnerable when pop culture is used in the classroom. Endsley (2013) incorporated spoken word poetry into the university classroom and found that "the open-ended structure of the assignment left many students uncomfortable" (p. 117). Similarly, with zines, teachers need to make sure they are not imposing zines on students "who may feel uncomfortable, or forced to share their stories" (Gibb, 2013, p. 20). One zine teacher points out that “people won't always feel comfortable writing a perzine (personal-zine) and sharing it with their teacher, particularly if they are then being graded on what they share" (Gibb, 2013, p. 20).

Another challenge to incorporating pop culture into the classroom is that it is often not seen as a legitimate form of literacy in school (Akom, 2009; Knobel \& Lankshear, 2002). According to Akom (2009), "hip hop is often associated with the realm of leisure and anti-intellectualism" (p. 53). Graphic novels have been met with criticism and denial as a legitimate form of literature and have been seen as substandard (Yildirim, 2013). Researchers note that "students question why these texts are not seen as legitimate school knowledge" (Moeller, 2008, as cited in Mathews, 2011, p. 417). Similarly, zines face the challenge of not being real reading material or real writing. Schemmer (2104), a zine writer, expresses her frustration. She says, "What makes my words that belong in zines any different from my words that will eventually belong in my book? Is there a difference? If it's written words, isn't it all literary? Certainly, there are people in the literary world who would look down on me publishing my professional work in zines. Maybe because they don't see it as legit, or because I am not being paid, or because it devalues my work. I don't believe in any of that" (par. 9). 
Because the zine culture thrives outside the mainstream, zines have not been recognized as legitimate forms of literacy in the academic world (Knobel \& Lankshear, 2002). According to Knobel and Lankshear, (2002), "despite their direct relevance to studies of literacy practices, zines have scarcely been featured in the literature of educational research" (p.1).

What is allowed, not allowed, or appropriate in schools is another big challenge when incorporating pop culture or zines in the classroom. When Callahan and Bronwen (2004) incorporated rap and spoken word poetry into their classroom they found that some of the challenges included the controversial nature of some of the language of hiphop culture, in particular, about the prevalence of terms in rap and youth culture such as nigga and bitch (Callahan \& Bronwen, 2004).

Appropriateness is also a common point of criticism targeting the content of graphic novels. Graphic novels are sometimes accused of depicting and illustrating explicit scenes of violence and sex (Yildirim, 2013). "In fact, many people associate the word graphic with pornography and view it as a source of danger for young learners" (Yildirim, 2013, p.124).

Teachers are often reluctant to allow expression in the classroom that might not be appropriate (Duncum, 2009). When students produce work that is "just plain silly, or ostensibly sexist, racist, homophobic, vulgar, offensive to people with physical disabilities, and so on, what are teachers to do?" (Duncum, 2009, p.232). According to Duncum (2009), many teachers deal with the dilemma of popular culture in the classroom by simply avoiding it. 
Similarly, the content of some zines can be viewed as inappropriate and an issue that needs negotiation. Teachers and administrators may fear losing control when it comes to zines (Gibb, 2013). Gibb (2013), editor of the Broken-Pencil zine magazine, recounts an experience of making her own zine as a teen and taking it to school and "a couple of days later, an announcement came over the PA during my art class. I was wanted in the principal's office. I was banned from bringing my zine to school. The people in charge thought that my zine would lead to the creation of other zines, and since they couldn't control the content, they banned it outright" (p. 18).

Challenges of appropriateness also include issues of censorship (Lymn, 2018). These issues must be navigated in the constraints of a classroom setting while trying to maintain freedom of expression and authenticity (Lymn, 2018). In her reflections on incorporating zines in the classroom, Guzzetti et al. (2015) states, "We caution that teachers will need to carefully select zines for school appropriate subject matter, graphics and written language" (p. 599).

Bott (2002), who integrated zine-making into her language arts classroom as a creative writing project, addressed the issue of language due the fact that the students intended to distribute their zines in a public library. According to Bott (2002), "We talked about who would be our reader... hell and damn were deemed acceptable. Other curse words would be inappropriate however, several of the students had fun in different fonts that were unreadable such as \#@\%!, \&\%\$* or even $\% \$ \wedge \&(* \% "$ (p. 29).

Critics of mainstreaming zines in the classroom would contend that this form of censorship is anti-ethical to the essence of zines (Jacobi, 2007). However, zinester, Joe Biel, who was a subject of Guzzetti's research, notes that teens are "painfully aware of 
what they can or cannot say in a school setting." He sees zining in school a positive experience for teens and believes that zines are "a medium that respects their intelligence" (Guzzetti et al., 2015, p. 599).

Another challenge faced is the co-opting of pop culture into the mainstream. While on the one hand, it's exciting to bring hip hop and rap into the classroom, according to Callahan and Bronwen (2004), some students pointed out the downside to critically analyzing rap. In an interview one student explained, "It sort of takes away from it, you know what I mean" (p.55). According to Callahan and Bronwen (2004), an important aspect of the pleasure of popular culture is that it exists outside of school. Some doubt whether popular culture can ever be introduced to the classroom without turning the fun into motivational strategies or "without killing it" (Duncum, 2009, p. 236).

Similarly, with zines, educators run the risk of missing the point of zines by bringing them the classroom (Gibb, 2013). Jenna Freedman, zine librarian at Barnard College says, "In some ways I think that any zine that's made for a class or for a teacher is not in fact a zine... as soon as zines get known, they get co-opted" (Gibb, 2013, p. 19). Some researchers have gone as far as to say for many of these reasons, zines don't belong in classrooms at all (Guzzetti et al., 2015, as cited Lymn, 2018).

One zinester interviewed by Guzzetti et al. (2003) expressed, “our writing is kind of anti-school writing" (p.). Knobel and Lankshear (2002) share a similar concern about the place of zines in school, "as happens all too often with new literacies, zine literacy will become domesticated within the classroom so that the zines are produced according to the teacher's vision and purposes, rather than according to the grassroots, personal 
motivations of authentic zines" (p. 29). Assessment of zines can further ruin the point of zines. As zine librarian Kelly McElroy puts it, "What makes an 'A' zine, and who the hell are you to decide that?" (Gibb, 2013, p. 19).

Bott (2002) based her decision to assess her students' zines on the fact that the zines were a major project and so they deserved a major amount of points. When assessing the zines, Bott (2002), looked for clarity, originality, creativity, thoughtfulness, and completeness of thought.

There are no rules for assessing zines in a classroom setting. Kawai and Cody (2015) address the issue of assessment in their civics classroom zine project. The students participated in informal assessment through discussions about how they felt about the phrase, making a difference in the world. In addition, students were assigned a final reflection paper that answered reflective questions such as: "What did I learn (from the zines)? How has this project changed me? What disappointed me? What conclusions can I draw?” (p.25). According to Kawai and Cody (2015), these reflective activities were important for students to understand the role of active citizenship. The question of whether zines should be assessed is challenging, and any assessment of zines should give students the opportunity to explain their decision-making (Londsdale, 2015; Lymn, 2018).

Although teachers may be enthusiastic about incorporating pop-culture such as hip hop, spoken word and graphic novels into the classroom figuring out how to do it is challenging. According to Hagood (2012), some teachers recognized the value of new literacies but were at a loss about how to implement them in their classrooms. One first year teacher noted, "I've always been open to these ideas, but my mindset didn't include 
them as a form of literacy, and I was overwhelmed with figuring out how to include them" (p. 66). Research also shows the biggest challenge to the use of graphic novels in the curriculum is that teachers don't know how to integrate them. Teachers just don't know "about the potential benefits of these materials, lack of teacher testimonials or lack of policy regarding the use of graphic novels as a pedagogical tool" (Carter, 2008, cited in Yildirim 2013, p. 124). Mathews (2011) examined pre-service teachers perspectives on using graphic novels and found that "although pre-service teachers were willing to read and reflect on a new medium for teaching social studies," they were "still apprehensive of using content or issues that might be considered controversial” (p. 436).

Similarly, zines are hard to integrate because the ideology of zines is opposed to the constraints of school itself, as Knobel and Lankshear (2002) state, "Zines present us with a tactical challenge ... How can we get the kinds of orientations, ethos, perspectives, world views, orientations, insights, etc., encapsulated in zines into classroom education when to do so necessarily involves maneuvering on enemy terrain?" (p. 21). Here, Lankshear is referring to enemy terrain as the dominant culture to which zines are a counterculture (Knobel \& Lankshear, 2002).

\section{Zine-Making Benefits}

So, why bring popular culture and zines into the classroom in the face of all these challenges? Because integrating popular culture and zines into the classroom also has benefits.

According to Callahan and Bronwen (2004), "popular culture can become a site where the intersection of student and teacher expertise results in genuine dialogue, a dialogue that holds potential for literacy learning that goes beyond a recitation script" 
(p.55). Although taking on pop culture can be overwhelming for teachers, Callahan and Bronwen (2004) suggest that rather than trying to keep up with youth culture, teachers should draw on their expertise of their students to bring popular culture into the classroom. "Not only do students bring insider knowledge to youth culture, but they also bring a passion for and investment in its texts and practices" (Callahan \& Bronwen, 2004, p.55).

For example, when discussing the use of the words nigga and bitch that are commonly used in rap lyrics, Callahan and Bronwen (2004) discovered that the students held a particular theory of language "in which words could lose their historical baggage and be reinvented for new purpose” (p.53). "In dropping the n-word's suffix 'er' for an 'a,' for instance, the students felt that they could transform the racist pejorative into an expression of camaraderie within particular communities of African American youth" (p. 53). Callahan and Bronwen (2004) felt that this kind of understanding the student's perspective of the use of language was part of what made the experience of bringing hip hop into the curriculum worthwhile. Fisher (2005) researched spoken word writing communities in a school setting and found that students who participated felt that the spoken word communities were "their impetus for attending school" (p. 127). Furthermore, "literacy in these writing communities depended on relationships between peers and adults ... that they could access while building their own literate identities" (p.127).

Similarly, youth who make zines connect and find community in zine-making while they negotiate their identities. According to Knobel and Lankshear (2002) "zines exemplify in varying degrees diverse forms of spiritedness (gutsiness), a do it yourself 
(DIY) mindset, ability to seek, gain and build attention, alternative (often in-your-face anti-establishment, although not always nice) perspectives, street smarts, originality and off-beatness, acute appreciation of subjectivity, tactical sense, self-belief, enterprise, and a will to build and sustain communities of shared interest and solidarity" (p. 165). More simply stated, according Piepmeier (2008), zines fulfill the desire for community and connection.

Pop culture can also promote critical thinking. Mahiri (2000) has found that "rap in particular can serve as a powerful discourse able to effectively critique other discourses - including dominant ones. This capacity offers urban youth possibilities for counter hegemonic actions in their social worlds" (p. 383). Similarly, Morrell (2002) found that when students linked poetry and rap, they were also inspired to create their own critical poems as social commentary. "They moved beyond reading of literary texts to become cultural producers themselves, creating and presenting poems that provided critical social commentary and encouraged action for social justice” (Morrell, 2002, p. 74).

Akom's (2009) community case study used a problem posing methodology by using hip hop culture to hold a mirror to society; to name problems, to identify relations among problems, and to re-imagine them. Akom (2009) used what Freire (1972) calls critical praxis to engage students in real world issues, such as environmental racism, police brutality, school safety, school closure, tracking, and racial profiling, youth learn confront unjust social and economic conditions. Similarly, zines engage students in critical thinking by challenging the dominant discourse (Knobel \& Lankshear, 2002). Incorporating pop culture critically in the classroom can also give students voice and 
power. Spoken word poetry organizations such as Youth Speaks, link the writing and performance of poetry to "identity voice and empowerment" (Fisher, 2005, p.117). Similarly, zines are a powerful student for student voice (Congdon \& Blandy, 2003; Guzzetti et al., 2003; Guzzetti et al., 2015; Knobel \& Lankshear, 2002; Piepmeier, 2008). The use of pop culture in the classroom also promotes learning. For example, despite reservations towards the use of graphic novels in the classroom, they have proven to be effective as teaching tools (Yildirim, 2013). According to Yildirim (2013), graphic novels promote critical thinking skills creativity and imagination. In addition, by combining visual and verbal elements, graphic novels may serve as effective tools to stimulate interest in reluctant readers who are generally discouraged by their failure to cope with the difficulty of the traditional texts (Frey \& Fisher, 2004; Thompson, 2007, through Yildirim, 2013, p. 126).

Similarly, when it comes to zines, teachers who have described zine-making projects in their classroom have found that zines are a powerful tool for developing critical literacy skills. Because zines serve as models for using multi-textual forms in their writing including collage, images, graphics, photographs and drawings, zines can serve to teach students "to read and write texts like experts" (Guzzetti et al. 2015). According to Gibb (2013), one zine teacher, after seeing how engaged new English learners became with zines, began using them in mainstream literature classes as well. "When the students write their own zines, they are finally and magically masters of a subject," (Gibb, 2013, p.19). In addition, "many high school students, whether or not their first language is English, have never felt mastery. Zines allow that on many levels. 
The zines are an example of writing and storytelling that they can match, live up to and maybe excel at" (Gibb, 2103, p. 19).

Much of the resistance and confusion surrounding the inclusion of popular culture and zines stems from a lack of understanding. Furthermore, Mahiri (2000) states that “pop culture works in young people's lives in context specific ways that often could not be reproduced in the contest of schools" (p.2). However, upon examining the pros and cons of doing so, incorporating any of popular culture into the classroom "should include critical pedagogy where students and teachers learn from and with one another while engaging in authentic dialogue that is centered on the experiences of youth as participants in and creators of popular culture" (Morrell, 2002, p. 73).

\section{Summary}

Chapter II discussed the definition of zines, the historical background of zines, zines, zines as student voice, zines in schools and communities, and zines in the context of pop culture, subculture and counterculture. Parallels were drawn between the benefits and challenges of integrating pop culture into the classroom and zines in the classroom. Based on the synthesis of the current literature, zine pedagogy is complex, providing many benefits to student learning, yet poses many challenges as well. Among the areas that are yet to be explored are teachers' experiences zine-making in the classroom. 


\section{CHAPTER III}

\section{METHODS}

\section{Restatement of the Problem}

Zines are a medium that have the power to create critical readers, writers and thinkers, yet there are challenges to integrating zines into the constraints of a classroom setting. If we want to employ zines as a pedagogical practice to promote literacy, learning and student voice, then examining the use zines in the classroom is worthy of continued attention.

\section{Research Questions}

The qualitative data collected from the participants in the present study will be utilized to answer the following research questions:

1. What are the different ways educators experience, think about and approach zine-making in the classroom?

2. From their experience what do educators view as the purpose and literacy benefits of zine-making in the classroom?

3. How do educators create space for student voice to thrive in the classroom through zine-making?

4. What do educators see as the benefits and challenges of integrating zinemaking in the classroom?

\section{Research Design}

The present study used a qualitative phenomenographic research design to focus on educators' experiences with zine-making in the classroom. 


\section{Phenomenography}

Phenomenography has been defined as "awareness or ways of experiencing a particular phenomenon" (Marton \& Booth, 1997). Phenomenography is a subset of phenomenology and developed from an educational framework in order to provide feedback to the teaching process (Dawes, 2017; Marton \& Booth, 1997). Phenomenography differs from phenomenology in that "phenomenography results in descriptions of experiences with the phenomenon and not descriptions of the phenomenon itself"' (Dawes, 2017, p. 4). Because the present study was focused on a range of teachers experiences with zines, and how those experiences connect and overlap, a phenomenographic design is best suited to answer the research questions.

\section{Participant Selection}

Sample. The qualitative sample for the present study consisted of educators who met the following criteria: (1) teachers or educators (2) who had at least one experience making zines (3) with elementary, middle, or high school students (4) in a U.S. public or private school. The criteria set forth ensured that the sample population had knowledge of integrating zines across grade levels and settings.

A total of nine educators participated in this study. This number was guided by Akerlind (2008), who recommends 5-15 participants because of the time-consuming nature of phenomenographic analysis.

Because the present study sought participants using specific criteria a purposeful sampling method was used (Patton, 2002 through Suri, 2011). Participants were recruited in two ways: from zine fairs where zine educators participated; and from online articles or social media platforms where teachers posted content about zine-making. In addition, 
the researcher asked participants to identify other teachers who might also qualify to participate in this study. Increasing sample size using participants to recruit others is known as snowball sampling or chain sampling (Patton, 2002 through Suri, 2011 p. 69). Because zine-making occurs within the zine community, educators were able to refer other educators who were willing to participate in the present study. Snowball sampling was instrumental in finding participants who might have been otherwise hard to reach. The nine participants were assigned pseudonyms. Figure 3 represents the participant recruitment path.

\section{Figure 3}

\section{Participant Recruitment Path}

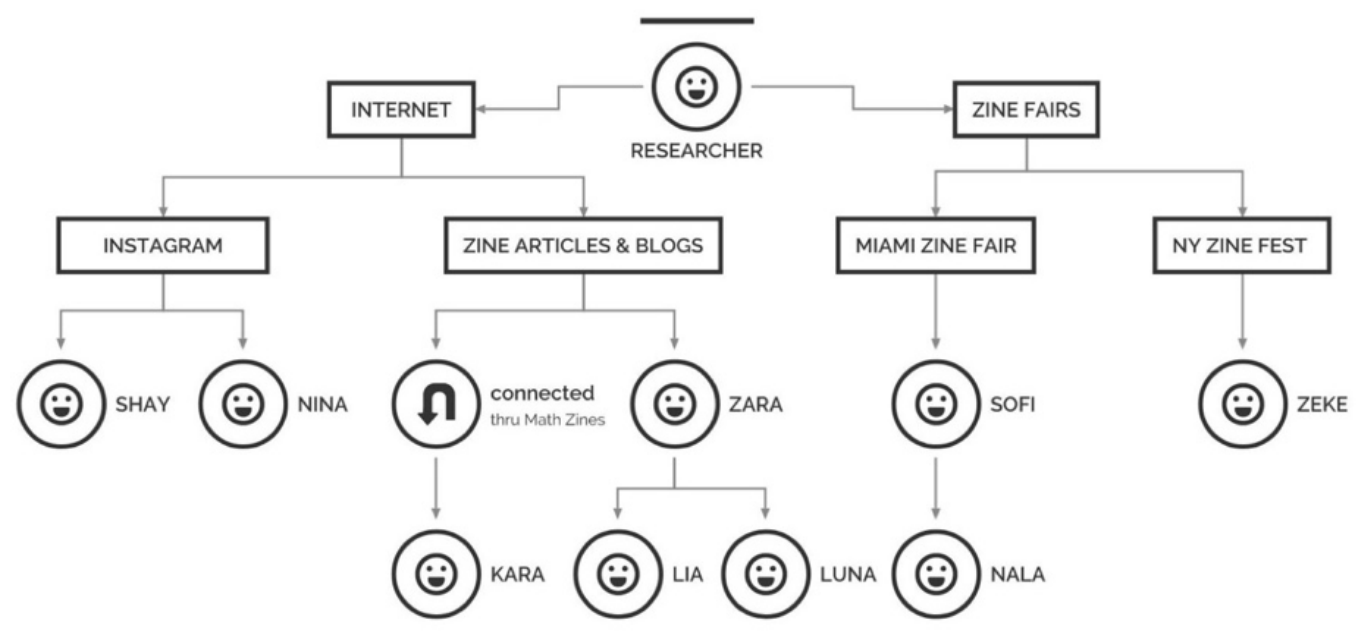

Participant Demographics. Participants were asked the following questions in order to gather demographic data that would be useful in describing the sample: What is your gender identity? What is your age range? What is your highest level of education? What is your cultural identity?

Of the nine participants, eight identified as female and one identified as male. The participants ages ranged from 21 to over 60 . There was one participant in the 18-24- 
year-old range; five participants ages 25-34; two participants ages 35-59, and one participant over 60 . Of the nine participants, six held master's degrees and three held bachelor's degrees.

Although it was a sample size of only nine educators, a diverse range of cultural identities were represented in the group. The group self-reported their cultural identities as follows: Latina-Asian-gay (1), white (2), Hispanic-Puerto Rican (2), Hispanic-Cuban American (1), Mixed black and white (1), Sicilian-white (1), and Greek-American (1). See Table 1 for a summary of participant demographics.

\section{Table 1}

\section{Participant Demographics}

\begin{tabular}{lllll}
\hline Pseudonym & $\begin{array}{l}\text { Gender } \\
\text { Identity }\end{array}$ & Age Range & $\begin{array}{l}\text { Highest } \\
\text { Level of Ed }\end{array}$ & Cultural Identity \\
\hline Shay & F & $25-34$ & Bachelor's & Latina-Asian-Gay \\
Sofi & F & $25-34$ & Bachelor's & White \\
Nina & F & $25-34$ & Master's & Hispanic-Puerto Rican \\
Zeke & M & $25-34$ & Master's & Sicilian-White \\
Kara & F & $60+$ & Master's & Greek American \\
Nala & F & $25-34$ & Master's & Hispanic-Puerto Rican \\
Zara & F & $35-59$ & Master's & White \\
Lia & F & $18-24$ & Bachelor's & Mixed Black White \\
Luna & F & $35-59$ & Master's & $\begin{array}{l}\text { Hispanic- Cuban } \\
\text { American }\end{array}$ \\
\hline
\end{tabular}

Participant Educational Setting. Participants were asked the following questions about their educational setting in order to gather data useful in describing the 
setting of their zine-making projects: What subject area(s) do you teach? What grade level(s) do you teach? Why kind of school do you teach in? Where is your school located?

Of the nine participants, two made zines with elementary students, three with middle school students, and four with high school students. Out of the nine participants, one worked in a private school, eight worked with public school students and three of those eight were working as a collaboration between a local museum education program and public school.

The nine participants taught different subject areas and disciplines. There were five art educators, two language arts teachers, one science teacher and one social studies teacher. Of the two language arts teachers, one was the school media specialist who worked in collaboration with the arts teacher at the school. The other was a language arts teacher who did zines in the school's creative writing elective. See Table 2 for a summary of participant educational setting. 


\section{Table 2}

Participant Educational Setting

\begin{tabular}{lllll}
\hline Pseudonym & Subject & Grade Level & School & Location \\
\hline Shay & Art & High School & Public & Los Angeles, CA \\
Sofi & Art & Middle School & Public & Miami, FL \\
Nina & Social Studies & High School & Private & New York, NY \\
Zeke & Art & Elementary & Public & New York, NY \\
Kara & Language Arts* & Elementary & Public & Boston, MA \\
Nala & Art & High School & Public & Miami, FL \\
Zara & Art & High School & Public** & Miami, FL \\
Lia & Science & Middle School & Public ** & Miami, FL \\
Luna & Language Arts & Middle School & Public ** & Miami, FL \\
\hline *Note: Media specialist schoolwide & & & \\
$* *$ Note: Public school and museum program partnership & &
\end{tabular}

\section{Data Collection}

The primary data collection method in a phenomenographic research design is the individual interview (Akerlind, 2005, 2012; Dawes, 2017). To gather rich descriptive data of participants experience with zine-making, the researcher conducted in-depth, hour-long, semi-structured interviews using a responsive interview method (Rubin \& Rubin, 2012). As the goal of the research was to gain understanding of teachers experiences and learn their perspectives on integrating zines into the classroom, responsive interviews were an appropriate method. The methods were approved by the Institutional Review Board at FIU (IRB-19-0149). 
A responsive interview is like an ordinary conversation where two people take turns speaking, commenting, and clarifying, however during the interview process, the researcher's goal is to answer the research questions. In the present study, the purpose of the interview was to engage educators in the process of reflecting on their experiences with zine-making (Rubin \& Rubin, 2012). In a responsive interview design, there are three types of questions; main questions which align with the overarching research questions; follow up questions which aim to seek further details; and probing questions which keep the conversation going and also clarify ambiguities (Rubin \& Rubin, 2012). A key element of the responsive interview is for the researcher to capture details, depth, vividness and nuances of the participants responses The steps of the responsive interview include introducing oneself, asking questions beginning with easier ones and moving towards more difficult ones and closing the interview in a way that maintains connection with the participant in the event that follow up interviews are needed (Rubin \& Rubin, 2012).

The interview protocol was created by following the guidelines set forth by Jacob and Furgerson (2012). The interview questions in the present study were guided by research and designed to be open-ended and expansive in order to obtain depth and detail in participant replies. On the protocol instrument, each lead question is followed by follow-up questions (Jacob \& Furgerson, 2012). An example of an expansive question could be a question such as "Tell my about your experience with zines?" which can then be followed up by prompts such as "What made you want to bring zines into the classroom?" See Appendix A for the Individual Interview Protocol. 
The interviews were conducted either in person or using Zoom meeting online technology. Although in person interviews are the most common method of data collection for qualitative research (Creswell, 2007), using synchronous (real time) technology such as Skype or Zoom has become increasingly recognized as a way to conduct qualitative interviews remotely (Hawkins, 2018; Janghorban, Roudsari \& Taghipour, 2014). Remote interviews have the drawback of being less personal, but the advantage of including the perspectives of participants who would be otherwise been difficult to reach. As almost half the participants in the present study were located outside of South Florida, Zoom served as an effective way to include those experiences of teachers outside the local area. Each interview was recorded, with the participants consent, and automatically transcribed using Zoom or Otter by Zoom transcription. The researcher found the automatic transcription to be efficient, however, to ensure accuracy the researcher reviewed each transcript while simultaneously listening to the audio recording and making corrections. A frequent error found on the automatic transcription was that the word zine was not recognized and was automatically transcribed as scene, xene, mean, scream, queen or any word that rhymed with zine. Corrections were made to each transcript before analysis. Ellipses were used to remove redundant or excess words or phrases.

After collecting data from the nine interviews, the participants were contacted by email and provided an opportunity to review their transcripts. In qualitative research, allowing subjects to examine the transcript is referred to as member checking. Although member checking is a common practice in qualitative research as a reliability check, member checking is not commonly used in phenomenographic research because the 
analysis is conducted using transcripts as a group, making one to one matching difficult (Akerlind, 2012). Of the nine participants, none made changes to their transcript. The qualitative data collected in the interviews provided rich descriptions of teachers' experiences of zine-making in the classroom.

\section{Data Analysis}

Although phenomenographic studies collect descriptions from individual interviews, the data are analyzed and examined as a whole, rather than individually (Akerlind, 2005, 2008, 2012; Dawes, 2017). "Each individual response is a valid contribution to the group's experiences and conceptions, however phenomenography seeks to identify how the phenomenon is experienced by the group and does not concentrate on the individual experience" (Dawes, 2017, p. 5).

The phenomenographic analysis of the data followed the work of Akerlind (2012). The goal of data analysis in phenomenographic design is for the researcher to arrive at a set of "logically related categories that together make up the outcome space" (Akerlind, 2005; MacMillan, 2014; Marton \& Booth, 1997).

Using an iterative and interpretive approach, quotes from interviews are analyzed to identify broad themes. The themes were examined, refined, and grouped together by relationship into categories of description. Variations within the categories of description are used to identify qualitatively different ways in which the phenomenon is experienced by the group, called categories of experience. The results of the phenomenographic

analysis are presented as an outcome space (Akerlind, 2012; Dawes, 2017). The steps in the researcher's analytic process are detailed below: 


\section{Analytic Process.}

1. After all the interviews were completed and transcribed, the researcher conducted a first reading of the transcripts in order to gain a holistic view of the data (Akerlind, 2012).

2. The interviews were read a second time, using In Vivo method of coding in which the researcher uses the participants own words or phrases to create codes (Saldana, 2009). For example, a participant stated, "I've never received any sort of backlash or pushback from administration, like my principal. I'm really fortunate that my principal is super understanding." Using the In Vivo method, the researcher would code the following words or phrases: backlash, pushback, administration, principal, understanding. These codes were handwritten in the margin of the transcript.

3. After the first method of In Vivo coding, the transcripts were uploaded to NVIVO, a qualitative data analysis software program designed to help researchers organize qualitative data. Using a Descriptive Coding method, in which the researcher uses a word or phrase to summarize the basic topic of the excerpt (Saldana, 2009), the transcripts were read and reread to identify themes and create codes. Using the example from above, the participant stated, "I've never received and sort of backlash or pushback from administration like my principal. I'm really fortunate that my principal is super understanding." Using descriptive coding the researcher would code this theme as support from administration. Themes using NVIVO software are organized into NODES. 
4. As the themes were refined, the researcher looked for relationships between the themes (nodes) and grouped into categories of description (Akerlind, 2012). For example, themes nodes such as personal stories, social and political issues, humor were grouped into a parent node labeled zine content. In a phenomenographic analysis, the parent node zine content, represents a category of description. The categories of description will be discussed further in the findings in Chapter IV.

5. The categories of description were analyzed in order to find differences and variations within the category. For example, one participant described serious topics such as mental illness and depression, while another described more lighthearted humorous topics such as bacon. This is an example of variation in the descriptions of zine content.

6. The variations within the categories of description were used to identify qualitatively different experiences of zine-making among the participants called categories of experience (Akerlind, 2012), and will be discussed in detail in the findings in Chapter IV.

7. The categories of experience collectively make up the outcome space (Akerlind, 2012; Dawes, 2017) that describes the different ways teachers experience or approach zine-making in the classroom. The outcome space will be discussed in detail in the findings in Chapter IV.

\section{Validity and Reliability}

Validity and reliability in qualitative research are often referred to as credibility and trustworthiness (Akerlind, 2012). 
Validity (Credibility). In phenomenographic research two types of validity checks are common: communicative and pragmatic (Kvale, 1996, as cited in Akerlind, 2012). Communicative validity emphasizes that there is "no longer a search for the right interpretation, but for an interpretation that is defensible" (Marton \& Booth, 1997, as cited in Akerlind, 2012). According to Akerlind (2012), qualitative methods often seeks feedback from participants as a validity check, however this is not regarded as an appropriate phenomenographic validity check because “the researcher's interpretation is made on a collective, not an individual interview" (p.124) and the goal is to capture a range of understandings in a particular group.

A second type of validity check in phenomenographic research is pragmatic validity. Pragmatic validity refers to the extent to which the research is considered useful and meaningful to their intended audience (Kvale, 1996, as cited in Akerlind, 2012). For researchers in education, validity is not dependent on the phenomenography's theoretical purity, but rather its value in producing useful insights into teaching and learning (Entwhistle, 1997, as cited in Akerlind, 2012). The present study aimed to establish pragmatic validity by producing valuable knowledge about teaching with zines.

Reliability (Trustworthiness). Two common reliability practices in qualitative research are coder reliability check, and dialogic reliability check. Both try to offset the singular perspective of having only one researcher (Akerlind, 2012). Coder reliability check is a method where two researchers independently code and compare the data. Dialogic reliability check is a method where two researchers discuss and critique each other's interpretation. (Bowden, 1996, as cited in Akerlind, 2012). However, these two methods are not commonly used in phenomenographic research for the same reason that 
member checks are not used (Akerlind, 2012). According to Akerlind (2012), dialogic reliability is not used in phenomenographic analysis because the categories of description are derived from an analysis of the interview transcripts, as a group, making one to one matching difficult. A more common alternative form of reliability in phenomenographic studies is to for the researcher to fully detail their interpretive steps and illustrate them by providing examples (Akerlind, 2005).

\section{Reflexivity}

Reflexivity is a commonly recognized practice in qualitative research to maintain the validity of the study (Dodgson, 2019; Mackieson, Shlonsky, \& Connolly, 2019). Therefore, as a qualitative researcher, it was important to include my own voice in order to distinguish my voice from the voice of my participants. A personal reflection of my experience with zines is included as Appendix C.

\section{Summary}

This chapter outlined the components of phenomenographic research design, data collection, and data analysis process used in the present study. This chapter also provided information on participant sampling, recruitment, and demographic data. The concepts of validity, reliability and reflexivity in a qualitative phenomenographic research design were discussed. 


\section{CHAPTER IV}

\section{FINDINGS}

As set forth in previous chapters, the purpose of the present study was to explore the experiences of elementary, middle, and high school teachers using zine-making as a pedagogical tool to promote literacy, learning and student voice in the classroom. This chapter presents the results of the study.

The findings are organized into descriptions of participants' zine-making projects, followed by an explanation of the categories of description, and categories of experience that emerged from the data. The outcome space is the culminating result of the phenomenographic analysis of the data and holistically represents the different ways teachers think about and approach zines in the classroom. Additional themes, including mindset, experience, inspiration, resources, support, and setting are discussed as forces that influence a teacher's disposition and ability to introduce a zine project in a classroom setting.

\section{Participant Zine Projects}

This section will give a brief overview each participant's zine project. The purpose of this summary is to provide context for the descriptive data subsequently presented within the categories of experience. The nine participants in the present study are Shay, Sofi, Nina, Zeke, Kara, Nala, Zara, Lia and Luna.

Shay. Shay, a high school art teacher, structured her zine project by having students do one lighthearted zine topic to start with and then one serious one. The class spent approximately three weeks on the project, researching, planning their layout, writing, drawing and editing. The zines were made with paper and ink. The zines were 
photocopied in black and white, shared with each other, and displayed during the school art show at the end of the year.

Sofi. Sofi, a middle school art teacher, used zines throughout her curriculum in a variety of ways. Some of her zine projects were collaborative class zines and others were individual zines about a variety of topics. The students made their zines in black and white or color using a variety of art materials. Sofi displayed and sold her students' zines at a local zine fair. Sofi also collaborated at times with a language arts teacher at her school, mixing writing and art to produce zines.

Nina. Nina, a high school social studies teacher at a private school, had nine years' experience making zines with her students. Zines were a regular part of her curriculum for teaching history as well as for assessment of learning. Students produced zines as a culminating project for a unit of history. She also was instrumental in developing an extracurricular zine-making class during her school's winter session where students created zines about any topic at all. Nina has created and circulated her own zine about teaching with zines as an instructional guide for other teachers.

Zeke. Zeke, a kindergarten through fifth-grade, elementary school art teacher, developed his zine project through an environmental lens. The students made information zines about animals. The zines were displayed at the school's art showcase and copies were sold as a fundraiser to support animal causes as well as to continue to fund further zine-making projects.

Kara. Kara, an elementary school media specialist, organized a schoolwide kindergarten through fifth-grade zine project. Kara used a schoolwide read as a springboard to her zine project. The selected novel, featured zine-like illustrations. Kara 
collaborated with the art teacher and the students made their zines in the makerspace. The culmination of the project was a schoolwide zine contest and all the zines were displayed in the school library and are kept there as a permanent collection. Students can check out other students' zines from the library.

Nala. Nala, a high school visual arts teacher in an arts-centered high school, uses zine-making as a medium to inspire students to develop compositions for their paintings and their art portfolios. From the beginning of the semester students start their zine and construct the pages by combining and overlapping colorful images into different compositions that are later used to inspire the paintings in their portfolios.

Zara. Zara, the education director at a museum, coordinates a zine outreach program that collaborates with public schools in her district. Ten public high school classrooms participate in her program yearly. The program has been running for four years. The intention of the program is to give students a platform to communicate about social issues that are important to them. The program culminates in a Teen Zine Fair, in which students share their zines with others. In addition to the high school program, Zara coordinates one middle school zine program focused on integrating arts and science.

Lia. Lia is a teaching artist within Zara's larger zine program. Lia visits a mixed $6-8^{\text {th }}$ grade creative writing elective classroom to make STEAM zines. which integrate art into the STEM subjects. Lia also creates her own illustrated research zines that promote scientific communication through art.

Luna. Luna is a middle school creative writing teacher whose class is participating in Zara's middle school zine program. Luna is responsible for following through with the zine-making project in her creative writing elective class. Lia and 
Luna's zine projects are related under the umbrella of Zara's larger museum education zine program.

\section{Categories of Description}

During the interview process teachers provided rich descriptions about his or her experience with zines. Through an iterative and interpretive process of data analysis previously described, common themes associated with zine-making emerged. Related themes were grouped into categories of description and were labeled by the researcher as content, process, product and purpose. Content refers to the topic, subject or information included in the zine. Some theme nodes in the content category of description included personal stories, art images, social and political issues, and specific subject areas. Process refers to the making of the zine from beginning to end. Some theme nodes in the process category of description included writing, design, critical thinking, and research. Product refers to the published zine and how it is shared. Some themes in the product category of description included published book, portfolio, zine fairs, and library archives. Purpose refers to the intention behind making the zine. Some themes in the purpose category of description included communication, creativity, activism and authentic assessment. See Appendix B for the codebook with a complete list of codes.

Analysis of the data identified the elements content, process, product, and purpose as categories of description common to all participant descriptions of their zine-making projects. Furthermore, these four elements were interdependent elements and it was often difficult to describe one without touching upon the others. See Figure 4. 


\section{Figure 4}

\section{Categories of Description}

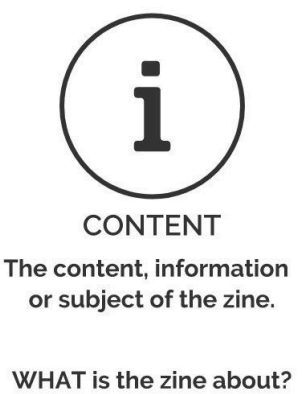

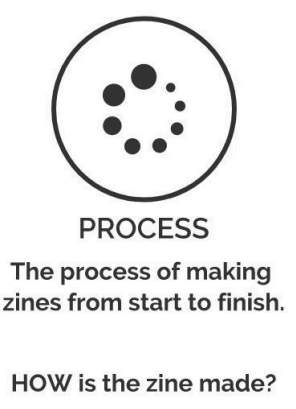

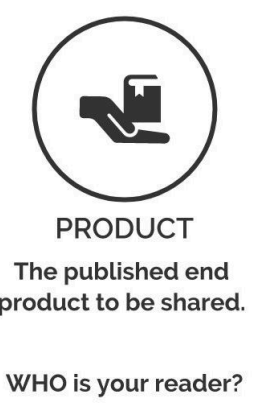

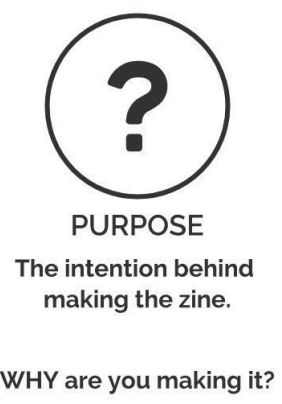

\section{Categories of Experience}

Although each participant had described his or her zine project in terms of content, process, product and purpose, there were variations within their descriptions. Depending on the zine project, different elements were foregrounded, backgrounded or balanced in different ways. For example, Shay, a high school teacher allowed students to choose any topic they wanted, including sensitive subjects such as anxiety and mental illness, while Zeke, an elementary school teacher decided to focus the content of his class zine-making project on animals. This example highlights two different descriptions of zine content, situated within the context of their respective classrooms.

After coding and analysis of the data, variations within the categories of description emerged. These variations revealed four distinct categories of experience: The Author, The Artist, The Academic and The Activist.

The categories of experience represent four qualitatively different ways the participants in the present study approached zine-making. These qualitatively different variations of experience are described holistically as the outcome space (Akerlind, 2012). 


\section{Outcome Space}

A phenomenographic outcome space represents all the different ways that a group experiences and thinks about a phenomenon. (Dawes, 2017). Participants' descriptions of content, process, product, and purpose, revealed four qualitatively different approaches to zine-making: The Author, The Artist, The Activist, and The Academic approach. The results describe a broad vantage point of teachers' experiences in the classroom and may provide insight for other educators who are considering introducing zine-making into their classroom practice.

Note that the order in which the categories of experience are discussed is not hierarchal in any way. For example, the Author approach is presented first, but does not signify any rank or privilege as an approach to zine-making compared to the other approaches.

Although a detailed analytic process was conducted, the researcher acknowledges that this outcome space is more or less complete, but does represent all possible categories of experience, as "any outcome space is inevitably partial, with respect to the hypothetically complete range of ways of experiencing a phenomenon" (Akerlind, 2012, p. 121). Moreover, in the present study, the categories of experience refer to the participants approach to the zine project described, rather than a description of the individual participant. This is because zine-making is a situated activity and teachers tend to use different approaches for different purposes and in different settings. One individual could express different conceptions of zine-making in the same interview and therefore, some participants descriptions may appear in more than one category of experience. However, participants placement in a category was determined based on the holistic 
interpretation of participants descriptions, rather than an individual quote or experience that fit within a category of experience (Akerlind, 2012).

The outcome space should not be seen as binary "rather they are end points on a continuum of experience" (MacMillan, 2104 p. 947). Marton and Booth (1997) theorized the phenomenographic outcome space as having three criteria "1) distinctive categories presenting unique relationships with the phenomena as experienced by the participants; 2) these distinct categories are presented as they logically relate to each other, frequently hierarchical; and, 3) the fewest number of categories possible are used to represent the data" (p. 125).

In the forthcoming sections, each category in the outcome space will be described in general terms that capture the essence of the category, then in detail using the data collected from participants descriptions. Content, process, product, and purpose may foregrounded or backgrounded in each description depending on the project and the purpose. The purpose, or intention behind the zine-making project, was the most powerful of the elements in distinguishing between approaches in the outcome space.

\section{The Author}

The Author approach is oriented toward zine-making as communication, creative writing, self-expression, storytelling, publishing, sharing and having an awareness of the reader. The participants in this category, Kara, Sofi, Nina, Zeke and Luna shared multiple descriptions of zine-making with an author-oriented approach.

Content: The content of zines described by participants in this category ranged widely from whimsical to serious. Kara described the content of the zines in her schoolwide zine contest: 
The zines could be about anything. So, some kids did almost like a research project. So, it was like if they had been studying, you know, an animal or something they would do a zine about it or so it could have been creative writing, just like they would write a story. The most popular one. I think was about bacon. Someone that loved bacon.

Sofi described the use of simple prompts to facilitate zine-making:

Sometimes I'll just randomly have a prompt like, being 13 and then they all make a page and they write something or whatever about being 13 and they're in like a really gooey sweet wonderful space. And then boom! Here's like a little 20 something page zine on being 13 and that was so easy.

Writing prompts for zines can be whimsical or anything at all. Sofi states:

I think the simplest, most immediately gratifying thing is to come up with just kind of like a fun riddle of a prompt something easy like if termites ruled the world, whatever. Or like, I don't know. What if the earth was just a shoe or just whatever comes to your mind. And then you give them a piece of computer paper and you give them a pile of supplies and 30 minutes...it was just this random little thing. And it can actually be relevant to their curriculum. It doesn't have to be something so random. But then after that 30 minutes you have this stack of you know, these really beautiful expressions of a totally abstract thing and the students love that... and then you can just throw it in a photocopier make a few copies distribute them to the kids. And then they realize like, oh, we all did this one piece and it came together to become something bigger than the sum of its parts. It's really, it's so motivating for everyone involved for the teacher to realize that you can make a group project.... It can be a really easy thing.

Nina described the personal nature of the zines:

What I told them was like they're certainly free to write about whatever they want. And they should know that it will be read by me and the goal is to share it with other people. So just keeping that in mind in terms of like the content that you're using. And like pretty sensitive things came out, like one student wrote a short story... about like having the experience of having to go buy Plan B. And she's like... I want to share this with my people and (she) certainly wasn't going to get in trouble for having had that experience or for like having written about that experience.

There was one that was a really earnest exploration of a student and it was like, I have two dads. So, it was talking about being raised by like her two dads, but she came to be raised by her two dads because her birth parents were killed in an accident. And so, one of her dads is her biological uncle 
and his partner. And so, she just explored this story of, like, I'm a teenager and I live with a lot of grief. I also live in this family structure that people don't always get or understand, and it was just really like thoughtful, earnest, compelling. I think that was really amazing.

Process. Zine-making involves multiple processes. From an author orientation,

these including reading, writing and publishing. Kara describes the multiple processes involved in zine-making.

Well, when we, when the art teacher and I, started collaborating in makerspace, we were just um, how can I say excited, very excited, to see the writing and the art and the creativity all coming together, so we just couldn't have been happier with the educational value of the zine. It just hit all the points that you know you would want to hit in in any class really, the writing the planning, the organizing, you know, because you have to map out the pages, you know, like storyboard. Basically, this is page one, and this is page two. So, there's the organizational component, there's you know, the information and the writing and the art. I mean, it all comes together. It's just there's so much there that you know, so they can be used in a classroom setting for to show learning of any kind, whether it's poetry creative writing, expository writing. I mean there's just so much potential value with the zine.

Sofi described the process of writing a collaborative zine:

Well, so when we're doing the collaborative zines everyone's kind of like focused on their own page because they're writing their own content and then they're illustrating their own content...I think there's a celebration of how weird and surprising you can make yours. You know... we had such whacked-out stories last year that I don't know where they came from. And so, they're all like constantly trying to surprise themselves and each other.

Nina, describes the many elements that go into the zine making process:

The way I teach other people to make them is with like a scissors and glue stick. And so that process of like hand making and hand crafting something I think is really powerful. And cool. And like there's so many literacy tools involved in making a zine and so you're either making a zine that has like a theme through the whole thing. So, like how you structure that argument, whether it's like a formal paper just talking about your experience. Or you're compiling a bunch of little pieces. And in that case, how do you like edit and choose and curate and order those things so it's a compelling experience for other for like a reader for yourself. And I certainly know art is like a skill that's taught in schools, but like the curating or compiling. I often don't think 
comes up in like school curricula, which, and I think that's something that people are being like increasing asked to do, so that I think is really cool.

Nina created about how to make a zine. In her zine she describes zine planning,

writing, images, layout, organization and supplies, printing and distribution. On writing, she wrote:

You can use different kinds of writing like essays, poetry, vignettes, history, fiction or memoir. Start collecting writing about your own work. Start collecting other text you may like to use. This could be work from your friends, quotes, excerpts, primary sources, etc. Collect all the writing that you can.

Sharing the published zine is also part of the process as described by Kara:

You're writing and you're reading and you're sharing and that was the other thing, the excitement of sharing the zines and kids talking about them, like the bacon one was so popular, you know, you got to read the bacon one so I don't know, it just ticked all the boxes you know I just there's just so much that goes into making a zine. And if you've made one yourself. And if you haven't, I think you should. Going through the process, you'll realize what goes into it, you know, and it's one of the most creative things you can do. I think it's really amazing.

Product: Zines offer something different as a platform that other formats do not.

Kara explains:

I think there's a creative element that you know like the visual how it looks, visually, that really plays a part in the finished product. So, you know, it requires visual literacy skills of which images support the message, you know, so those are conversations, you can have, you know, does your image support your information or your message or your theme, you know, so it brings in that whole element. So, there is like the visual component. It's not just words, but it's the images that go with the words. So, I don't know. I think that's different and important if you're just writing a paper. You don't have to think about what it looks like, you know, follow APA format or I don't know... So, there is more ownership of the end product because it's not tightly structured... I think they have more freedom in the design and conception of what it's going look like. So, I think it's a it offers more independence and creativity than the average PowerPoint or paper. 
Similarly, Zeke described the tangible quality and student ownership of the published zine.

You can put it out there and you can hold it. I just think it's just way more powerful than like writing an essay. What are you going to do with an essay? How many essays do you save... Nobody cares. It goes in the garbage pail. ... Meanwhile, the zines. I won't throw one away, we're all like hoarding them. They're like so special. They're all signing each other's zines, you know. It's great. That's awesome. They give us I know it seems it gives them I think ownership.

Participants discussed themes of ownership and publishing. Sofi stated "it's like they realized that they can self-publish that they have an idea, they can make it happen. They can make copies; they can share it. End of story"

Purpose. The purpose described by participants in the author category of experience relate to communication and self-expression. Sofi shared, "I just hope they feel empowered to know how to put their idea out there." She reflects:

I think in school, often, at least I had this feeling, that whatever I do in school is kind of isolated, like I would you know, just work so hard on an essay for days and days and that would be read by one person and then it would go away. It felt kind of isolated. And I didn't really realize until college like whoa, wait, what I can write. It's that's a thing that's a vehicle that can be shared and like wanting to read other people's things and just take I guess I've. It's a little goofy, but like I just realized how powerful the written word is.

And it's not just that you can self-publish your ideas and let them expand put them out there, you can be a middle school student and sure a lot of society, thinks you don't have fully formed ideas, but like you can put them out there and then people respond in a huge way to. And I think that's a really powerful statement.

When asked what she thought was the most important thing about a zine, Luna replied, "Voice. It gives them an opportunity to put their voice out one way or another, they're able to put their voice out." Luna further explained: 
It does empower the students it does help them feel like they have an idea, and they're capable of expressing it. And it doesn't always have to be so structured. And even though it is structured they feel like okay this is another way that I think, how I feel, or what I've learned that I've done I've definitely noticed that gives them an empowerment, whether they're artistic or not because I've had some kids say, well, I'm not artistic at all and I said, this isn't an art project. This is a voice project... and no one's here to judge, you know, your zine drawings. You know, how do you put out your voice. How do you make an impact how do you tell somebody what you learned about this topic, you know, that creative writing is about communication.

\section{The Artist}

The Artist approach is oriented towards zine-making as a creative process, use of artistic elements such as design, color, layout, and the composition of overlapping text and images to create a message. Nala's description of her zine-making was most representative of an artist orientation.

Content: The content of Nala's students' zines focused colorful and layered images. To provide resources for her students, Nala printed color images from the internet and collected images from magazines to serve as visual inspiration for her students' zines. Nala said, "so, for me, it was nice having those images because my students would kind of pull from that, and instead of just having a very logical image that they would come up with, the zines kind of make a composition that they might not think about right away." Nala described how the content of the zine differed from the content of traditional paintings or drawing:

In painting... for a very long time people would paint a still life or paint a portrait and you would have to paint the person and make it look like them... and there's like gravity, so objects, you know like fall or sit, and (the zine) doesn't have to be that way, ...(it) can have this imaginary three dimensional space that can literally have anything in it. So, I think this allows them to kind of do that and think in that way, because, like, just seeing how the world works. Like you become accustomed to that, but you 
can have something floating or like a cat but bigger than a person. Yeah, I think this format, kind of helps them see that.

When asked what kind of themes she saw emerging from the students' collection

of images, Nala replied:

The ones that I really enjoy are the students who kind of take their own images. So, for example, in the beginning I have printed out images. But then later on, some students kind of turn away from that and start bringing images of their own and I think that's when it becomes like a really interesting, because it's all super personal to them... So, Andrew, for example, he likes to do images of civil rights leaders. He already knows all that stuff, for me what I try and do is get him the resources to do that because he doesn't have like a color printer that he can print that out from right...I try to pay attention to what it is that they're interested in. So, I kind of have that in the photos, like Jena was doing her whole portfolio on like very strong African American women. So, I like went and printed out like some photos of, like, Angela Davis.

Students in Nala's class chose the images they wanted to use in their zine, but they also

had to justify their artistic choices. Nala explains:

So, they definitely have to talk about concept and kind of explain what's happening. Why they might have chosen those images, why they're arranging those images together. So, I think that definitely helps them out as like, just an artist in general because they're going to have to be explaining like, why did you put those oranges with Angela Davis or why do you have like, you know, this dog. next to something else.

I think it's very much part of my curriculum and .... And I think now the images that they're choosing are more interesting and they're pulling from different things. So, it's not just like I'm going to paint my mom like sitting at the kitchen table anymore, but you have people like Daniella who are choosing images of like some place in Honduras and like painting that and its very much tied to her.

Nala describes how her students eventually find their artistic voice through the collection of images:

I think many of them do (find their voice) some of them it's just like image based for them, and they might not find like the narrative right away, especially when they're first working on it, they're just like putting images 
that they like together but I think later on...the more successful ones are the ones where they start like trying to figure out how to like, tell the narrative that they're interested in talking about...they're choosing images and putting together these images that kind of speaks to the narrative that they want to talk about in their work, or the concept that they want to talk about in their work.

Process. Nala describes zine-making as an important part of the artistic process:

When I started teaching painting, they have to have a sketch book. But when I was looking at their sketch books, ... they would just like draw whatever they saw at home. So, it gets repetitive. And what I wanted to do was a zine because I wanted them to start thinking about the space and the composition of the painting differently. So ... I'm like okay we're going to do a zine, and that was the first project in our class so the first day that I got there, I just had a bunch of like printouts of different images and I would do it based on like color. So, I just had a page I had like a bunch of purple images and a page I had a bunch of like yellow images and just go from there. And then I would bring markers and crayons and cellophane like color cellophane paper and tissue paper, and I would just like, put it all on table. I had paper that I would just like staple together. And I'd be like, okay, like, start. And they would start like putting stuff together. And then from there I kind of introduced to them like different zines that I had picked up from the fair. And I explained to them like if you want to make photocopies later on, then like distribute them you can do that. But it was more of a way, it wasn't like we're going to print out like multiple zines to have... it was more just like a way of keeping kind of like a sketch book that was different from their like normal sketch book.

When asked how the zine-making process looks in her classroom, Nala replied:

My room is kind of crazy, but I just have a tray that has like the images and the magazines That I bring in to class. And seriously the first time I did it. It was like doing, like, I don't know, it was crazy because I just put the magazines, and all the images and then they were like Give me that one, that one I want that one, gimme that one! I'm like woah. And I was like you guys can like rip the pages for magazines, and I had all these other catalogs and they're like ripping them apart I was like, wow, okay. I guess this is a success. Um, but yeah it was insane. But now when I introduce it, I just put everything on...a giant modeling stand. So, I put everything on there I put the markers, like glue sticks and different little cases.

Nala describes the zine-making process as a way for the students to practice creative thinking and artistic freedom: 
It's more like a springboard for their art. So for them, it's kind of freedom. I give them pointers as to like, maybe you should like try different materials or like becoming a little bit redundant, or like, I don't know it having more of a narrative or more like a logical setting,, but, um, yeah, I think the zine kind of gives them a lot of freedom to experiment with like different things and fail a little bit sometimes, because I think that's really what they're afraid of like when they're sketching in their sketchbook and they do something like you have to make sure that the eyes are like proportionate if you're going to do a figure and I think with the zine they can kind of mess around a little bit more I might have more freedom to like mess up and try again. And not have to invest like hours into like drawing a face or something.

Product. Nala shared pictures of her students' zines. The colorful vibrant layered compositions were works of art in themselves. They are somewhere between the concepts of a sketch book and an artbook: Nala explained how the zine "ends up being an artist book ... and I tell them like you can photocopy this, you can even cut up that photocopy and make something like another one. Um, but I think it's like very unique to them."

Nala's students select a page from their zine book to use as inspiration for a painting. At the end of the term, there is an art show where the students display their zines and their paintings. The zines also serve to build the students' art portfolios for college applications.

Purpose. Nala describes how zines can be used to foster creative thinking:

It can be used for so many things. Seriously, it can be, I feel like it can be used for everything. But it makes them think about it differently. And I think they're going to retain that information better, because even though sometimes my kids are like, oh, really, I don't want to. They use it later on when they don't know like how to fix a composition or what to paint, they just start putting stuff together and I'm like, there you go, zine page right there.

A primary reason Nala uses zines is to challenge her students out of their comfort zones:

You know, hopefully, I just for me like, I want to show them that different things are allowed, especially now in contemporary art like you're allowed to, you know, not paint. In this traditional style you're allowed to overlap like images you're allowed to like break this traditional space, you can have 
some floating you can overlap things, so you can have a line drawing like with a very photorealistic drawing like behind it. So, I don't know, I challenge them sometimes and I think the zine is like the perfect way to kind of start that way of thinking

I think the zines and kind of using cutouts and different materials and clippings, it forces them to, like, try something new and think of the space differently. ... I think it allows them to like have something like a giant person that they cut out of a magazine next to something like very small and it doesn't really make sense in the real world but it makes like a good composition, so it forces them out of the box.... and it's more of just getting them to see like differently and to create like different images that might not be so obvious to them you know, like, I think art kids, and art school can be like very traditional. And I think the way that we're seeing it is a way to create like an image that they're not used to.

\section{The Activist}

The Activist is oriented towards zine-making as a platform for empowerment, amplifying student voice, having conversations about social and political issues that students are passionate about, advocating and taking action. Zara, Shay and Zeke shared multiple descriptions of zine-making with an activist oriented approach.

Content. The subject of zines in this category covered broad spectrum of

personal, social and political issues aimed at bringing difficult conversations to the table. Shay explained:

My kids know that I'm completely open and honest with them. If there's a topic that they want to talk about or if they have questions about, they know that they're able to come to me. And I won't shut them down. So, if it is a sensitive subject, we will talk about it. I don't believe in, so I don't I don't want to say censoring necessarily um, I will talk to my kids about school shootings, I will talk to the kids about mental health, like we talked about body positivity, like we talked about all those things, regardless if we're working on the project or not. Because sometimes those conversations come up...So it wasn't, it wasn't difficult for me to talk to them about it. It wasn't anything that I couldn't handle.

Shay acknowledged that not every teacher is comfortable or vocal about the issues: 
These teachers aren't necessarily as vocal or as comfortable with the subjects that I talk about that we talk about in class. On my door, I actually have a safe space poster. That that's the first thing that the kids see. I don't think anyone else here has that same poster at their door. I can tell you though that these are the teachers here they, they're great they are but they're not as vocal as I am about the issues.

Similarly, Zara's zine program gives students the opportunity to open up about the issues:

A lot of the girls especially, they'll talk about body image. You know, insecurities, the pressures of the pressures of being a teenager comes up a lot, the workload, debt, finding a job, the climate ...more and more boys are addressing issues of body image body dysmorphia, the pressures to be macho to be this that the other thing, and the more you like you sit and talk and say tell me more about that, and then they'll just kind of open up.

When asked how the students select their zine topics, Zara replied "I leave it, leave it really open I want those topics to belong to them." When students ask if their topic is okay. Zara replies, "Well, are you interested in it? Do you care about this? Do you have a point of view that you want to share? (If) yes, then it's a good topic." When identifying a topic Zara emphasizes that "We want this to be a proactive effort, it's not just slamming something, it's trying to contribute some sort of a positive point of view, even if its consciousness raising. You know, bring your heart to it bring your mind to it. " Zara shared a list of hundreds of social and political issues that have been explored through student zines as part of the museum education zine program. Among many, the list of topics included women's empowerment, teen depression, climate change, police brutality, world hunger, immigration, cyber bullying, rape culture, homelessness, environmentalism, feminism, euthanasia, child-trafficking, beauty standards, stereotypes, racism, gender identity, queer and trans culture, legalization of marijuana, income inequality, animal rights, and toxic masculinity. 
Not every activist-oriented zine-project undertakes such heavy topics. For example, Zeke, an elementary school art teacher, frames his zines through an environmental lens. Zeke explained, "the idea is ...you're trying to pick an issue with your community and then do something and go out into the community. The whole idea with my zines...was this environmental kind of advocacy vehicle...that's how I've decided to teach it." Zeke further described his approach:

My whole zine program we started with just the environmental lens. Now I'm not going to get political. But my partner and I at work we're not really happy with the current state of politics in the United States, because we're both really into the environment, forget about anything else. You know, we're just worried about the planet, yada, yada, yada. What can we do that's like, what will be our action that we do? And we're like, let's just focus on animal stuff only and start doing fundraisers at school and doing this with our kids in the community. So, we started doing this, like animal movie night and dress like an animal day and all these things to like raise money and get our kids to be helping and out there and helping charitable organizations. So last year when I came into the zines. I was like, it'd be really cool if we make these zines and we sell the zines. And the zines become our way to fund the program so we can get more ink and make more zines and we'll have enough to let the kids take them home and a bunch of them. And then we'll sell them, and that money will be the money we send to World Wildlife and like you know that conservatory and stuff. And that's what we did. Like it was like our whole idea we sold a bunch of zines, we made like $\$ 1,500.00$ dollars last year, it seems like it was crazy, you know.

Process. Zeke explains the process of his animal zine-making project:

Really the whole idea was kind of what I do with my own art, too, is like instead of being like, here's a painting of polar bears dying because their iceberg is melting, it's more like, oh, let's think about polar bears, here's this wacky zine that I made to get you thinking about a polar bear, and learning about it and you love it and then you care about it. So that's the whole idea of these zines. The zines are like cool stuff about these animals and you learn about them and so it's so exciting...it never really says like, you should do this, or you should do that. It's just like a research-based thing they're choosing an animal, and they're just going with it and we did a very open format on sizing too, and we just made like a list of criteria like choosing animal, and some fun facts- something funny. And maybe like what's 
happening with an animal that we should be concerned about. And then after that, I was like, just go crazy with it.

Shay explains how she structured her zine project in her high school art class:

So, when I introduced it, I gave them the handouts ... and then we spent the first day doing research, we spent the first day that they were going over topics. So ...they're picking things that they think they're experts in... and then from there they go on and do further research. So, um, and they only have eight pages to tell their story. So, they have to figure out what's going to be said. They have to figure out placement. They have to turn in a rough draft to me first with their sketches and their ideas.

Zara explains that part of the zine-making process is about:

Teaching people how to activate their own imaginations and render their ideas... and challenging those kids around...their point of view to make sure that they're not being myopic. You know that they'd be fair to the topic, which means in terms of being fair to the reader is you want to think about your audience. You know, if you want to have your audience feel alienated or unsettled because that's part of what you're trying to convey about your topic. Then you know you can do all kinds of things visually and materially to engender that experience in the reader. But you also want to have your reader feel like you're not some crazy person on a rant. So, he's (the program teaching artist) really good at helping them, defend their choices.

Product: The process should come together into a tangible zine that serves your

message. Zara explains:

In the zine everything is about, does it make sense? does it support? does it serve your story? does it serve what you're trying to say? It's subtly telling them that they, they are responsible for what they say and do. And that extends beyond just making a zine and talking about that particular topic. It implicitly it's about everything...including what you put in this zine. If you can justify it, if it makes sense, if that serves your intention, if it represents your intention, do it. And then you can think about that in every other aspect of your life.

So, and you get all kinds of formats we get pop ups, last year somebody was dealing with ocean level rise and the cover had a plastic bottle with blue liquid pasted to the cover so you could see it swish, and I mean they do all kinds of things, it's incredible. 
Zara shared examples of student zines produced in her program. They were a wide array of shapes and sizes and used a variety of creative materials and techniques. To share the zines, Zara displayed the zines at the Miami Zine Fair, and zines were scanned and archived into a searchable database by subject in the museum's online collection.

Purpose: The purpose of zines in this category is to bring important conversations to forefront, raise awareness and to take action. Shay says, "(the) zines, give them a freedom to advocate for themselves and for others using words using text using images, you know, whatever they can put on into these ...it gives them that." When asked how zines give her students voice, Shay replied:

So, I guess there would be different settings for their voice to be heard. There's like the classroom setting, then there's a school setting. And there's the community and then maybe like the world. My classroom yes absolutely $100 \%$ like they will always have a voice in this class...so I wouldn't necessarily be able to tell you if the kids who wrote the zines have the freedom with their voice in every classroom. Or if they would feel comfortable speaking to maybe the principal or someone in the office about these kinds of topics and advocating for them. And the community, I think it would be the same. So, I don't live in the in the community, I just work in this community. And then in terms of like the world as their voice like I do think I do think actually that them being in my class, ... I do think that I am making some sort of difference in how they're able to use their voice and how comfortable they are using their voice. And I hope that you know, it translates into home and translates into the communities and the world. But we'll see. We'll see if that happens.

In addition to providing a platform for her students' zines at the zine fair and creating an archive collection online, Zara explained how the students her program were able to connect to each other and to their community:

So, last year I tried to do a Teen Zine Fair ... and I only had three schools, but still that's three classes (out of 10), it's 20-25 kids per class so that's like still seventy-five kids, but it was incredible to see these kids meet each other....And so, I had a woman who is one of the founders of a nonpartisan organization here called 16 Plus Vote. So, she not only registered the kids 
to vote, because I tell them you can register to vote now so that you're ready to rock your franchise when it comes time. And then one of the things she did, we had all the topic areas clustered thematically up on the wall and then got the authors to go sit in their clusters so that was one way to get them to start meeting each other. They showed each other (their zines). They even talked about why they made them the way that they did... it was so amazing. And then she did kind of a talk back with them where she would look at their topics, and then locate where those topics intersect with the policy framework, sometimes at the city level in the municipal county, state and federal level, and sometimes nationally, where organizations are coming together to address these issues so the kids really can see again, how they are talking about the real world.

Zara explained one of the reasons she believes zines resonate with students:

I think most youth are innately activist, you know, when we're all children is like, 'that's not fair.' You know, like that. We have a sense of justice, somehow, we're born with it. Right. And so I think being given the opportunity to express their point of view, this is not for testing, you don't have to regurgitate something that you can barely remember and that does not resonate or represent you, right, this is about what you care about. It's in your own words you have complete control over every aspect of this, and it's a school project. And that's significant.

\section{The Academic}

The Academic-approach is oriented to zine-making for learning a specific subject, producing knowledge, researching, as authentic assessments for learning and as primary sources of information. Lia and Nina shared multiple descriptions of zine-making with an academic oriented approach.

Content: Lia is a scientist and teaching artist who uses zines as a vehicle to teach science concepts. Lia began integrating science and art in her personal practice as a form of scientific communication called illustrated research. She explains how she became interested in science zines:

The problem that academia has with communicating research is that...I think people will talk about climate change ...(but) it just has not been communicated effectively ... because research is kind of done like within 
the small little sphere like a lab or like even just doing fieldwork and the scientists don't necessarily like, put it out there like what they're actually doing so I feel like visual communication, whether it's like art or illustration or even like better design for scientific journals, is a better way for people that maybe aren't within that scientific field to understand what they're doing better, because people want to know, like it's cool stuff, but scientists often get caught up in like the nitty gritty stuff of it and they need that extra like layer of someone to be like okay but let's break it down and let's explain it so other people can understand it, and I think that's where like visual communication comes in. Because saying, okay, 1.5 degrees of global warming versus two degrees, people don't remember numbers, but like if you show them what the difference will look like that's more impactful than just saying like the coral reef will die, like okay, but what does that look like for us, and then that's where like the visual stuff comes in, I think.

For the science zine program where she works with middle school students, Lia talked about the topic of the zines:

The overall theme was supposed to be environmental responsibility. So I brought in a book that I had read in one of my classes called Drawdown, which is 100 solutions for like a greener future, like here 100 things that if we do this and this and this, this will, you know, stop global warming and climate change and stuff like that. So, I brought in the book and the kids looked through the book and kind of picked different topics that they're interested in. And they were in groups of like four to five, ... and then they just kind of picked the topic that they all wanted to do and then we just set them loose. And we're like, make a zine about this.

Process. The academic orientation to zine-making introduces students in the

research process. Lia describes the process of her science zines project:

We had five sessions with them, so the first session was just me as though going in. And we introduced like what is a zine and we kind of introduced like okay we're going to be doing environmental responsibility so brought in some examples ... And the kids could look at the other zines ... and then we introduce the topic. ... then we had a field trip where we went to the museum. I've had them walk around the fifth floor and I gave him like a guided tour of some of the artwork there. And it was kind of looking at the different artwork through like in more environmental lens instead of (an) art history lens so like where is the nature? How is it you know placed within the painting? Or for a sculpture, what materials are they using? Why you would think they're using what more wood at this point and there why are 
they using more plastic at this point, and kind of talking about those kinds of things with like the collection that they have at the museum.

Diana: So, looking through like the art through an environmental lens?

Lia: Yeah. So ...I made like a little mini zine for the kids to kind of go over what we were talking about that day...And then, so I broke it down. I took a research paper... about using a different type of substrate for a greenhouse green roof, and then had each, and what I did was I broke, each section up so like the introduction was on a page and the methods got broken up into two different pages and the discussion was two pages and then the conclusion was a page and then I printed out copies of those. And then gave one page to each kid. And then, so we have like a group of six kids that are reading the introduction and then another five kids that were reading part one of the methods... So each kid, read their page, and then talked to their group about like some bullet points from each thing and then we got together as a class like wrote everything on the board we had had like five bullet points about like what bio-char was and like why was it important .... and so on and so forth and then. So that's what we did ... to kind of introduce them to doing a research more research-based zine stuff ...So I think this was one of the first time they've probably read like an actual research paper.

Lia also talked about the design of the zine in terms of the combination of text and scientific images:

(In science ) it's hard to explain things without words but then it's like, well what words do you use and like, how many and, like, how do you simplify it without taking away from what is the actual science, you know. I think, like, like the images, just kind of speak for themselves and then the text just like supplements it, you know like, reinforce what you're seeing as well that's at least what I do when I'm doing those things because I feel like you can't be super abstract with it you can't just have like a yellow circle and say like well this symbolizes this and this...you have to like explain it, and that whole thing is like well how do you explain it so that it's not too complicated, and that anybody could pick it up and kind of understand what's being said, so I think, using the images to kind of enhance what the key points are is where that's like the decisions have to be made, but like the kids did a pretty good job they like. A lot of them did a good job. ... the creativity just kind of comes out when they just like are able to just do whatever they want. 
When asked what kind of classroom research the students do on their zine topics,

Lia responded:

It was more like it was are like self-guided, it's like I know there was a kid that was doing bioplastics and he on his own in his own time went and printed out pictures and read some more information so that he could come into like one of the sessions and have stuff ready to go. Some kids just didn't do anything at all and that's fine. This year we're going to be a little bit more structured with that I think last year it was just like learning how do you teach middle school because ...it's not elementary school, it's not high school so where do these kids fall? And the classroom is sixth through eighth grade, so you get like the lower end of like just out of elementary school to the higher end of like, I'm done with this I'm ready for high school. So, we kind of had to like figure out, okay, well what like learning level (they were at).

Nina, a high school history teacher, talks about the research process in zine-making projects:

So, for the history classes, it's not terribly different than like the research help that I'm giving for students writing a research paper. So, we're going to look at books and book sources and how do you find information in a book. And because you only have like three weeks to work on this. Like, what is the fastest and most efficient way to get through the book. So, we talked about like going into table of contents, going to the index finding like compelling things, reading only the chapters that are relevant to you. We'll also look at like digital research. So, looking at digital databases, and just finding scholarly articles that support your work. We'll also look at sort of like popular websites and like what sort of like legitimate or not legitimate sources out there. So those are all the things that are like exactly the same as like writing a research paper. But I think here's like the added and exciting piece is like when you're talking about historical research and doing visual historical research, then we start looking into like visual archives. And you start looking at, like, where can I find images that are going to support my work and that often doesn't necessarily come up for writing research papers. I think a lot of times, I think like a high school research paper you're not having an appendix or an index of like images or maps or things like that. Um, and so zines I think create, especially like history zines in that way, create an opening to talk about primary sources other than like written primary sources. So, we'll look at posters we'll look at maps and we'll look at photos and we're talking about, like, what's the dangers of looking for image just a google image search which can be a really valuable starting point. But it's also like you can come up with like pictures of like craziness 
that are labeled as the thing that you're looking for. So, like, so we'll look at like that. And the New York Public Library has a really nice like photo archive that's digitized so we'll do like some archival research there.... So, um, Berkeley, it has a really beautiful collection of Spanish Civil War posters that are all compiled, um, NYU has the archives from the Abraham Lincoln Brigade, which were the American soldiers that went to go fight in the Spanish Civil War. So, we'll look at those like sources. So, we started looking at, like, what are kind of like visual places that you can go for that kind of stuff.

Product. The science zines were made by groups of four or five students per zine and they were made using a wide variety of materials including paper, plastic, ribbon, stickers, and other materials. Each zine was elaborate and unique. The zines were displayed a local zine fair as well as scanned and archived in the museum collection. When planning for next year, Lia talked about plans for students to make individual zines:

(We) brought all of the kids' zines to the Miami Zine Fair so people can see that. And then what I think we're going to do this year is something I wanted to do last year but we just didn't have enough time... but what we're going to do this year as each student is going to make their own, because we felt like with the group work it was like less, less productive than it could have been.

I think the overall topic that we're focusing on is like environmental engineering specifically in Miami, what are some solutions, or like topics to talk about when we're talking about climate change and seal level rise and things like that within Miami, and then having the kids, each, each kid make a single page that can be photocopied and then that way, in the end, they'll be a 45 page zine and that each kid can get.

In Nina's history class, her students' zines also become sources of information for others:

So, one of the things that I do to like also make students feel like their work counts is like we donate a copy of all those things to the Barnard zine library. So, any in that account one student made is there and it's catalogued and you can research you can like find it on there like database. So, if you search and like the Barnard library databases, all their work will come up. 
Purpose. Lia sees science zines as having potential to bridge art and scientific

knowledge to foster better scientific communication.

I think that's kind of where it can be really useful because, you know like, illustrated science is not something you see but it's something that a lot of people want, so you know so like I think zine has a potential unlike smaller publications, can be that like fill that those small little gaps of like what people or groups of people that are interested in things, but they don't really know where to get it and zines are smaller publications can kind of be that like supplemental like oh here's this one person doing this one really specific thing, but it's really well done. It's like a very nice, put together saying, I think that's where things can kind of fill in the gaps.

Nina describes one purpose of using zines in content areas, such as history or any

discipline, is as an assessment of learning. Teachers can create rubrics depending on the assignment and standards. Nina describes how she uses zines as an authentic assessment tool:

So, usually what I would do for like the final culminating project of like the world history class is given an open-ended assignment that has all the information that I need in it. Um, but the format that you choose to do is up to you...So like for example, um, it's like you could write an essay. You could do a presentation; you could make a short film. For the last couple years kids have been into making their own podcast. So, like, that was an option. Or making a zine. And so, if they were using the zine option, I was really clear that like you're choosing this format for a reason. like you're not just writing an essay and then folding it into a booklet. If that was the case, just write an essay, right. So, like, what does the zine offer that lets you get your point across more effectively? So, it would be like, are you incorporating maps? Are you incorporating images? Are you incorporating primary sources? Like what does this format allow you to do that a normal essay doesn't allow you to do, or that a presentation doesn't allow you to do.

Nina also uses zines in her history class is as a primary source of information. In her zine on teaching with zines, Nina writes:

As a history teacher, I hope to have my students interpret historical events or time periods through primary materials. Zines are amazing texts to introduce to people...it is a kind of source they may or may not be familiar with but almost certainly have not encountered in an academic setting. This 
is especially appealing to me because zines are products of youth culture often written by young people, people of color, women, gender nonconforming and queer people. These are all voices that are actively excluded from academic canons and what is seen as legitimate sources of information.

\section{Outcome Space}

Together the categories of experience, The Author, The Artist, The Activist, and The Academic, make up the outcome space. A visual representation is useful in conceptualizing the outcome space.

\section{Figure 5}

Phenomenographic Outcome Space

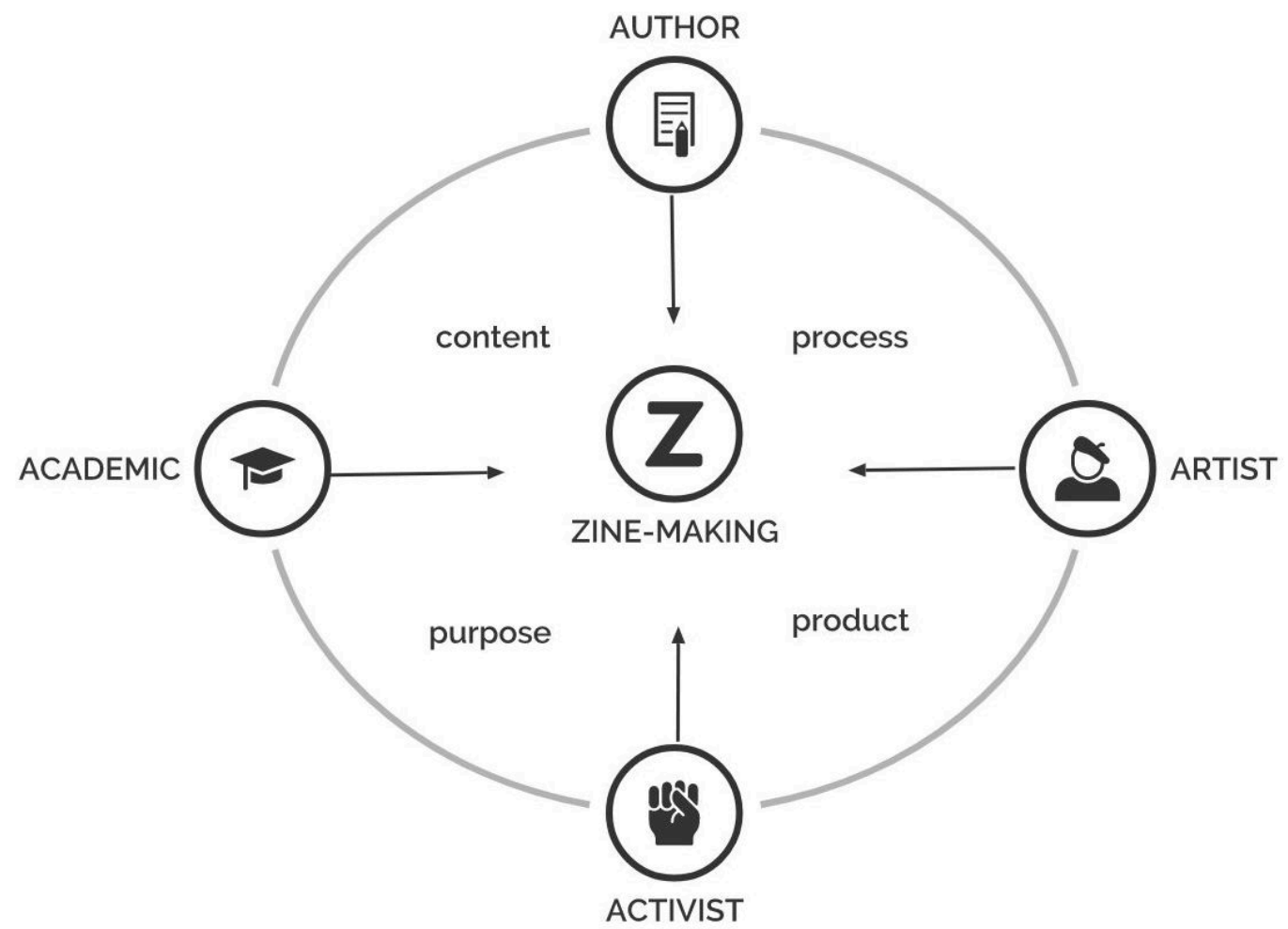

The order in which the categories of experience are presented is not hierarchal, nor does it assume that one approach is more beneficial than another. Furthermore, zine- 
making is a situated activity and teachers tend to use different approaches for different purposes and in different settings. One individual could express two different conceptions of zine-making in the same interview. Therefore, some participants descriptions may appear in more than one category of experience, or overlap categories. Participants placement in a category was determined based on the holistic interpretation of participants descriptions, rather than an individual quote or experience that fit within a category of experience. For example, Zeke described his zine-making project through an environmental advocacy lens, indicating an activist orientation. Zeke also placed emphasis on the authorship and publishing of the zine. Therefore, Zeke overlaps activist and author approaches. The figure below, represents the participants' approach to zinemaking in the continuum of the outcome space.

\section{Figure 6}

Participants in Outcome Space

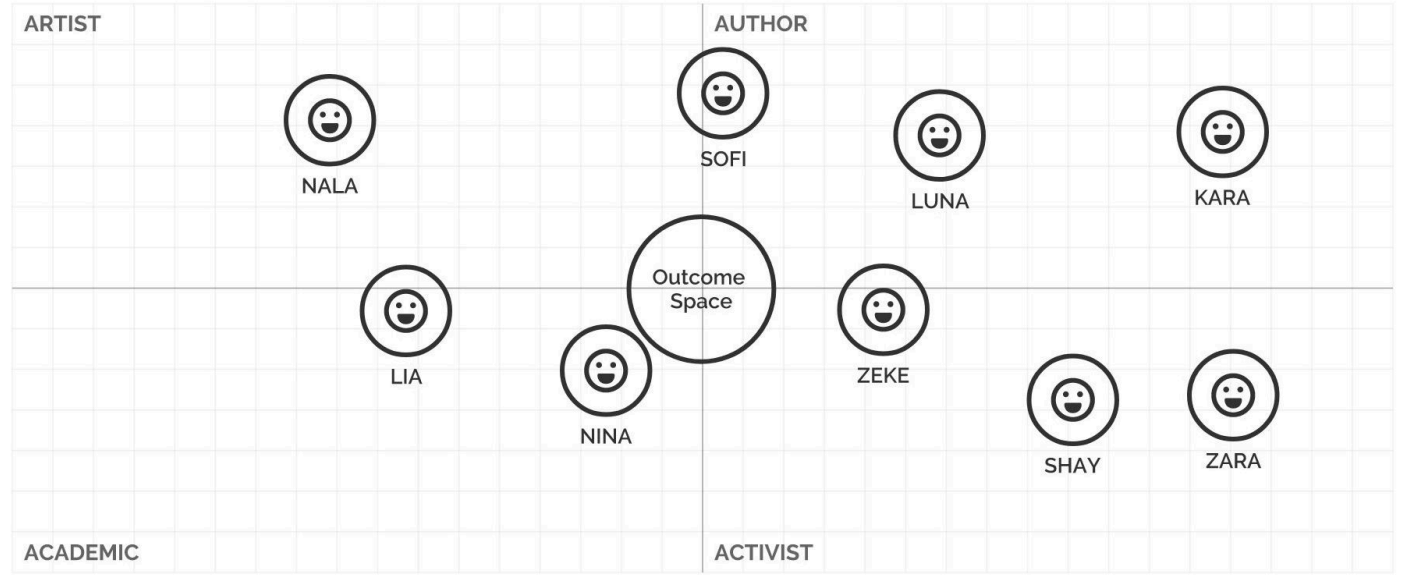




\section{Forces of Influence}

This section will discuss the finding of additional themes present in the data that influence a teacher's disposition and ability to implement a zine project. These themes, described as forces of influence, can be distinguished from the categories of description in that they are not central to the content, process, product, and purpose of a zine-making activity. However, the researcher determined that these themes merited a separate analysis because these themes play a role in a teacher's disposition and ability to introduce zine-making in the classroom. The themes discussed include experience, inspiration, mindset, resources, support, and setting. Furthermore, these themes can be viewed as internal forces stemming from the teacher (experience, inspiration, mindset) and external forces stemming from the system (resources, support, setting).

\section{Experience}

In order to introduce a zine-making project, teachers must have an awareness of or experience with zines. The participants in this study had prior experiences with zines before introducing the project at school. Shay first learned about zines when she was in a teaching credential program:

It was one of our classes where the students had to introduce a lesson plan...and one of the lessons that one of my classmates did was a zine...and that was really cool. I was able to like this little zine that I made in less than, like, an hour...so that was my first experience with zines and then it wasn't until maybe like six months to a year later when I got my position here that I was able to make the zines with the kids...so when I introduced the project last year, not everyone knew what it was so I think that's part of the problem, maybe is that not everyone knows what zines are...I think it's just a matter of introducing the format. It's definitely the format that you know people aren't used to.

Nina also tells the story behind her zine background: 
So, ...when I was in high school. In like the late 90 s, early 2000 s ... had wanted to make a zine for a long time. And I'm like, mobilize all of my friends to try and make a zine, but we did not get it together. ...And then the first the first actual zine and I worked on was at college, ... and my first year there was like a social justice like radical zine collective, so I participated in that. And that was my introduction to actually physically making a zine.

Kara has a long history with zines. She described her zine background:

Okay, so I've known about zines for about 40 years and I basically started in the punk years. It came out of punk rock culture, basically. So back in the day. You know, we did a lot of zine-making and clashing with, you know, you'd cut something from a newspaper and paste it here and make a poster for a band or there was a whole zine culture ... around punk rock and music so zine is it started as a fanzine for punk bands, I would say, like that's maybe the history and kind of took off from there. So that's where I personally became involved.

Sofi knew a lot about zines through her own educational experience. She says, "I

went through a lot of art education from middle school. I went to an art magnet school, and in high school and then in college I think at just some point in there, I locked into like an alt-arts culture, and zines are just in that, you know, it's just a part of that." Zeke doesn't recall exactly where he first saw zines, but he remembers that he started liking zines personally:

I had a motorcycle zine... somebody gave it to me. And I was like, wow, this is really cool. I should probably do this in my own I'm one. Oh, then I signed up (at) a place in Manhattan... that had a zine workshop for the weekend. It was like two-hundred bucks. And it was like, come, make zines and print them with our risograph! So, I did like zine training and I did like all like four color prints and stuff like that. And left with like my own zine.

Nala recalls first seeing zines at a local book fair:

My husband and I were doing like comics for the book fair. And then they had like that zine table. And they had like a printer and they were just like printing stuff out. And I was like this is awesome and I was doing some of that because we've always drawn, we just didn't think about like maybe cutting and like having other images in there. So that was pretty great. 
Zara first became involved with zines when she started her position as art education

director of a museum where there was an existing pilot zine program:

It had been piloted the year before... and I don't know very much about it (the pilot program), there wasn't a lot for me to run with when I arrived, so I just kind of took what there was and then just built it up. So I eventually came on full time and started running all the education programs, so I do all the $\mathrm{K}$ to 12 for the museum, but zines is like one of the hallmarks, it's a big program it takes a lot to run it. So, this is my fourth year running it.

Lia recalls becoming aware of zines through the internet:

I think I saw someone that I followed on Instagram had made one and then I was like oh what's this. And then I started seeing things for like them, I don't I know if it was, it was a Miami Zine Fair, it was held on campus freshman year of college. And I was like, what's a zine? and I don't know so I started looking it up, found other people that were doing it, and then I went to the actual zine fair and was like this is so cool. I want to make one.

While almost all the participants had a previous awareness of zines, Luna's first

encounter with zines was when her class was selected to participate in Zara's museum

zine outreach program. She explained that it was "the first time I've ever heard of this."

Not having an awareness of zines is an obstacle to introducing zines to the

classroom. When asked why other teachers aren't doing zines, Zeke replied:

I think honestly I really think it's the most innocent, obvious answer is just people have no idea what a zine is. I think it's just people not knowing what they are. I don't think I've told anyone in a public school that wasn't in the arts that I was doing a zine, No one knows what a zine is. And especially not in like our regular neighborhood. You know, like, like where I am now like in Staten Island where like North Shore, Staten island. Like people don't know what a zine is they're not, they're just not thinking about that kind of stuff. So you say zine and they have no idea. They've never seen that this is a way to teach because no one's exposed them to it, that's all. They just, they just need to see it. Anyone that sees it and really sits down with it. I think is going to get excited about it. It's just they don't have any idea, they've never been to a zine store or art bookstore. They don't know what it is they don't collect zines you know they're just regular people like we're just living our lives here. We're trying to put food on the table...that's like what it comes 
down to. It's like, then that's why you'll see the affluent schools, like the school in Manhattan, where the parents are like wealthy or in the arts or something and they're exposed to that stuff and excited about it. But I think in just general normal conversation, no one knows what a zine is.

\section{Inspiration}

In addition to having an awareness of or experience with zines, participants described feeling inspired to bring zine-making into their classrooms.

Shay said, "last year actually it was my first time doing it. I did them because I saw other teachers doing them, other art teachers. And I thought they were kind of cool, I thought that they're interesting. I thought I could do something with them." Nina explained how her own personal zine-making stage "coincided with the time that she started teaching: The school had a program called Winter Session:

We suspended regular classes for like a whole week and then teachers just teach something ...that they were excited or passionate about for the whole week all day, so I offered a zine class for students. So that was the first kind of like starting to work with zines with students.... and then we made them, and it was really to me, that was a really transformative teaching experience.

Although Kara had known about zines for 40 years, since the punk rock era, it wasn't until two years ago that she introduced a zine-making project. Kara said, "we had a whole school read and it was called the First Rule of Punk by Celia, Perez, and our entire school read the book. And so, the author Celia Perez herself is zine-maker."

Zeke recalls being inspired after he printed his own zine at a workshop using a risograph printer:

I was like, wow, this is really cool. I need a risograph, (and at) work and they had a broken risograph. And I was like, damn, I could fix this and make these zines at my job for free. Like I should probably make these things with my students... I wonder if the kids would like making zines? and then, I was like, yeah, I probably should make them with the kids. And then I started making them with the kids. And then I was like, wow, this is way 
cooler than making them myself. I just kind of want to make them with my students and then that's it. Now I'm making zines. I guess this is what I do. And we never were able to fix the Risograph.

\section{Mindset}

A teacher's individual mindset plays a role in the disposition to do a zine project.

Participants described themes of courage, fear, rule-breaking and openness. Luna

believed that in order to do zines:

You have very creative teacher, and you have to be a very brave teacher. And when I say brave I mean like, you have to be able to back it up...you have to be brave and confident, you have to be confident ... you know, prove that it meets the requirements, even if it's creative and it takes a lot of guts to go outside the, the boundaries that they've created for us... you know, and sometimes I do get scared, I still get scared I'm like oh man, am I doing this right, you know should I just stick to the rules, you know.

Similarly, Shay described the tension between staying in the boundaries and breaking the rules:

So, the thing with education and the thing with like standards and stuff is that there's some teachers that strictly adhere to the standards are strictly adhere to the schedule. And then there's teachers like me. Maybe that don't necessarily like yes, we have a standard yes, I teach I introduced the standard, but there's just so much I can do with that. Um, so...I break rules. Um, there are some teachers that don't break rules and that's fine.

When asked if other teachers in the school were doing zines Shay described one of the English teachers, "She's a brand-new teacher... or new to the school rather, so I don't think she's comfortable if I were to introduce this to her. I don't think she would be comfortable necessarily introducing a project like this." When asked why other teachers may not be open to doing zines, Shay replied:

And, like, I guess ... I don't want to say, fear, I don't know if fears is too strong of a word, but the fear of introducing something new to the curriculum that they haven't done before, especially if they've been teaching for five years 10 years 15 years right that's something that I've 
noticed too is that teachers that teach for so long there they're afraid to do something new or they're afraid to change stuff up in the curriculum. They're stuck in the oh this has worked for the past 10 years. Why am I going to change it? 10 years ago, it was completely different, though, you know, and maybe what happened what worked for the past 10 years isn't going to work anymore. They also just don't want to hear that either.

Zeke expressed some disappointment that other teachers were not of the same mindset that he was about making zines:

I was kind of disappointed in the in the like the response the zines got from just the like the teachers in my old school .. I think they were like, Oh, those are cool and my principal was, you know, he's the man, he was a sweetheart. And he was like, they're nice. Oh wow, just really cool, but no one really like actually absorbed the amount of time that went into them. And no one seemed to draw that it just seemed very obvious to me that this could be an important teaching tool across all curriculum and everything like making these books. Um, but I might be off base with that and maybe just cuz I'm an artist, and I want to make little books and things, and I love books now, and I'm more into it than a normal person

\section{Resources}

Access to resources played a role in how a zine projects were carried out in the classroom. When asked about resources participants felt that having access to funding supplies was important to their zine projects. Paper, ink and photocopies were mentioned frequently.

Zara had the most access to resources because her zine program was fully funded by major outside sponsors, not from within the school district. When asked about resources she replied, "We have funding it's fully supported fully, financially supported ...including covering the substitute costs the busing of the kids here, all the supplies that we give, the artists fees, everything. So it costs nothing."

Luna, whose classroom participated under the umbrella of Zara's zine program, talked about how supplies were provided to her. When asked if resources would be a 
limitation for other teachers not in the program, she replied, "A huge limitation. As a matter of fact I had a teacher walk by my room when they were working on it and that teacher said. 'Oh my gosh, where'd you get all that stuff? If I had all that stuff ... my kids would do so much."”

Nina, who worked at a private school, also talked about the advantage of having resources available at her school. She said, "This seems sort of like silly, but I think matters a lot. (I was able to make the zines) without any photocopying restraints ... and we didn't have to pay for them. There weren't any limits. It was just like photocopy the hell out of whatever you want." When asked if she was also able to make color copies, Nina replied, "No, they were just black and white because those were the machines that we had at school. But, I mean, that's a huge, just a huge resource to have available.” Nina also pointed out a difference between public and private school resources, "And again, because they are kids with a lot of like economic privilege like just opted to photocopy them in color themselves." Kara also felt that she had resources available for her zine project. When asked where the resources were coming from, Kara, replied:

It varies from year to year. Sometimes our parent association pays for the books and the first year it was grant funded. So, either a grant or the parent association... the art supplies are just things the art teacher had in the art room. She just has a great selection of things...I don't recall that we purchased anything extra for the makerspace. I think she had everything...we had like a cart that had all our supplies on it and she has some amazing supplies like stamps and different like paper cutting tools and tape and collage materials ribbon, you know, she just has an amazing collection of things. So, these were really fancy zines.... they were great.

Zeke was resourceful in finding resources and funding for his art program. When asked if he had a budget for his schoolwide art program, Zeke replied:

Not really, 600 bucks, ... I got some printmaking ink and stuff. So, I mean, 
the thing is, if it's not Title I. There's no money. That's how it is in New York. That's so you know. And the other thing is they need to slowly learn here what an art program looks like and what that requires for a really good program and that it does cost money. So, I'm kind of like slowly rolling out things. I got some stuff... and we'll have a giant art show at the end of the year ...when they see that, then they'll be like, okay. We need to fund you. That that's what's happening here.

When talking specifically about the zine-making, Zeke said:

So last year when I came into the zines. I was like, it'd be really cool if we make these zines and we sell the zines. And the zines become our like way to fund the program so we can get more ink... The other inherent problem with it, though, is it does kind of cost money like it seems like just cheap, easy to do thing, but like, in reality, you need to like print all of these zines and even if printing is cheap. And it's black and white, you're still like using a lot of paper.

Zeke believed that a zine was the best way to showcase the value of the zine:

And I pop this on my boss's desk to like real quick. I was like here's what we did ...YYou know, you get this great thing, and it's like to be able to take this...now it's like advocating for your art program as an elementary school teacher. Be like, oh, here, here's the thing we did. Now you have an artifact, with all the information that you need and all the writing and everything and you exist. This is better than any lesson plan, you know, like, it's great. And then they see that your boss sees that and then they give you money for art supplies which is really all you're trying to do all the time. More money for more for more art supplies. I suppose. How can we trick the squares and to giving us more money.

Zara, Kara and Nina felt they had sufficient resources, while Zeke looked for outside sources of funding for his program such grant funding and community partnerships. However, Shay, Sofi and Nala supported their zine-making projects by sometimes having to spend their own money to cover the cost of printing and copying. Nala said, "We actually don't have (a color printer). I mean, we need a printer. I can't print all those pages at my school. So, there's that. But I just go and print a bunch of stuff 
at Office Depot." Nala said that she also gets glue sticks and "I'd like to bring like better markers and crayons tissue paper stuff like that for them to use...magazines as well." Nala explained that she gets old magazines from a university library where she used to work.

\section{Support}

Many participants expressed that they felt supported by their principal and administration. Nina explained:

So, I guess I should start this by like the school that I taught was very much like open to whatever was coming out of there. And so, I did not have a lot of fear or apprehension about how, how the administration would deal with me or deal with any of the students in terms of sensitive content.

Similarly, Shay stated:

I've never received any sort of backlash or back, push from admin like my principal. I'm really fortunate that my principal is super understanding, like she knows, she knows what's happening in the world, and she knows that if I want my kids talk about it or to do something about it, then she's going to be okay with it.

Kara described her school as very supportive as well, “It's a great school. It's very creative. We innovate and try a lot of new and interesting things here; we have a principal that really supports creativity and innovation. So, it's a very nurturing, you know, forward thinking school."

Similarly Luna described feeling supported, "My principal is ...very supportive of me and our team, when we go a little bit, you know, when we skirt around, especially to meet the needs of our gifted leaders or our reluctant readers." One important factor in gaining support for a zine project is being able to back it up. Luna said:

You have to be able to back it up. Why are you doing this? Or is this just a coloring class? You know, what is your true goal and how does it meet 
the requirements? And so, if you can prove that, and you have a supportive administration, which, as a school we have a very supportive administration. Then you're fine. But you're on your own for resources you're on your own for cleaning up you're on your own for everything.

Sofi felt supported, but she also expressed a small amount of apprehension when

going out of the box:

I was really like vigilant about asking at every step of the way. And I think I established a rapport with my principal that I'm doing things as sensitively and holistically as possible, trying to see things from a lot of different perspectives and making sure that I don't put my perspective, I acknowledge the limits of my knowledge and so I have an incredibly supportive administration. This isn't true for everyone, but for the most part, there's just kind of a respect for what's going on. But ... it's a precarious thing being a teacher and you're always a little bit nervous.

Nina described one situation where administration became involved regarding the content

of a student zine:

One of the things that did come up, that did end up like coming back to me ... was this one student that wrote...a kind of satirical guide to Earth... about like, how do you have a romantic like encounter.... using substances to help like facilitate romantic or sexual encounters. And so that was something that they were like - uh no. Because this is kind of date-rapey. So that was something that we had to deal with the administration...they took it as a teachable moment, like whoever you're having this relationship with needs to consent. So that was kind of definitely dealt with as a teachable moment. And the kid was like, it's satire. it's a joke. It's like, whatever. And so, like the other teachable moment was like, what is okay as a joke and not a joke, right, like date-rape is not a joke. We're not going to make those jokes.

Other sources of support, aside from administration, came from finding like-minded

teachers to collaborate with. Sofi said:

In the last two years, I've collaborated with the language arts teacher, where I'll send them up to her. They'll send her students down to me. So, it's a kind of fun exchange and they'll do writings and then we'll make visual responses to those writings and then we scan them all together as a collaborative zine." 
When asked how she ended up collaborating with the language arts teacher, Sofi replied:

"A lot of time with my art or my teaching I'll reverse engineer things around wanting to make connections. ... and I said, hey, I have this idea. and then we went from there to jump into it, which doesn't always happen. I'm kind of like dorky and my desire to collaborate. It's not always received well because teachers often feel like super overworked and some of these questions about, hey, do you want to do this extra thing? It takes a special kind of someone to be like, yes, that they'll take one more thing on to the complete, one more thing into their curriculum. But for me, like, I really like I didn't come from studying teaching. I came from studying art, so I really feel like this is my creative practice.

Kara's schoolwide zine project was also a collaboration. She explained, "The art teacher and I run makerspace together as a collaboration, so this just fits perfectly...I find everything goes better with collaboration and having a team, you know, to work on something, it's so much nicer when there's support for something like that." Zara, the coordinator of a zine program, creates opportunities for the teachers in her program to connect and support each other. She said:

Oh, the other thing that I do in January, I call it wine and whine , right, so the teachers come here...they come for a Friday happy hour on the house, and we just talked about how's it going, what did you do (with your zine project)...they come here and they can 'whine', but it's more constructive it's really great.

Teachers who are part of Zara's program receive a great deal of support in terms

of resources and collaboration and connection, while other participants like Zeke, were

looking for that kind of connection and collaboration. Zeke described his experience:

My whole thing when I went to Brooklyn last year, to a zines workshop. I was really just hoping to connect to other teachers doing zines. That really didn't pan out as much as I would hope... so that's part of my mission to is just like I need to like get this to be a thing where like it'd be cool if there was like a zine fest for kids in your city. That was just all these elementary schools made crazy fun zines. 
Zeke added:

I mean you know what would be cool if you could put me in touch with some of those people (in this study) eventually, You know, be nice to have more teachers that are doing it. Besides visual artists because I know a lot of artists that do zines, but not many teachers.

\section{Setting}

Participants in this study described how grade level, subject and school setting, could shape a zine project. Shay expressed that she was able to touch on subjects with high school students that she wouldn't be able to with younger students:

I think I have a lot more freedom with the kids because I actually teach high school. And a lot of these kids are a lot more mature obviously than middle school or than elementary school at that. So, I think that's why my stipulation for having them do a serious topic. It comes a little bit easier to me because I don't know how, I mean I know I would still do it with younger kids because I don't believe in censoring it for them either like they need to know about this stuff. I just don't know how I would go about introducing those sorts of subjects to them.

Similarly, Zara recognized that her zine program was oriented towards working with high schoolers. She said, "I just think the young ones are too young for it... I don't think we can get into the substantive issues that I think are important to activate."

Zeke also described how many mature subjects touched upon in high school don't work in elementary school setting.

My biggest gripe with zines in general is ...people use them to talk about like some very heavy stuff so the lens around them as usually that, and a lot of it is not appropriate for children at all. So, when they have zines fest and everyone has to have some kind of like sexual thing or whatever it is...And I'm like, this could be like so much more ... I understand that it's important to talk about. gender rights and things like that and mental health and like 
is the zine is a great vehicle for that. But like, it's also a great vehicle to talk about like my five favorite pizza is in Brooklyn, or like why I love platypuses. And that's what I think school about zines personally.

Besides grade level considerations, participants' subject area also played a role in the amount of curricular freedom they had to implement zine-making projects. Shay said, "So, I am the only art teacher at my school, so I have complete free reign, I don't have to turn in lesson plans to my principal. I don't have to run anything by them... I know what's not okay. And what is okay." Nina expressed how teaching in a private school afforded her the benefit of freedom, "and it was both time freedom content freedom. And I think just openness, where it's like we don't have to meet any sort of state standards we don't necessarily have to do any test." Luna attributed the ability to do zines to the fact her class is a creative writing elective and not a regular Language Arts class where she would be constrained by testing:

Another thing I'm sure you're aware of, but like the whole standardized testing thing ... it just messes with the whole flexibility of teachers to be able to teach what they want to teach ... at least in high school with like AP testing and things like that, it just gets so restricted and the teacher doesn't have a lot of wiggle room to do other things like this so I think that's why we're allowed to it in a creative writing class because they don't necessarily have the standardized testing.

Similarly, Shay said, "definitely the AP (language arts) teacher doesn't have any room in his curriculum to do any of these, I don't think." Nina pointed out that class size also makes a difference in planning a zine project. She said, "I think also like size, classroom size. I've done this with groups of students around 15 , right so if you're working in a classroom with like 30 kids with scissors like that can be a real challenge." Nina believed that working in a private school afforded her more freedom with zine-making than other settings: 
I think the I've been able to use them so freely and so integrated into my curriculum because of a lot of like structural privileges of being a private school being in a school that like specifically embraces progressive education of having administration administrators that are like hip enough to know what zines are. And I think to be in New York where zine culture is a thing. Like, you don't need to be that cool to know what a zine is in New York because there's like major events like a couple of them every year. So, I don't think there's like a sort of sub cultural barriers to like explaining, like, what is it that we're doing and why does it matter.

Nina added:

I mean, frankly, like if this is like little like piece to wrap up with like I think all the things that make zines possible in the classroom. Are like things that would make like teaching and learning better. So, having like more time having more resources, having smaller class sizes like I mean, those, those let you do not just zines in the classroom.

From participants descriptions of zine-making, the findings support that

experience, inspiration, mindset, resources, support, and setting all play a role in a

teacher's disposition and ability to implement a zine-making project. These themes were explained as forces of influences. Figure 7 provides a visual representation of forces of influences discussed in this section.

\section{Figure 7}

Forces of Influence

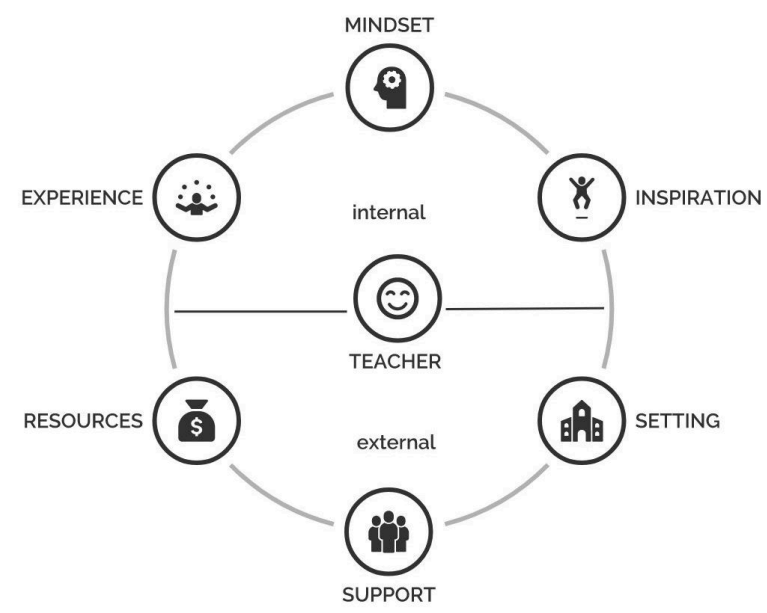




\section{Summary}

This chapter presented four phenomenographic categories of experience that describe qualitatively different approaches to zine-making. The categories of experience are: The Author, The Artist, The Activist, and The Academic. Together, these the categories of experience make up a holistic outcome space. The categories of experience were arrived at by analyzing variations in participants' descriptions of the content, process, product, and purpose of zine-making. Furthermore, the chapter presented additional themes described by teachers that play a role in shaping an educator's approach to a zine-making. These include experience, inspiration, mindset, resources, support, and setting. The categories of description, categories of experience, outcome space, and the forces of influence that shape zine-making projects provide the rich detail for discussion of the findings and interpretations Chapter V. 


\section{CHAPTER V \\ DISCUSSION}

Chapter V includes a summary of the study, interpretation of the findings in relationship to the four research questions, followed by discussion of the limitations of this study, the implications for theory and practice, and the recommendations for future research. This chapter will conclude with a final summary.

\section{Summary of the Study}

The present study explored the experiences of educators using zine-making in elementary, middle, and high school classrooms. Phenomenographical analysis of nine, in-depth, semi-structured interviews revealed that participants described the content, process, product, and purpose of zine-making in four qualitatively different ways. These categories of experience are The Author, The Artist, The Activist, and The Academic. The categories represent a phenomenographic outcome space that can be useful in understanding teachers' experiences with classroom zine-making. Additionally, the data revealed six common themes that influence a teachers' disposition and ability to introduce classroom zine-making projects: experience, inspiration, mindset, resources, support, and setting. The results of this study provide insight into the understanding of zine-making as a classroom practice that promotes critical literacy, transdisciplinary learning, and student voice.

\section{Findings and Interpretations}

After multiple readings of the manuscripts, the common themes were coded and grouped into categories of description called content, process, product and purpose. Variations within those descriptions resulted in four qualitatively different ways that the 
participants in the present study experienced zine-making. The categories of experience are The Author, The Artist, The Activist, and The Academic. Together these categories make up the phenomenographic outcome space. The findings of the study are useful in answering the research questions.

\section{Response to Research Questions}

\section{Research Question 1}

What are the different ways educators experience, think about, and approach zinemaking in the classroom?

In order to answer this question data was collected from nine educators who practice zine-making in the classroom. The data were collected using open ended, semistructured interviews that asked teachers questions about their experience with zinemaking in the classroom. Data gathered from the nine participants in the study were analyzed to reveal categories of description described by all the participants in the study. The different variations of those experiences yielded four qualitatively different categories of experience. Each category represents a different approach to zine-making in the classroom. The four approaches are The Author, The Artist, The Activist and The Academic.

The Author approach is oriented toward zine-making as communication, creative writing, self-expression, storytelling, publishing, sharing and having an awareness of the reader. Participants in this category included Kara, Sofi, Nina, Zeke and Luna.

The Artist approach is oriented towards zine-making as a creative process, the use of artistic elements such as color, layout, and design; and the composition of overlapping text and images to create a message. Participants in this category included Nala. 
The Activist is oriented towards zine-making as a platform for activism, empowerment, amplifying student voice, having conversations about social and political issues that students are passionate about, and taking action. Participants in this category included Zara, Shay and Zeke.

The Academic approach is oriented towards zine-making for learning a specific subject or content area, producing knowledge, researching, using zines for authentic assessment of learning and as primary sources of information.

Together, the categories of experience are represented as an outcome space. The order in which the categories of experience are presented in the outcome space is not hierarchal, nor does it assume that one approach is more beneficial than another. Zinemaking is a situated activity and teachers tend to use different approaches for different purposes and in different settings. One individual could express two different conceptions of zine-making in the same interview and therefore, some participants descriptions may appear in more than one category of experience. However, participants placement in a category was determined based on the holistic interpretation of participants descriptions, rather than an individual quote or experience that fit within a category of experience.

In addition, the researcher identified internal and external forces that influence a teacher's disposition and ability to implement zine-making in the classroom. These include internal forces; experience, inspiration, mindset; and external forces; resources, support, and setting. 


\section{Research Question 2}

\section{From their experience what do educators view as the purpose, significance and}

\section{literacy benefits of zine-making in the classroom?}

The results of this study revealed that participants integrated zines into their classroom for a variety of purposes that included activism, advocacy, artistic freedom, authentic assessment, collaboration, communication, creativity, critical thinking, empowerment, learning, literacy, ownership, production of knowledge, self-publishing, researching, self-expression, storytelling, and student voice.

The participants in the study articulated the many literacy benefits experienced through zine making.

Shay stated:

If a teacher were to look at it, they would automatically think it's an art project. It belongs with the art teacher right. I don't think that I definitely don't think that this is just an art project. Like, I definitely think an English teacher could do it. I think a math teacher could do a or a physics teacher or chemistry teacher because I can guarantee that if I were to go into all of their classes. Right now, there's some sort of assignment or project that they're doing that has some sort of image component and a text component that they could easily put into a book.

Sofi stated:

So, there's like literally reading literacy, and I think it's a really accessible medium or connecting with issues and subject positions that aren't normally represented by, you know, big media publications. You know, it's like the voice of the little guy. So, there's that. But there's also like this idea of social literacy to us in terms of content, but I'm form. And it's not that you know you can self-publish your ideas and let them expand put them out there and you can be a middle school student and sure a lot of society, thinks you don't have fully formed ideas, but like you can put them out there and then people respond in a huge way to. And I think that's a really powerful statement. 
Nina stated:

I think the literacy benefit of reading them is introducing them to a new source and because it's maybe a source that there are less familiar with it lets you kind of talk about things that seem more hidden or more imperceptible with like sources that like you're familiar with. Right, so like with a book or like a magazine article, I think it can be harder to recognize things like bias or authority or we assume authority because it's been published and when it's a zine I think because it's new and novel, you can ask kind of interesting questions about like credibility, legitimacy, who's making this knowledge. Is it valuable? is it not valuable? Yeah, and you also asked about like visual literacy and because so many zines use text and image side by side and you're really talking about, like, what's the conversation between those two media of images and text.

Zeke stated:

It's the ultimate art-literacy combo plate.

It has a lot of potential in ways I probably haven't explored yet, but I thought like the research based like a way to a way to research and learn about animals and combine that with drawings was a really strong kind of tie in like the science literacy component of researching animals was really cool because it gets them to do that reading and you could read a book about animals and, you know, usually there's the kid or two that loves animals or loves planets and they read the book and they memorize it all, but the rest of us don't really memorize it all. We read it and it goes away. But now you're like reading and learning and then you're cataloging and researching and writing it, and it you absorb, you know, and then you're teaching it to other people through writing and I don't know. I think that's pretty powerful, especially in his community like this where these children...they're learning English, and now they're making a book in English. That's, like, very good.

Kara stated:

When the art teacher and I, started collaborating in maker-space, we were just um, how can I say excited, very excited, to see the writing and the art and the creativity all coming together, so we just couldn't have been happier with the educational value of the zine. It just hit all the points that you know you would want to hit in in any class really, the writing the planning ,the organizing, you know, because you have to map out the pages, you know, like storyboard. Basically, this is page one, and this is page two. So, there's the organizational component, there's you know, the information and the writing and the art. I mean, it all comes together. It's just there's so much there that you know, so they can be used in a classroom setting for to show 
learning of any kind, whether it's poetry creative writing, expository writing. I mean there's just so much potential value with the zine.

It just ticked all the boxes.

Zara stated:

They're learning, they're learning negotiation...compromise, collaboration, especially on something artistic that is not easy. And I think these are all skills that are really important...these are all skills you need out in the workplace,

I think that it (zine-making) engenders a different way of thinking, as well. It's fun, so they do it. The kind of feedback I get, it's like I've never done anything like this in my life before, (school is) completely paperless so this is the first time in my life I handed in something with my hands, that I made to my teacher... and so I'm really trying to push visual literacy and media literacy on them really pushing what I call the 21 st century skills.

Lia stated:

I think if you introduce a word, having the kids, kind of get what they think it means and then having an explanation so like, for example, biochar with the words that we like we're using last time and I said okay well what do you think it means, and it kind of broke it down, okay, well what does bio mean and what does char mean and then it's like okay, living charcoal and then has a little definition for them and then they kept using it throughout the whole entire lesson so as they became more and more familiar with it, I think, saying things and then having them say it and then interact with it multiple times is what helps them retain those words.

\section{Research Question 3}

\section{How do educators create space for student voice to thrive in the classroom through zine-making?}

As discussed previously in the findings, participants in the present study described that they felt supported by their administration and their principals for the choices they made in the classroom. They also described having a certain amount of curricular freedom in their classrooms. Of the nine participants, five were art teachers, one was a 
creative writing elective, one was the school media specialist and one worked in a private school. The participants described feeling a greater amount of curricular freedom compared to their colleagues, in other disciplines who they felt were constrained by standards, pacing guides and standardize testing. They described that having curricular freedom afforded more space for zine-making and allowing space for student voice.

Teacher mindset also played a role in how much freedom and space they allowed for student voice. Words and phrases such as brave, confident, and rule-breaking, were used to describe the kind of teacher that makes space for zine-making in the classroom, as opposed to other teachers might be afraid of introducing something new.

The findings of this study revealed that the participants valued their students' voices and provided them opportunities to have conversations about a myriad of topics, tell their stories and take action about issues that mattered to them. Participants challenged their students to use multiple processes and skills to create combinations of text and images that would best serve their message and amplify their voices. They also provided platforms for students to have a tangible voice by publishing their work in a variety of formats as well as creating platforms for the students to share their voices through art showcases, zine fairs, displaying them in the school media center, and including their zines in online zine library collections. In all these ways, the teachers created space for student voice to thrive in their classrooms through zine-making 


\section{Research Question 4}

\section{What do educators see as the benefits and challenges of integrating zine-making in}

\section{the classroom?}

In addition to the rich descriptions of about the literacy benefits of zine-making

previously discussed in Research Question 2, participants described additional benefits to zine-making. These descriptions revealed themes that included agency, ownership and empowerment.

Participants described that students often took agency over their learning because they were motivated by things that were meaningful to them. For example, Sofi describes one student:

There's this one girl last year that or I guess it was two years ago, I never heard her say more than like 10 words at a time. But then she started making these zines, like a whole series of them and then other students would see them on my desk before scanning them. They'd be like, I want to buy that. And then I made a lot of copies and then she became known as like the zine girl and she was training the younger people to make them and. You know, and that was really when it started to blossom.

Zines also allow students to have ownership of what they create. Kara said, "If you are truly letting the students drive the bus, then you know you're putting more power into your hands with the zine. So, there is more ownership of the end product." According to Luna, "It does empower the students it does help them feel like they have an idea, and they're capable of expressing it." Zara said that zines serve to empower students because their voices sometimes they feel "that nobody takes them seriously... what do you have to worry about? You're a teenager, and then getting it out onto a physical product legitimizes it." 


\section{Challenges}

As previously discussed, potential challenges to zine-making include lack of resources, lack of support and lack of curricular freedom. Additional themes that pose challenges to zine-making include appropriateness, assessment and legitimacy.

The content of some zines may not always be considered appropriate in school.

Especially for younger students. Nina explains:

People are writing about their personal experiences or things that, like they're writing about sex they might be writing about drug use, they might be writing about you know whatever is going on in their lives. And those aren't always seen as like appropriate for young people school age kids to have access to that as well.

Sometimes the use of inappropriate language comes up and teachers need to set

parameters they feel comfortable with. Shay said, "I've told them. That if they want to include a curse word. It has to be maybe just the first letter, and then the asterisk. Zara explains how if they use curse words, they have to have a reason for it:

I had a kid ask me if he could use swear words and it seems yeah that was weeks ago and I said, listen, I said I'm fine with it. But it can't be gratuitous. It has to be there to serve the story, if that makes sense to you, and if it's obvious to the reader it's there to serve the story. That makes sense. And I'm okay with it. You do though have to check with your teacher, and administration, because the school might have other regulations that I'm not aware of when you need to be aware of yourself.

Assessing zines can also be a challenge. Participants described assessing student zines different ways depending on the purpose. Some did not grade the zines at all, but of those who did, but most described using some kind of criteria or parameters in a zinemaking project. Some created rubrics to assess elements such as effort, completion or development of an idea. Sofi describes how she assesses zines: 
I have a kind of general rubric for scheduling things and for basic design things. And I think that's how I've used it in the past for when they had to do the poem with illustration page. It was like, cover all the paper. I had written guidelines and they were kind of just parameters like measurable things to say like, oh, it really looks like he cared about this. so, like on effort. Like did they put effort into it right but I'm adding that I can't just say like, oh, this looks like (they made an) effort. I need to distill it to particular things so, cover most of the page, more positive space and negative space, things like does it have to have both text and illustration, or can it be all texts or all illustration, or like it really depends on which project we're talking about and ....(also) like a fully developed idea.

Similarly, Shay describes setting parameters for assessing student zines:

I wouldn't want to be able to tell you off the top of my head what the rubric included, but I do remember everything had to have a text component and that text was graded on like spelling and grammar and punctuation and all that. Just because if any of that is messed up... but if they happen to get a low grade. I actually give them opportunities to take back their work redo it or fix it and they turn it back into me for the full amount. So, it's very rare that I give out a fail in my class for a project. The only time would be is if they've absolutely done absolutely nothing in my class. Or if they did the project sloppily and they didn't take the opportunities are the chances to redo it ...

And so that's kind of like what I do with all my projects, especially if there's an, opinion behind it. I tell them I never grade necessarily for what their opinion is or if we have different opinions or I never grade them because they say they can't draw. I grade on, you know, technical stuff. Sometimes I grade on effort. Most of the times on completing it on how much they basically tried in the class. So yes, there are some zines that are better than others, but the amount of effort put into the zines, while they aesthetically look different, their effort would be exactly the same.

An additional challenge is that zines are often not seen or recognized as legitimate

knowledge. Nina says:

I think just this idea or narrative that this is not like a legitimate source of information. Ok, because it's not published. It's not edited. It's sort of like photocopied and often it's written by young people right who are seen as like not having knowledge or being knowledge producers themselves. 


\section{Limitations}

The limitations of the present study include those inherent to qualitative research studies, in that the results are not generalizable to the larger population of classroom teachers. The small sample size of only nine participants, as well as the specific criteria used to select the sample population, further limit the generalizability of the findings.

Another limitation of the study specific to the phenomenographic analysis process is that the categories of experience may not be complete due to the small sample size. Four categories emerged from the data collected from nine participants, however, more participants would have served to strengthen the phenomenographic analysis, and additional categories may have emerged. In addition, in the cases where a participant described different approaches in the same interview, it was difficult to assign the participant to only one category. A holistic view of the transcript guided the researcher in making decisions as to where to place any individual participants in the holistic outcome space (Akerlind, 2012).

Another limitation of the study was that because zine-making in the classroom is not a common practice, it was difficult to find and recruit local participants. Five participants were from Miami, two from New York, one from LA and one from Boston. Therefore, four of the interviews were conducted by Zoom meeting. Although Zoom is less personal than an in-person interview, every effort was made by the researcher to establish a personal rapport with remote participants.

Another limitation of the study was that the participants in this study all described very positive experiences with zine-making in the classroom and were enthusiastic in sharing their experience. Therefore, the perspectives of teachers who may have had 
unsuccessful, disappointing or frustrating experiences with zine-making in the classroom are not represented.

A final limitation of the study, as was delimited at the outset of the research, was that the study only represented the perspectives of classroom teachers who made zines with their students. Therefore, the present study does not include the perspective or voices from the students, administration or the larger zine community.

\section{Implications}

\section{Theoretical Implications}

The results of this study propose theoretical implications and may provide new directions for research on the pedagogical practice of zine-making. It is useful to reexamine the theoretical framework of the present study which situates zine-making within a sociocultural orientation of literacy, using a participatory literacy and critical literacy framework in which, zine-making sits at the intersection of critical text production (Janks, 2010), student voice theories (Robinson \& Taylor, 2007; Rudduck \& Feilding, 2006; Talyor \& Robinson, 2009), and transdisciplinary learning theories (McGregor, 2004).

The findings of this study are supported by Janks (2013) critical text production theory. Janks (2013) Independent Model of critical text production. proposes four interdependent elements that are central to critical text production: design, power, access and diversity. design refers to text production and multimodality; power refers to the struggle of "whose meanings, identity, values and culture prevail" (p. 234); access refers to who has access to real audiences; and diversity recognizes that different communities use literacy for different purposes (Janks 2010). 
A possibility for further theoretical research could examine how the content, process, product, and purpose of zine-making described in the present study, fit within the concepts of design, power, access and diversity. Janks (2013) further theorizes that as these four elements are interdependent, each one of the elements can become foregrounded or backgrounded in different literacy projects. This findings of the present study are supported by Janks (2013) model and have implications for further theoretical research on zine-making as critical text production.

The findings of this study also hold implications for examining zines as a form of transdisciplinary learning. Zine-making as described by participants, requires high levels of integration of multiple literacy skills. Zine-making traverses all disciplines to produce something entirely new, making them difficult to fit them into one box of a compartmentalized educational system. Sofi expresses the transdisciplinary nature of zine-making:

I think there's something to be said for working in between disciplines and working in between mediums to try to get at the essence of things right and zines can be a really good catch all. Like as, like, a teacher that is constantly doing like a lot of different things in different forms. It's a good place to touch down to ground all of that different experience.

The theoretical implications of zines within a transdisciplinary learning framework may open avenues of research on using zine-making a pedagogical practice to move classroom learning beyond disciplinary, multidisciplinary and interdisciplinary approaches.

Finally, the theoretical implications of zine-making within student voice theory should be examined. The current literature supports that student voice is central to zinemaking. Therefore, is valuable to examine zines within a student voice framework that 
takes into the account the themes of power, authenticity and inclusiveness (Robinson \& Taylor, 2007; Rudduck \& Fielding 2006; Taylor \& Robinson, 2009).

\section{Implications for Practice}

The findings of this study hold several implications for classroom teachers, teacher preparation and professional development programs, and for museum and community outreach programs. These implications include the possibility of using zines across the curriculum for a variety of purposes. Zines can be used to promote critical text production and $21^{\text {st }}$ century skills of creativity, communication, collaboration and critical thinking. Zines can be used as legitimate sources of information or as authentic assessments of learning. Zines embody a breadth of literacies and zines can foster agency, ownership, and empowerment as well. Furthermore, the four qualitatively different orientations to zine-making described in this study, The Author, The Artist, The Activist, and The Academic, can serve a way to understand how other teachers introduce zines to the classroom.

The findings support implications for teacher preparation and professional development programs as well. Participants indicated that many teachers simply do not know what zines are. Simply becoming aware of zines or making a zine oneself, can serve to inspire a teacher to introduce zine making to the classroom. Participants in this study indicated that participants support the idea of zine workshops and zine-making curricula. As Zeke stated, "I mean I think someone needs to sit down and write some zines curriculum. I really do.”

Implications for museum education and community programs include the awareness that they serve an important role in bringing innovative programs to youth in 
places where schools do not have resources or curricular freedom. Museum programs should continue to seek out partnerships in the community to promote literacy, learning and student voice.

\section{Recommendations for Future Research}

The present study was designed to understand how teachers approach zinemaking in the classroom, rather than what effect zines have on learning outcomes. As stated previously in the literature review, a minimal amount of academic research exists on school-zines and therefore the subject is wide-open for exploration. Future research can include:

- Research into how zines help us learn.

- Research that distinguishes school zines and out of school zines.

- Research on using zines in pre-service teacher education programs.

- Research on introducing zines for teacher professional development.

- Research on analyzing the thematic content of zines as a snapshot of youth voices of today.

- Research from the students' perspective on making zines.

- Research on introducing, implementing and integrating a zine-making program. into new and diverse school settings.

- Research on using zines as authentic assessments of learning.

- Research on using zines as legitimate, primary sources of information.

- Research on the efficacy of existing zine programs in our community such as FIU's Wolfsonian Zines for Progress. 
It is my position as the researcher that zines play an important role in learning. Further research on zines would allow us as educators to develop teaching practices that help students become producers of knowledge and communicators of their ideas in meaningful and authentic ways.

\section{Summary}

The purpose of this study was to explore the different experiences of teachers using zine-making in the classroom, in order to contribute to the development of usable zine pedagogy. The participants in this study described diverse approaches to zinemaking that can serve as models of how to implement zine-making in a variety of settings for variety of purposes. There is no one approach that is better than other. Foremost, these approaches do not exclusively represent the only four ways to approach zine-making in the classroom. Educator can combine approaches, move between approaches, change approaches or discover an entirely new way to do zines in the classroom. There is no right way or wrong way to make zines. Zine-making is an incredibly flexible tool for teaching and learning and its unique format has the power to traverse all age levels, disciplines and modes of learning. 


\section{REFERENCES}

Akerlind, G. (2005). Ways of Experiencing Being a University Researcher. In: Bowden, J., \& Green, P. (Eds). Doing Developmental Phenomenography. Melbourne: RMIT University Press, pp.145-155.

Akerlind, G. S. (2008). A phenomenographic approach to developing academics' understanding of the nature of teaching and learning. Teaching in higher education, 13(6), 633-644.

Akerlind, G. (2012). Variation and commonality in phenomenographic research methods. Higher Education Research \& Development, 13, 115-127.

Akom, A.A. (2009). Critical hip hop pedagogy as a form of liberatory praxis. Equity \& Excellence in Education, 42(1), 52-66.

Bernhardt, P. (2009). Opening up classroom space: Student voice, autobiography, \& the curriculum. The High School Journal, 92(3), 61-67.

Bott, C. (2002). Zines-The ultimate creative writing project. English Journal, 92(2), 27 33.

Callahan, M., \& Bronwen, E.L. (2004). At the crossroads of expertise: The risky business of teaching popular culture. The English Journal, 93(3), 52-57.

Congdon, K. G., \& Blandy, D. (2003). Zinesters in the classroom: Using zines to teach about postmodernism and the communication of ideas. Art Education, 56(3), 4452 .

Cook-Sather, A. (2002). Authorizing students' perspectives: Toward trust, dialogue, and change in education. Educational researcher, 31(4), 3-14.

Cook-Sather, A. (2006). Sound, presence, and power: "Student voice" in educational research and reform. Curriculum inquiry, 36(4), 359-390.

Cook-Sather, A. (2014). The trajectory of student voice in educational research. New Zealand Journal of Educational Studies, 49(2), 131-148.

Creswell, J. W. (2007). Qualitative inquiry and research design: Choosing among five approaches (2nd ed). Thousand Oaks, CA: Sage.

Dawes, L. M. (2017). Faculty perceptions of teaching information literacy to first year students: A phenomenographic study. Journal of Librarianship and Information Science, 16 pp. doi: 10.1177/0961000617726129 
Dodgson, J. E. (2019). Reflexivity in Qualitative Research. Journal of Human Lactation, 35(2), 220-222.

Duncum. P. (2009). Toward a playful pedagogy: popular culture and the pleasures of transgression. Studies in Art Education, A Journal of Issues and Research, 50 (3), 232-244.

Endsley, C.L. (2013). Performing blackness: spoken word poetry and performance.

Transformations: The Journal of Inclusive Scholarship and Pedagogy, 24, (1-2), $110-120$.

Fletcher, N. M. (2017). Designing a space for thoughtful voices: aligning the ethos of zines with youth-driven philosophical inquiry. Journal of Unschooling \& Alternative Learning, 10 (22).

Fisher, M. T. (2005). From the coffee house to the schoolhouse: The promise and potential of spoken word poetry in school contexts. English Education, 37(2), $115-131$.

Freire, P. (1972). Pedagogy of the oppressed. New York: Herder and Herder.

Gibb, L. (2013, November) Educating with Zines. The Broken Pencil, 61, 1820. Retrieved from https://brokenpencil.com/news/educating-with-zines/

Guzzetti, B., Campbell, S., Duke, C., \& Irving, J. (2003). Understanding Adolescent Literacies: A Conversation with Three Zinesters. Reading Online, 7(1), n1. 3551.

Guzzetti, B. J., \& Gamboa, M. (2004). Zines for social justice: Adolescent girls writing on their own. Reading Research Quarterly, 39(4), 408-436.

Guzzetti, B. J., Foley, L. M., \& Lesley, M. (2015). "Nomadic knowledge": Men writing zines for content learning. Journal of Adolescent \& Adult Literacy, 58(7), 591601.

Hagood, M. C. (2012). Risks, rewards, and responsibilities of using new literacies in middle grades. Voices from the Middle, 19(4), 64-71.

Hawkins, J. E. (2018). The Practical Utility and Suitability of Email Interviews in Qualitative Research. The Qualitative Report, 23(2), 493-501.

Helmane, I., \& Briška, I. (2017). What is Developing Integrated or Interdisciplinary or Multidisciplinary or Transdisciplinary Education in School. 
Jacob, S.A., \& Furgerson, S.P. (2012). Writing interview protocols and conducting interviews: Tips for students new to the field of qualitative research. The Qualitative Report, 17(42), 1-10.

Jacobi, T. (2007). The zine project: Innovation or oxymoron. English Journal, 96(4), 4349.

Jacobi, T. (2008). Writing for change: Engaging juveniles through alternative literacy education. Journal of Correctional Education, 59(2), 71-93.

Janghorban R., Roudsari , R.L., \& Taghipour, A. (2014). Skype interviewing: The new generation of online synchronous interview in qualitative research, International Journal of Qualitative Studies on Health and Well-being, 9:1, 24152,

Janks, H. (2013). Critical literacy in teaching and research. Education Inquiry, 4(2), 225242.

Janks, H. (2010). Literacy and Power. New York: Routledge

Jurmo, P. (1989). The Case for Participatory Literacy Education. New Directions for Adult and Continuing Education, (42), 17-28.

Kawai, R. \& Cody, J. (2015). Civic Zines: Writing, Discussing, and Doing Citizenship. Social Studies and the Young Learner, 28(2), 22-25.

Kia, C.M. (2017, February 8). High schoolers create 'zines for progress' with Wolfsonian-FIU [Blog post]. Retrieved from https://news.fiu.edu/2017/02/highschoolers-create-zines-for-progress-with-wolfsonian-fiu/108584

Knobel, M., \& Lankshear, C. (2002). Cut, paste and publish: The production and consumption of zines. In D. E. Alvermann (Ed.), Adolescents and literacies in a digital world (pp. 164-185). New York, NY: Peter Lang.

Lankshear, C. \& Knobel, M. (2018). Education and 'new literacies' in the middle years. Literacy Learning: The Middle Years, 26(2), 7-16.

Lonsdale, C. (2015). Engaging the 'Othered': Using zines to support student identities. Language Arts Journal of Michigan, 30 (2), pp. 8-16.

Lymn, J. (2018). Zines: Embodying literacy practices. Literacy Learning: The Middle Years, 26(3), 18-24.

MacMillan, M. (2014). Student connections with academic texts: A phenomenographic study of reading. Teaching in Higher Education, 19(8), 943-954. 
Mackieson, P., Shlonsky, A., \& Connolly, M. (2019). Increasing rigor and reducing bias in qualitative research: A document analysis of parliamentary debates using applied thematic analysis. Qualitative Social Work,18(6), 965-980.

Mahiri, J. (2000). Pop culture pedagogy and the end(s) of school. Journal of Adolescent and Adult Literacy, 44(4), 382-385.

Marcus, Sara (2010) Girls to the Front: The True Story of the Riot Grrrl Revolution. New York: Harper Collins.

Mathews, S.A. (2011). Framing Preservice Teachers' Interpretations of Graphic Novels in the Social Studies Classroom, Theory \& Research in Social Education, 39(3), 416-446.

Marton, F., \& Booth, S. (1997). Learning and awareness. New York, NY: Routledge.

McGregor, S. L. (2004). The nature of transdisciplinary research and practice. Kappa Omicron Nu human sciences working paper series.

Mitra, D. (2018). Student voice in secondary schools: the possibility for deeper change. Journal of Educational Administration, 56(5), 473-487.

Morrell, E. (2002). Toward a critical pedagogy of popular culture: Literacy development among urban youth. Journal of Adolescent and Adult Literacy, 46(1), 72-77.

Nemergut, N. (2018). Teaching with Zines. New York, NY.

Piepmeier, A. (2008). Why Zines Matter: Materiality and the Creation of Embodied Community. American Periodicals: A Journal of History \& Criticism, 18 (2), 213-238.

Porter, K. (2016, December 14). The resurgence of zine culture and why it's so important. Culture [Blog post]. Retrieved from: https://studybreaks.com/culture/the-resurgence-of-zine-culture-and-why-its-soimportant/

Quinn, S., \& Owen, S. (2016). Digging deeper: Understanding the power of 'student voice'. Australian Journal of Education, 60(1), 60-7.

Robinson, C. \& Taylor, C., (2007). Theorizing student voice: Values and perspectives. Improving Schools, 10(1) 5-17.

Rubin, H.J., \& Rubin, I.S. (2012). Qualitative interviewing: The art of hearing data (3rd ed.). Los Angeles, CA: Sage. 
Rudduck, J., \& Fielding, M. (2006). Student voice and the perils of popularity. Educational Review, 58(2), 219-231.

Saldana, J. (2009). The coding manual for qualitative researchers. Los Angeles, CA: Sage.

Schemmer, C.A. (2104, November). The literary binary: Zines within literature. The Media, 46. Retrieved from http://www.fvckthemedia.com/issue46/the-literarybinary

Spencer, A. (2008). DIY: The rise of lo-fi culture. London: Marion Boyars.

Suri, H. (2011). Purposeful Sampling in Qualitative Research Synthesis. Qualitative Research Journal, 11, (2), 63-75.

Taylor, C., \& Robinson, C. (2009). Student voice: Theorizing power and participation. Pedagogy, Culture \& Society, 17(2), 161-175.

Thomas, S. (2018). Zines for Teaching: A Survey of Pedagogy and Implications for Academic Librarians. portal: Libraries and the Academy, 18 (4), 737-758.

Tress, B., Tress, G., \& Fry, G. (2005). Defining concepts and process of knowledge production in integrative research. Heidelber: Springer.

Vasquez, V. (2017, March 29). Oxford Research Encyclopedia of Education. Ed. Retrieved from doi: 10.1093/acrefore/978019026493.013.20.

Wrekk, A. (2000). Stolen Sharpie Revolution A DIY Zine Resource.New York.

Yang, A. (2010). Engaging participatory literacy through science zines. The American Biology Teacher, (9), 573-577.

Yang, R. (2017) Why zines need to be part of your curriculum. The art of education magazine. Retrieved from: https://www.theartofed.com/2017/12/14/zines

Yildirim, A. H. (2013). Using graphic novels in the classroom. Journal of Language and Literature Education, 8, 118-131. 


\section{APPENDICES}

\section{Appendix A}

\section{Individual Interview Protocol (Jacob \& Furgerson, 2012)}

\section{Guiding Research Questions:}

1. What are the different ways educators experience, think about and approach zinemaking in the classroom?

2. From their experience what do educators view as the purpose, significance and literacy benefits of zine-making in the classroom?

3. How do educators create space for student voice to thrive in the classroom through zine-making?

4. What do educators see as the benefits and challenges of integrating zine-making in the classroom?

\section{Individual Interview:}

Introduction Question: I would like to start off by having you tell me little bit about yourself as a teacher.

\section{Possible Follow-Up Questions:}

- Over your teaching career, what subject areas and grades have you taught?

- Over your teaching career, what kinds of schools have you taught in? (public, private, charter, urban? rural?)

- What is your general teaching philosophy?

- What motivates you as a teacher?

- What challenges you as a teacher?

- What do you see as issues in education?

- You mentioned . Please, tell me a little more about that?

Lead Question One: Tell me about your experience with zines.

\section{Possible Follow-Up Questions:}

- How did you first become interested in zines?

- When did you make your first zine? What was it about?

- What made you want to bring zines into the classroom?

- Had you ever participated in any zine workshops about teaching with zines?

- Can you describe the school in which you did your zine-project?

- How did you go about setting up your zine project?

- Can you describe how zine-making looks in your classroom?

- Where did you get the materials and resources to do zines?

- Do you feel you had the curricular freedom to do what you wanted with zines?

- Did you have the support of administration, your team, parents or the community? 
- You mentioned . Please, tell me a little more about that?

Lead Question Two: What do you see as the purpose of zines?

\section{Possible Follow-Up Questions:}

- Why do zines matter to you?

- Why do you feel zines important in your classroom?

- Why do you feel zines important on a larger scope outside of your classroom?

- How do you see zines making a difference?

- How do you think your students feel about their zines?

- You mentioned . Please, tell me a little more about that?

Lead Question Three: What do you see as the relationship between zines and literacy?

\section{Possible Follow-Up Questions:}

- What do zines have to offer in terms of literacy?

- Compared to other literacy tools, how are zines different?

- How do zines help your students communicate their ideas?

- How do you see zines in relationship to reading and writing?

- What kinds of literacy activities do you see students engaged in while creating zines?

- You mentioned __. Please, tell me a little more about that?

Lead Question Four: What do you see as the relationship between zines and student voice?

\section{Possible Follow-Up Questions:}

- How did your students get their ideas for their zine topic?

- What range of ideas emerged?

- Were you uncomfortable with any of the ideas or content of your students' zines? If so, how did you handle that?

- How did you respond to students who say don't have any ideas or aren't good at zines?

- Did your students share their zines with each other? Describe that.

- How do you respond to students who are reluctant to share their zine?

- Did your students take any civic or community action because of their zine? Describe that.

- What kinds of conversations were opened because of your student zine project?

- You mentioned . Please, tell me a little more about that?

Lead Question Five: What do you feel are the overall benefits of zines?

\section{Possible Follow-Up Questions:}

- What do you think your students gained from the experience? 
- What changes did you observe in your students over the course of the project?

- If you were talking to a teacher who wanted to try zines, what would you tell them about the benefits of a zine-making?

- What positive impact do you think zine-making had in your classrooms?

- What did you, yourself gain from teaching with zines?

- What future zine projects are you thinking about?

- You mentioned . Please tell me a little more about that.

Lead Question Six: Tell me about any challenges you faced during your zine project?

\section{Possible Follow-Up Questions:}

- If you were talking to another teacher about a zine project, what issues you would want them to consider when planning their project?

- Did you face any issues of appropriateness of student zines? How did you handle those issues?

- Did your students produce zines that raised any concerns? If so, how did you handle that?

- Did you encounter any challenge that you did not foresee? How did you handle that?

- Did you ever feel frustrated with your zine-making project? In what ways?

- Would you change anything about your future zine projects?

- You mentioned . Please tell me a little more about that.

\section{Lead Question Seven:}

How did you grade your students' zines?

\section{Possible Follow-Up Questions:}

- Did you grade your students' zines? Why or why not?

- What criteria for evaluating zines did you set forth?

- How do your students feel about having their zines graded?

- Is there a way to assess zines other than by traditional grades?

- Have you used zines as an assessment to demonstrate other learning?

- How would you advise other teachers who are thinking about grading zines?

- You mentioned . Please tell me a little more about that. 


\section{Demographic Questions}

\begin{tabular}{|l|l|}
\hline What is your gender identity? & What subject area(s) do you teach? \\
\hline $\begin{array}{l}\text { What is your age range? } \\
18-24,25-59, \text { or } 60 \text { or over }\end{array}$ & What grade level(s) do you teach? \\
\hline $\begin{array}{l}\text { What is your highest level of educational } \\
\text { preparation? }\end{array}$ & Why kind of school do you teach in? \\
\hline What is your cultural identity? & \\
\hline
\end{tabular}




\section{Appendix B}

List of Codes

\section{NVIVO Codebook}

\section{NODES}

\section{Name}

Teacher Experience

Teacher Inspiration

Teacher Mindset

Teacher Resources

Teacher Setting

Teacher Support

Zine Content

Appropriateness

Art Images

Curse words

Freedom \& Censoring

Humor

Personal Stories

Sensitive subjects \& Issues

Social \& Political Issues

Subject Specific

Zine Process

Artistic Process

Collaboration

Creative process

Creative Writing

Critical Thinking

Design elements

Ideation 


\section{Name}

Literacy Process

Multiple Processes

Organizational Skills

Reading Process

Research Process

Scientific process

Special Needs \& ELL

Visual Literacy

Writing Process

Zine Product

Art Portfolio

Assessment of the Zine

Audience - Reader

Distribute Sell Trade

Format

Legitimacy

Ownership

Publish Share Archive

Tangible Product

Zine Fest

Zine Purpose

Activism

Advocacy

Artistic Freedom

Assessment of Learning

Call to Action-Activism

Communication

Connection \& Community

Consciousness Raising 


\section{Name}

Creative Freedom

Empowerment

Production Knowledge

Scientific Communication

Self-Expression

Social Justice

Sources of Information

Story Telling

Student Voice 


\section{Appendix C}

\section{Researcher Reflection}

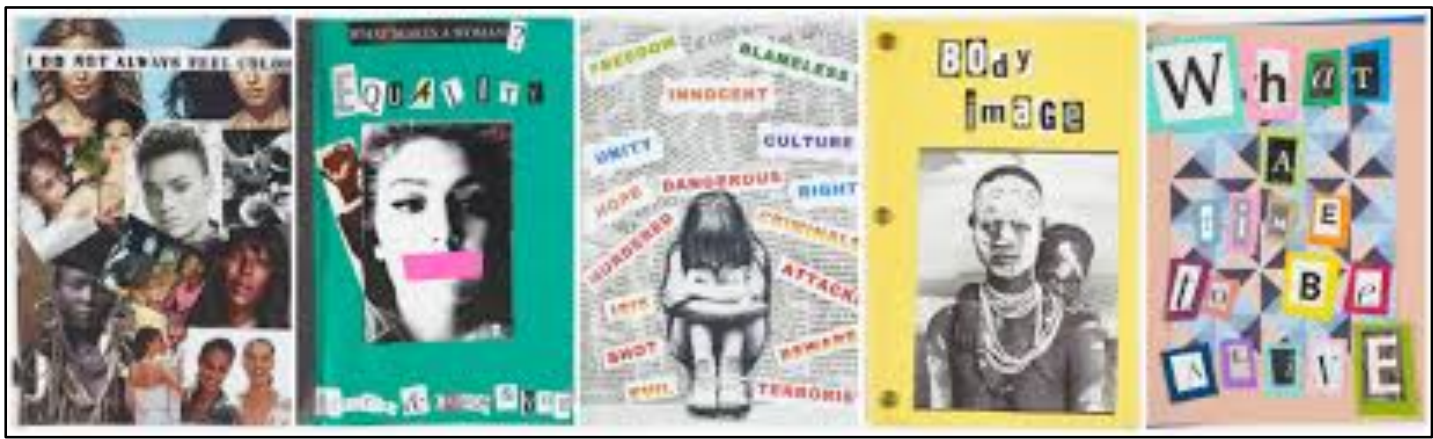

A collection of zines produced by high school students during Zines for Progress project at the Wolfsonian-FIU. (Full zines can be found at zines.wolfsonian.org)

My first encounter with zines was in 2017, when I came across an online article posted in the Florida International University News Bulletin with the headline "High Schoolers Create 'Zines for Progress' with Wolfsonian FIU.” I had never heard of the word zine, so I read to find out more. I learned that a zine (derived from magazine) is a short self-created and self-published booklet that combines images and text. Programs such as the Wolfsonian-FIU Zines for Progress community outreach program use zinemaking to create a space for students to find their voices on social issues and express their creativity. The above image was part of the article and by just looking at the image, I immediately understood, connected, and was inspired by the concept of zines.

Shortly thereafter, while attending the Florida Art Education Conference, I came a across an art teacher's exhibit table where she was displaying a basket of student-made zines. As I flipped through the pages of the tiny booklets filled with writing and art, I could instantly see how zines had the power to engage students as readers, writers and critical thinkers. 
From then on, my search for zines became intentional. I started looking for zines, and once I started looking, I found them everywhere. I followed zine-making social media accounts, I searched for zines at independent bookstores and I attended a zinemaking workshop at FIU's Frost Museum, and I attended the Miami Zine Fair. I discovered Barnard Zine Library (zines.barnard.edu) which was filled with a myriad of zine resources. My introduction to zine culture revealed that the zine-making was thriving. And while there is a lot happening in the zine community, almost all of it happens outside of school.

I wondered why in all my years of practice as a literacy professional, had I never encountered zines until now? The literacy benefits were almost intuitive. An online article entitled "Why zines need to be part of your curriculum" by Robert Yang made me ask- why aren't zines part of the curriculum? And that question was the impetus for the topic of my dissertation.

Once I decided I would do my dissertation on zines, I became overwhelmed with the possibilities of all the different ways I could research zines. I started making some zines of my own. I brought in supplies and introduced the idea of zines to the pre-service teachers in my methods class, I volunteered to make zines with a small group of high school students who were part of the Algebra Club summer enrichment program.

My experience is at the Algebra Club what led me to narrow my research focus and led to my primary research questions; How do teachers approach zine making in the classroom? While I was making zines with the students, I experienced my own internal tensions with knowing what was allowed or not allowed in a school setting and I was 
worried about whether the students would connect with me and the zines in a meaningful way.

While reading over the transcripts of the data collected for this study, I noticed that I had included the anecdote of my experience at the Algebra Club in conversations with several participants. This was significant to me because through the reading of the transcripts I became aware my own story and recognized the tensions that I was feeling between allowing the students complete freedom or setting parameters.

Diana: So, one of my professors...she knew I was doing zines and exploring the topic and she said, like before I ventured into this full force. She said, do you want to come do some zines with the kids (at the Algebra Club summer outreach program) as an activity, a literacy activity because you know they're there all day. So I went with my cart, I had this rolling cart and I brought my scissors, glue sticks, magazines, everything, .... and some of them were like, looking at me, you know very skeptical that they were not going to even like listen ... and one of the kids just kept saying, this is stupid and y'all are stupid but he kept saying like things in between that were actually like important I said, I keep hearing you say, y'all are stupid, and this doesn't matter and you don't care, but in between I'm hearing you say a lot of things that you actually really care about. And I said, you know, you're not going to be able to change the world just by telling everyone y'all are stupid, you need to be able to articulate it and put it down and find the right words to be able to do it and like a zine is a way to do it and we did it. He ended up making this like incredible zine and he got really into it. He was kind of the group leader I could tell too, that once he picked his head up and started participating everyone started participating and they did it on gun violence, police violence. I wasn't sure if I was allowed to let them have a picture of guns in there, you know like that's where I found myself ...they were like, can we write about whatever we want? and I'm like yeah and then I'm like, but don't use bad words and don't draw guns like, because I was there representing FIU, and I didn't know what my parameters were and what push back I would get if these kids draw a gun and their zine is out there. And then, am I in trouble? you know, and I could get them in trouble. ... and so that's where I felt myself as a teacher ... and I feel like what you're doing (in your program) really supports teachers on how to approach those subjects, how to set whatever parameters, how to engage the kids...

Zara: Yeah, I had a kid ask me if he could use swear words ....and I said, listen, I said I'm fine with it. But it can't be gratuitous. It has to be there to serve the story, if that makes sense to you, and if it's obvious to the reader it's there to serve the 
story. That makes sense. And I'm okay with it. You do though have to check with your teacher, and administration, because the school might have other regulations that I'm not aware of that you need to be aware of yourself.

Diana: So, that's how you handled it?

Zara: Yeah. And then once this was last year at our workshop here, one of the kids fashioned a gun out of cardboard and tape, and both $\square$ and I saw and we were like you were not leaving this building with that you put that down, you get rid of that. You are playing with fire.

Diana: Right. Yes, because as educators we have to be careful.

Zara: Yes, we're putting them in a situation that is dangerous.

Diana: That's what I was worried about because when they were starting to draw the one on gun violence, and he was talking about like gun violence in context. And at that time this rapper, locally, had gotten killed. I don't remember the name, but they were all talking about it and he was shot...And so that's why I was like, you know myself with all of my open mindedness and education and everything I was still like, what do I do? (about letting them draw guns).

Zara: I think for teachers is really important to know the parameters before you even start opening the store, because the zine everything is about does it make sense does it support, does it serve your story does it serve, what you're trying to say. It's subtly telling them that they, they are responsible for what they say and do. And that extends beyond just making a zine and talking about that particular topic. It implicitly it's about everything.

Reflecting on this conversation, I heard my own story louder than my participants.

I recognized how I had initially felt insecure about my ability to connect with the students, and I felt unsure of how to navigate sensitive subjects, and I was unclear about what parameters I should have set. Zara, who coordinates a program with hundreds of students and provides support to the classroom teachers, was able to share her insight with me which demonstrates the importance of educators connecting with each other. As a final thought to my reflection, during the interviews, one of my participants, Luna, expressed that in order to do zines, you need to be a brave teacher, a confident 
teacher. I believe, I emerged from this study a little bit wiser and a little bit braver than before, in part because of the brave teacher who shared their experiences with me. 
VITA

DIANA LEVY

1985

Born, New York, NY

B.A., Advertising

University of Florida

Gainesville, Florida

1994

B.A., Elementary Education

Florida International University

Miami, Florida

1999

M.S. Elementary Education

Florida International University

Miami, Florida

2006-2015

Adjunct Lecturer

Florida International University

Miami, Florida

2016-2020

Graduate Teaching Assistant

Florida International University

Miami, Florida

2015-2020

Doctoral Candidate

Florida International University

Miami, Florida

1998-Present

President

Bookworm Kids, Inc.

Miramar, Florida 